\title{
CH Packaging Operations Manual
}

\author{
U.S. Department of Energy
}

Revision 7

November 2007

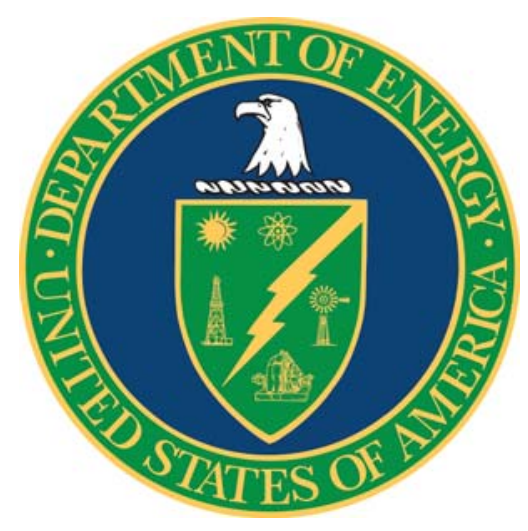

This document supersedes DOE/WIPP-02-3184, Revision 6. 
DOE/WIPP-02-3184

Revision 7, November 2007

\section{CH Packaging Operations Manual}

Approval on File

Casey Gadbury, Director

Office of the National TRU Program
November 29, 2007

Date

Processing and final preparation of this paper was performed by Washington TRU Solutions LLC, the WIPP management and operating (M\&O) contractor for the Waste Isolation Pilot Plant under U.S. Department of Energy contract number DE-AC29-01AL66444. 
This document has been submitted as required to:

Office of Scientific and Technical Information

P.O. Box 62

Oak Ridge, TN 37831

(865) $576-8401$

Additional Information about this document may be obtained by calling the WIPP Information Center at 1-800-336-9477. Copies may be obtained by contacting the National Technical Information Service, U.S. Department of Commerce, 5285 Port Royal Road, Springfield, VA 22101. 


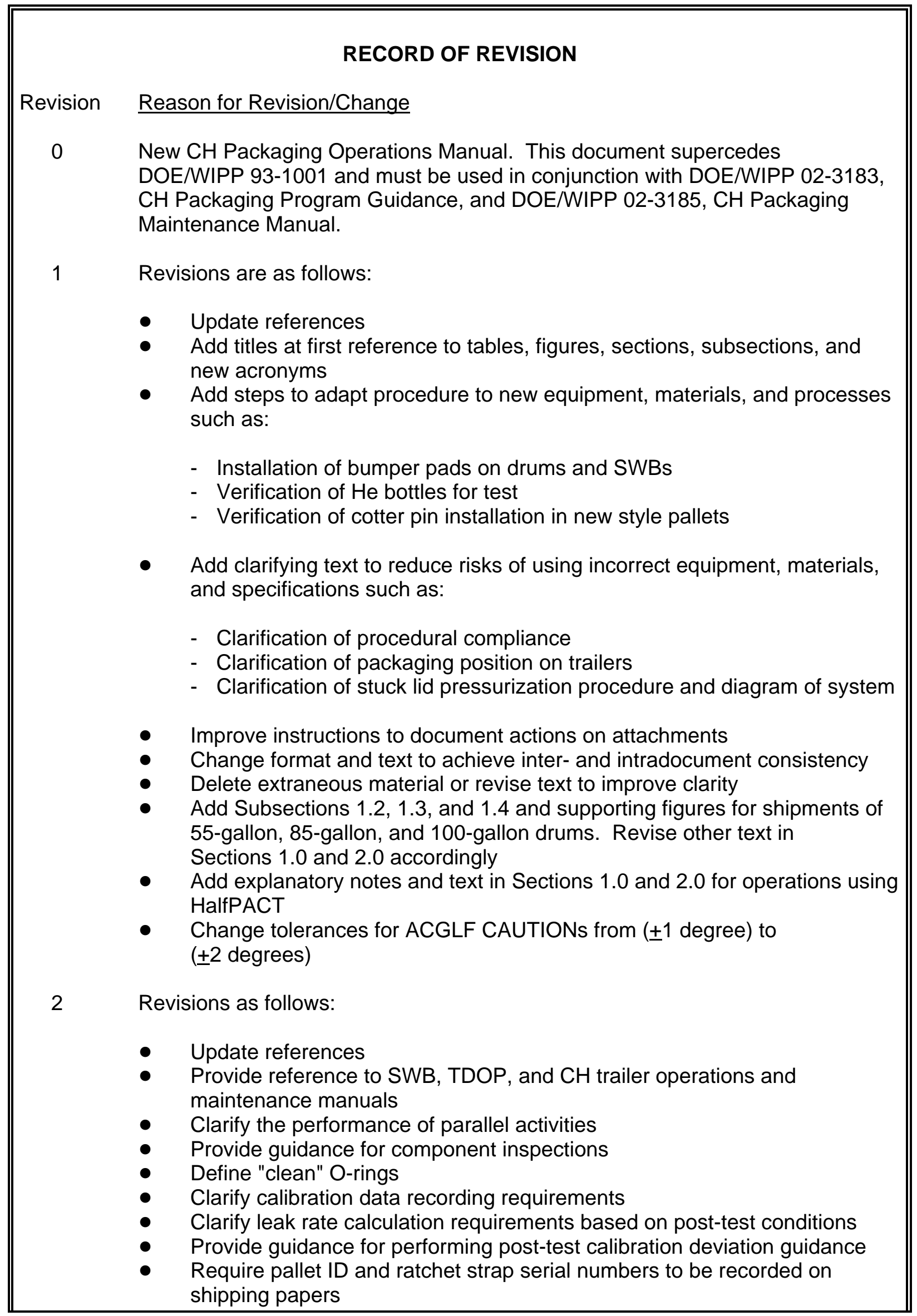


3 Revisions as follows:

- $\quad$ Added a torque value to OCV guide plates.

- $\quad$ Added an "or" to the torque paint on Z-flange screws and ICV upper spacer screws. This will allow the user to check torque if the torque paint was not used.

- $\quad$ Added a note to Subsection 4.3.16 clarifying the values for post-test calibration deviation.

- $\quad$ Added guidance for drum payload assembly height.

- Added notes to allow tape on reinforcing plate tabs.

- $\quad$ Deleted specified number of filters installed on SWB/TDOP.

- $\quad$ Revised range on pound-inch torque wrench.

- Moved step for verification of airflow through ICV/OCV test ports.

- $\quad$ Revised note in Section 2.16 regarding WWIS data.

- Clarified trailer inspection steps.

- $\quad$ Referenced DOE/WIPP 02-3183, Section 4.2.9, for leak test guidance.

- $\quad$ Corrected numbering in attachments.

$4 \quad$ Revisions as follows:

- $\quad$ Corrected nomenclature for consistency with the SAR.

- Added a precaution in Section 2.1.4 that requires marking devices to be low in chloride, fluoride, halide, and sulfur content.

- Clarified inspection requirements.

- $\quad$ Added additional inspection steps at Steps 2.18.1 and 2.34.1.

- $\quad$ Added a torque range to Steps 2.7.2 and 2.26.2.

- $\quad$ Added following text to Note preceding Step 2.19.7 to state, "If the total weight of the tractor, trailer, and payload is greater than or equal to $77,500 \mathrm{lb}$, the shipment should be scaled to ensure the $20,000 \mathrm{lb}$ trailer axle weight limitation and $80,000 \mathrm{lb}$ gross weight limitation are not exceeded."

- $\quad$ Revised bullets in Notes before Steps 2.19.1 and 2.35.1 to adjust weight difference from $2,000 \mathrm{lb}$ to $1,000 \mathrm{lb}$, and to revise table to remove items 2 and 4 and the notation of "Preferred method."

Revisions as follows:

- $\quad$ Changed the inspection and acceptance criteria for upper spacer and locking Z-flange screws found in Steps 2.7.2, 2.8.2, 2.26.2, and 2.27.2

- $\quad$ Changed cover page to indicate new Office Director.

- $\quad$ Added "C of C" (certificate of conformance) to last bullets of Steps 4.2.1 and 4.4.1.

- $\quad$ Added "C of C" to Attachment 7, Step 4.2.1; and Attachment 8, Step 4.4.1.

6 Revisions as follows:

- $\quad$ Changed reference step in Steps 2.10.7, 2.12.6, 2.29.7, and 2.31.6.

- $\quad$ Revised Steps 2.10.9, 2.12.8, 2.29.9, and 2.31.8 for O-ring installation.

- $\quad$ Added a note to Step 4.1.1.

- Updated attachments to reflect changes. 
7 Revisions as follows:

- Added bullet to Step 1.1.4 regarding ratchet strap and pallet inspection due date.

- $\quad$ Added new Steps 2.16.3 and 2.32.6 and corresponding steps in Attachments 2 and 5, respectively, to verify inspection due date on pallets and ratchet straps.

- $\quad$ Added new Steps 2.13.5, and 2.32.5 for inspection of ICV cavity.

- $\quad$ Corrected the leak test calculation in Steps 4.2.31, 4.3.16, 4.4.29, 4.5.16, and corresponding steps on Attachments 7 and 8. 
M\&O CONTRACTOR TECHNICAL REVIEW ORGANIZATIONS

WASHINGTON TRU SOLUTIONS

\section{CBFO REVIEW ORGANIZATIONS}

OFFICE OF THE NATIONAL TRU PROGRAM

QUALITY ASSURANCE

EDITORIAL 


\section{TABLE OF CONTENTS}

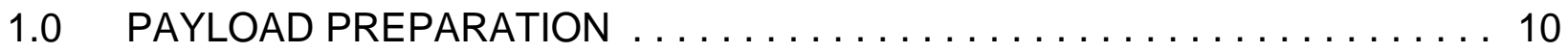

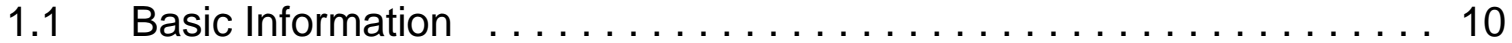

1.2 Preparing $55-$ Gallon Drum Payload Assembly ............. 11

1.3 Preparing "Short" 85-Gallon Drum Payload Assembly . . . . . . . . . 14

1.4 Preparing "Tall" 85-Gallon Drum Payload Assembly

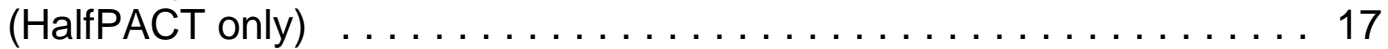

1.5 Preparing 100-Gallon Drum Payload Assembly . . . . . . . . . . . 19

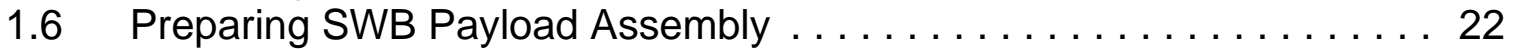

$1.7 \quad$ Preparing TDOP Payload Assembly $\ldots \ldots \ldots \ldots \ldots \ldots \ldots \ldots 23$

2.0 NORMAL OPERATING INSTRUCTIONS $\ldots \ldots \ldots \ldots \ldots \ldots \ldots \ldots \ldots$.

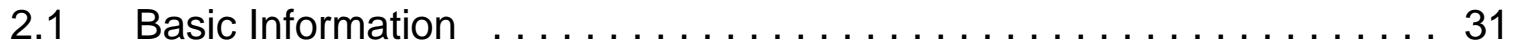

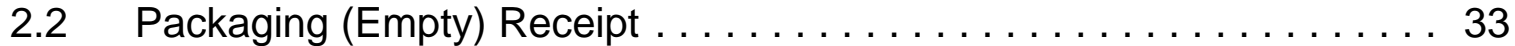

2.3 Releasing Tiedowns and Removal of Packaging from Trailer . . . . . 34

$2.4 \quad$ OCA Lid Removal . . . . . . . . . . . . . . . . . . . . . . . . . . . 35

$2.5 \quad$ ICV Lid Removal . . . . . . . . . . . . . . . . . . . . . 37

2.6 Preloading/Shipping Operational Checks and Examinations . . . . . . 38

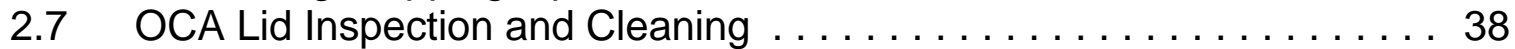

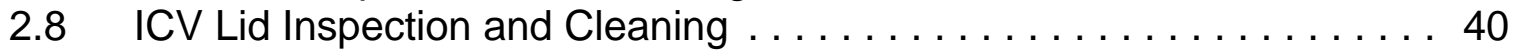

2.9 OCA Body Inspection and Cleaning $\ldots \ldots \ldots \ldots \ldots \ldots \ldots \ldots \ldots$

2.10 OCA Components Inspection and Cleaning $\ldots \ldots \ldots \ldots \ldots \ldots . \ldots 4$

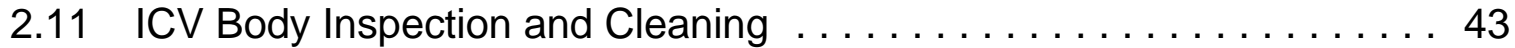

2.12 ICV Components Inspection and Cleaning ................44

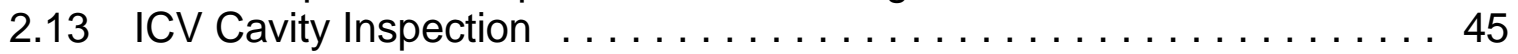

2.14 Pre-Loading Operations $\ldots \ldots \ldots \ldots \ldots \ldots \ldots \ldots \ldots \ldots \ldots$

2.15 Packaging Receipt and Inspection Data Sheet Validation . . . . . . . . 46

2.16 Loading Payload Assembly . . . . . . . . . . . . . . . . . . . 47

2.17 ICV Lid Installation . . . . . . . . . . . . . . . . . . . . . . . 49

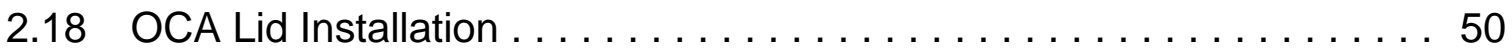

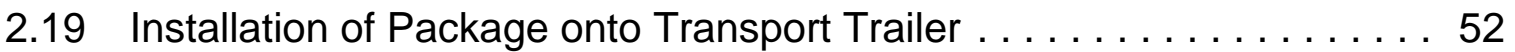

2.20 Package (Loaded) Receipt . . . . . . . . . . . . . . . . . . . 55

2.21 Releasing Tiedowns and Removal of Package from Trailer . . . . . . 55

2.22 OCA Lid Removal . . . . . . . . . . . . . . . . . . . . . . . . 56

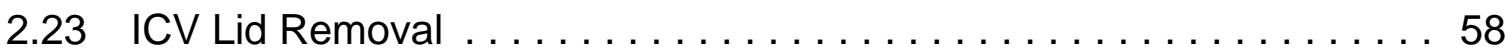

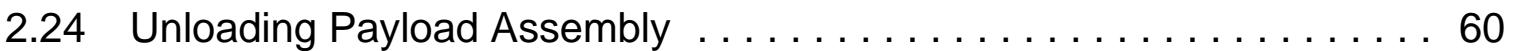

2.25 Packaging Operational Checks and Examinations $\ldots \ldots \ldots \ldots \ldots 60$

2.26 OCA Lid Inspection and Cleaning . . . . . . . . . . . . . . . 61

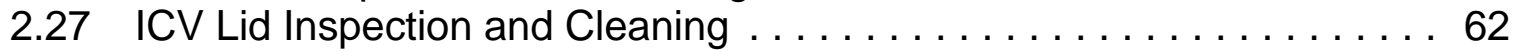

2.28 OCA Body Inspection and Cleaning $\ldots \ldots \ldots \ldots \ldots \ldots \ldots \ldots \ldots$

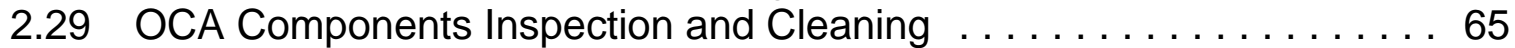

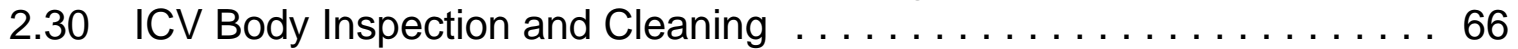

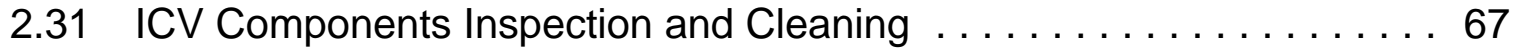

2.32 ICV Cavity Inspection $\ldots \ldots \ldots \ldots \ldots \ldots \ldots \ldots \ldots \ldots \ldots \ldots \ldots \ldots$

2.33 ICV Lid Installation $\ldots \ldots \ldots \ldots \ldots \ldots \ldots \ldots \ldots \ldots \ldots \ldots \ldots$

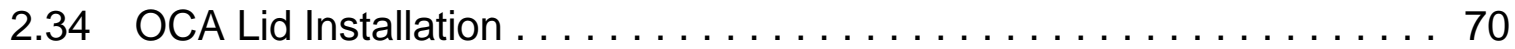

2.35 Installation of Packaging onto Transport Trailer $\ldots \ldots \ldots \ldots \ldots \ldots 72$ 


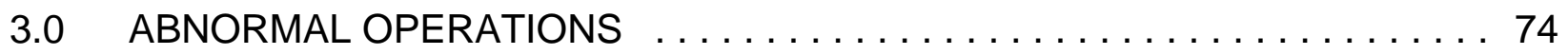

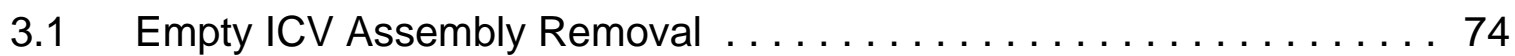

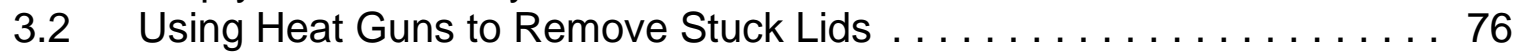

3.3 Pressurizing with Nitrogen or Compressed Air to Remove

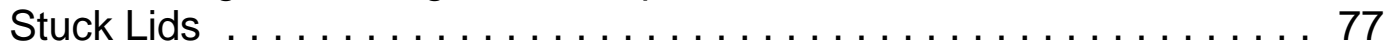

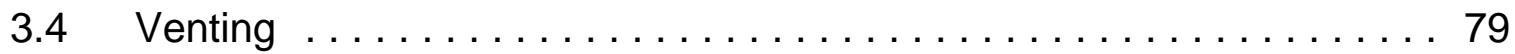

4.0 PRESHIPMENT LEAKAGE RATE TESTING $\ldots \ldots \ldots \ldots \ldots \ldots \ldots \ldots$.

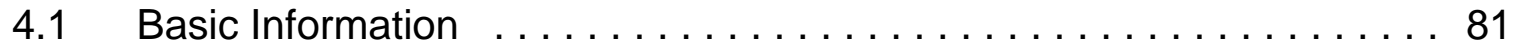

$4.2 \quad$ ICV Upper Main O-Ring Seal $\ldots \ldots \ldots \ldots \ldots \ldots \ldots \ldots \ldots \ldots$

$4.3 \quad$ ICV Outer Vent Port Plug Seal O-Ring $\ldots \ldots \ldots \ldots \ldots \ldots \ldots$

$4.4 \quad$ OCV Upper Main O-Ring Seal $\ldots \ldots \ldots \ldots \ldots \ldots \ldots \ldots \ldots$

4.5 OCV Vent Port Plug Seal O-Ring $\ldots \ldots \ldots \ldots \ldots \ldots \ldots \ldots$

Attachment 1 - CH Packaging Receipt and Inspection Data Sheet . . . . . . . . 102

Attachment 2 - CH Packaging Loading Data Sheet . . . . . . . . . . . . . . . . 104

Attachment 3 - Loaded CH Package Trailer Data Sheet ... . . . . . . . . . . . 105

Attachment 4 - Loaded Package Receipt and Processing Data Sheet . . . . . . . . 106

Attachment 5 - Empty Packaging Shipment Data Sheet . . . . . . . . . . . . . . . 107

Attachment 6 - Trailer Data Sheet . . . . . . . . . . . . . . . . . . . . 109

Attachment 7 - ICV Preshipment Leakage-Rate Test Data Sheet . . . . . . . . . . 110

Attachment 8 - OCV Preshipment Leakage-Rate Test Data Sheet $\ldots \ldots \ldots \ldots 113$

\section{LIST OF FIGURES}

Figure 1.1 - 55-Gallon Drum Placement $\ldots \ldots \ldots \ldots \ldots \ldots \ldots \ldots \ldots \ldots \ldots \ldots \ldots \ldots \ldots$

Figure 1.2 - 55-Gallon Drum Payload Assembly . . . . . . . . . . . . . . . . . 25

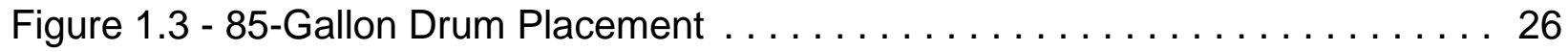

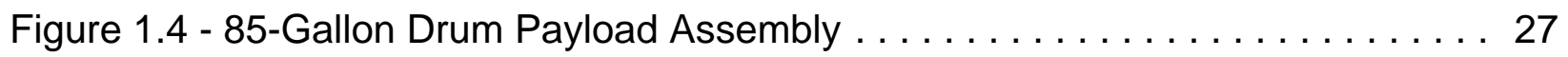

Figure 1.5 - 100-Gallon Drum Payload Assembly . . . . . . . . . . . . . . . . 28

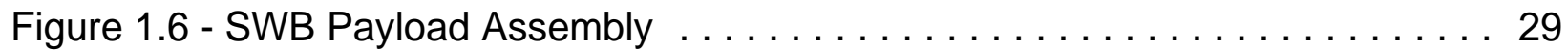

Figure 1.7 - TDOP Payload Assembly $\ldots \ldots \ldots \ldots \ldots \ldots \ldots \ldots \ldots \ldots \ldots$

Figure 3.1 - Flow Diagram for Nitrogen Bottle/Compressed Air ICV/OCA Lid

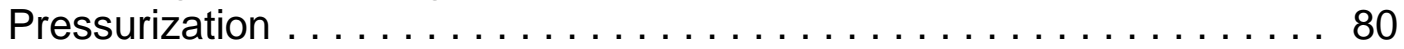

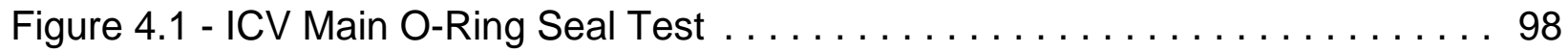

Figure 4.2 - ICV Outer Vent Port Plug Seal O-Ring Test . . . . . . . . . . . . 99

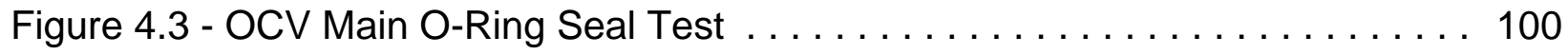

Figure 4.4 - OCV Vent Port Plug Seal O-Ring Test . . . . . . . . . . . . . 101 


\subsection{PAYLOAD PREPARATION}

\section{CAUTION}

If the payload pallet will be placed on a square pallet for subsequent movement by forklift, care must be taken to ensure all three pockets used for lifting with the Adjustable Center of Gravity Lift Fixture (ACGLF) rest on a flat surface. Failure to ensure this may result in pallet damage due to the weight of the ACGLF driving the pallet lift point through the pallet.

\section{NOTE}

This section provides the user with instructions for assembling a payload.

All the steps in Subsections 1.2, Preparing 55-Gallon Drum Payload Assembly; 1.3, Preparing "Short" 85-Gallon Drum Payload Assembly (TRUPACT-II and HalfPACT); 1.4, Preparing "Tall" 85-Gallon Drum Payload Assembly (HalfPACT only); 1.5, Preparing 100-Gallon Drum Payload Assembly; 1.6, Preparing SWB Payload Assembly; and 1.7, Preparing TDOP Payload Assembly, must be completed, but may be performed in any order as long as radiological control steps are not bypassed.

\subsection{Basic Information}

1.1.1 Introduction - This procedure provides instructions for assembling the following $\mathrm{CH}$ packaging payload:

- $\quad$ Drum payload assembly

- Standard Waste Box (SWB) assembly

- $\quad$ Ten-Drum Overpack (TDOP)

\subsubsection{References}

\section{BASELINE DOCUMENTS}

- U.S. Nuclear Regulatory Commission

(NRC)-Docket-71-9218, Safety Analysis Report for the TRUPACT-Il Shipping Package

- $\quad$ NRC-Docket-71-9218, TRUPACT-Il Certificate of Compliance, No. 9218

- $\quad$ NRC-Docket-71-9279, Safety Analysis Report for the HalfPACT Shipping Package

- $\quad$ NRC-Docket-71-9279, HalfPACT Certificate of Compliance, No. 9279 
- $\quad$ Contact-Handled Transuranic Waste Authorized Methods for Payload Control (CH-TRAMPAC), U.S. Department of Energy

- WP 08-PT.01, Standard Waste Box Handling and Operation Manual

- WP 08-PT.02, Ten-Drum Overpack Handling and Operation Manual

\subsubsection{Equipment}

- $\quad$ SWB ratchet straps or turnbuckles

- $\quad$ Payload spacer (HalfPACT only)

- Drum payload pallet

- $\quad$ Guide tubes

- $\quad$ Stretch wrap

- $\quad$ Slip sheets

- Reinforcement plates

1.1.4 Prerequisite Actions

- $\quad$ Each waste container and payload assembly shall be verified to meet $\mathrm{CH}$ TRAMPAC requirements before shipment.

- Verify that the annual inspection due date for SWB ratchet straps and drum payload pallets has not elapsed.

- Verify that each payload container is less than the limits specified in Table 3.2-1 of the CH-TRAMPAC (total external dose rate).

\subsection{Preparing 55-Gallon Drum Payload Assembly}

1.2.1 Verify that cotter pins are installed in lift pin assemblies on new style pallets.

1.2.2 Place clean pallet, right-side-up on floor or stretch wrap machine for use as the bottom support of the drum payload assembly.

1.2.3 Place slip sheet on top of pallet.

1.2.4 Verify that the guide tube holes on slip sheet and pallet are aligned. 


\section{NOTE}

The diameter of all drums, including the locking ring, must be less than or equal to 24 inches (in.). This dimension should not include the locking bolt. Tapping the locking ring with a hammer while torquing the lock ring nut may assist in ensuring the drum is tightly closed. The diameter of each layer of drums should not exceed 72 in. The adhesive backed bumper pads are excluded from the 24-in. and 72-in. diameter limits.

\section{NOTE}

If shipping less than 14 loaded drums in a TRUPACT-II or seven loaded drums in a HalfPACT, empty dunnage drums must be used to form the payload while adhering to weight management practices (see Figure 1.1, 55-Gallon Drum Placement). Dunnage drums shall have open vent ports (i.e., not filtered or plugged).

1.2.5 Verify that at least one approved filter is installed in each loaded drum in accordance with Section 2.5 of the $\mathrm{CH}$-TRAMPAC.

1.2.6 Verify that all waste drums are properly labeled and drums are approved for the shipment being assembled.

\section{NOTE}

In Step 1.2.7, at least one container ID label on each drum (except the middle) must be visible when drums are assembled into a payload assembly.

\section{NOTE}

Drums in an assembly should be approximately the same height such that a flat stacking surface is achieved. That is, the maximum difference between the shortest and tallest drums in an assembly shall not exceed $1 / 2$ in., with the exception of the center drum in a seven-pack assembly, which may be up to one inch shorter but no taller than the tallest drum in the seven-pack assembly.

1.2.7 Place seven drums on slip sheet using weight distribution shown in Figure 1.1.

1.2.8 Verify that the locking bolt on each drum is positioned between drum gaps that do not contain guide tubes.

1.2.9 Verify that the heaviest seven-pack is on bottom of drum payload assembly for TRUPACT-II (see Figure 1.1).

1.2.10 If HalfPACT, install adhesive backed bumper pads on top chine of the six exposed drums. 
1.2.11 Stretch wrap upper portion of drums with nine wraps so wraps extend down the sides of the drums a maximum of 22 in. with NO overlap on top of drums.

\section{NOTE}

The reinforcing plate should rest flat on top of the drums. Tape may be used to secure the reinforcing plate to the drums prior to applying stretch wrap.

\subsubsection{Place reinforcing plate on top.}

1.2.13 Verify that the guide tube holes are aligned with bottom slip sheet/pallet holes by inserting and removing guide tubes and adjusting assembly, as required.

1.2.14 Apply nine additional wraps of stretch wrap so there is overlap on top of drums (see Figure 1.2, 55-Gallon Drum Payload Assembly).

1.2.15 If loading HalfPACT, GO TO Step 1.2.25.

1.2.16 Place slip sheet on top of bottom layer of drums (on top of reinforcing plate) AND align white stripe with the one on lower assembly.

1.2.17 Verify that the guide tube holes are aligned with bottom slip sheet/pallet holes (if desired, guide tubes may be inserted to help maintain pallet alignment).

\section{NOTE}

In Step 1.2.18, at least one container ID label on each drum (except the middle) must be visible when drums are assembled into a payload assembly.

\section{NOTE}

Drums in an assembly should be approximately the same height such that a flat stacking surface is achieved. That is, the maximum difference between the shortest and tallest drums in an assembly shall not exceed $1 / 2$ in., with the exception of the center drum in a seven-pack assembly, which may be up to one inch shorter but no taller than the tallest drum in the seven-pack assembly.

1.2.18 Place seven drums on slip sheet using weight distribution shown in Figure 1.1.

1.2.19 Verify that the locking bolt (on each drum) is positioned between drum gaps that will not contain guide tubes. 
1.2.20 Install adhesive backed bumper pads on top chine of the six exposed drums.

1.2.21 Stretch wrap upper portion of drums with nine wraps so wraps extend down the sides of drums a maximum of 22 in. with NO overlap on top of drums.

\section{NOTE}

The reinforcing plate should rest flat on top of the drums. Tape may be used to secure the reinforcing plate to the drums prior to applying stretch wrap.

1.2.22 Place reinforcing plate on top.

1.2.23 Verify that the guide tube holes are aligned with bottom slip sheet/pallet holes by inserting and removing guide tubes and adjusting assembly, as required.

1.2.24 Apply nine additional wraps of stretch wrap so there is overlap on top of drums.

1.2.25 Verify that at least one container ID label on each drum (except the middle) is visible when drums are assembled into payload assembly.

\section{NOTE}

All HalfPACT payloads, with the exception of the "tall" (40 1/4 in.)

85-gallon drums require guide tubes labeled "PAYLOAD WITH SPACER."

1.2.26 If not already installed, insert guide tube(s) into drum payload assembly adjusting upper assembly, as required.

1.2.27 If beta-gamma, alpha, and neutron surveys are required, survey using site-specific procedures.

1.3 Preparing "Short" 85-Gallon Drum Payload Assembly (TRUPACT and HalfPACT)

1.3.1 Verify that cotter pins are installed in lift pin assemblies on new style pallets.

1.3.2 Place clean pallet, right side up on floor or stretch wrap machine for use as the bottom support of the drum payload assembly.

1.3.3 Place slip sheet on top of pallet.

1.3.4 Verify that the guide tube holes on slip sheet and pallet are aligned. 


\section{NOTE}

The diameter of all drums, including the locking ring, must be less than or equal to 29-3/4 in. This dimension should not include the locking bolt. Tapping the locking ring with a hammer while torquing the lock ring nut may assist in ensuring the drum is tightly closed. The diameter of each layer of drums should not exceed 72 in.

\section{NOTE}

If shipping less than eight loaded drums in a TRUPACT-II or four loaded drums in a HalfPACT, empty dunnage drums must be used to form the payload while adhering to weight management practices (see Figure 1.3, 85-Gallon Drum Placement). Dunnage drums shall have open vent ports (i.e., not filtered or plugged).

1.3.5 Verify that at least one approved filter is installed in each loaded drum, in accordance with Section 2.5 of the $\mathrm{CH}$-TRAMPAC.

1.3.6 Verify that all waste drums are properly labeled and drums are approved for the shipment being assembled.

\section{NOTE}

In Step 1.3.7, at least one container ID label on each drum must be visible when drums are assembled into a payload assembly.

NOTE

Drums in an assembly should be approximately the same height such that a flat stacking surface is achieved. That is, the maximum difference between the shortest and tallest drums in an assembly shall not exceed $1 / 2$ in.

1.3.7 Place four drums on slip sheet using weight distribution shown in Figure 1.3.

1.3.8 Verify that the locking bolt on each drum is positioned between drum gaps that do not contain guide tubes.

1.3.9 Verify that the heaviest four-pack is on bottom of drum payload assembly.

1.3.10 If HalfPACT, install adhesive backed bumper pads on top chine of each drum.

1.3.11 Stretch wrap upper portion of drums with nine wraps so wraps extend down the sides of the drums a maximum of 22 in. with NO overlap on top of drums. 


\section{NOTE}

The reinforcing plate should rest flat on top of the drums. Tape may be used to secure the reinforcing plate to the drums prior to applying stretch wrap.

\subsubsection{Place reinforcing plate on top.}

1.3.13 Verify that the guide tube holes are aligned with bottom slip sheet/pallet holes by inserting and removing guide tubes and adjusting assembly, as required.

1.3.14 Apply nine additional wraps of stretch wrap so there is overlap on top of drums (see Figure 1.4, 85-Gallon Drum Payload Assembly).

1.3.15 If loading HalfPACT, GO TO Step 1.3.25.

1.3.16 Place slip sheet on top of bottom layer of drums (on top of reinforcing plate) AND align white stripe with the one on lower assembly.

1.3.17 Verify that the guide tube holes are aligned with bottom slip sheet/pallet holes (if desired, guide tubes may be inserted to help maintain pallet alignment).

\section{NOTE}

In Step 1.3.18, at least one container ID label on each drum must be visible when drums are assembled into a payload assembly.

\section{NOTE}

Drums in an assembly should be approximately the same height such that a flat stacking surface is achieved. That is, the maximum difference between the shortest and tallest drums in an assembly shall not exceed $1 / 2$ in.

1.3.18 Place four drums on slip sheet using weight distribution shown in Figure 1.3.

1.3.19 Verify that the locking bolt (on each drum) is positioned between drum gaps which will not contain guide tubes.

1.3.20 Install adhesive backed bumper pads on top chine of each drum.

1.3.21 Stretch wrap upper portion of drums with nine wraps so wraps extend down the sides of drums a maximum of 22 in. with NO overlap on top of drums. 


\section{NOTE}

The reinforcing plate should rest flat on top of the drums. Tape may be used to secure the reinforcing plate to the drums prior to applying stretch wrap.

1.3.22 Place reinforcing plate on top.

1.3.23 Verify that the guide tube holes are aligned with bottom slip sheet/pallet holes by inserting and removing guide tubes and adjusting assembly, as required.

1.3.24 Apply nine additional wraps of stretch wrap so there is overlap on top of drums.

1.3.25 Verify that at least one container ID label on each drum is visible when drums are assembled into payload assembly.

\section{NOTE}

The "short" (35-in.) 85-gallon eight-pack requires standard length TRUPACT-II guide tubes.

\section{NOTE}

The "short" (35 in.) 85-gallon four-pack requires the guide tubes labeled "PAYLOAD WITH SPACER."

1.3.26 If not already installed, insert guide tube(s) into drum payload assembly, adjusting assembly as required.

1.3.27 If beta-gamma, alpha, and neutron surveys are required, survey using site-specific procedures.

\subsection{Preparing "Tall" 85-Gallon Drum Payload Assembly (HalfPACT only)}

1.4.1 Verify that cotter pins are installed in lift pin assemblies on new style pallets.

1.4.2 Place clean pallet, right-side-up on floor or stretch wrap machine for use as the bottom support of the drum payload assembly.

1.4.3 Place slip sheet on top of pallet.

1.4.4 Verify that the guide tube holes on slip sheet and pallet are aligned. 


\section{NOTE}

The diameter of all drums, including the locking ring, must be less than or equal to 28-5/8 in. This dimension should not include the locking bolt. Tapping the locking ring with a hammer while torquing the lock ring nut may assist in ensuring the drum is tightly closed. The diameter of payload assembly should not exceed 72 in.

\section{NOTE}

If shipping less than four loaded drums, empty dunnage drums must be used to form the payload while adhering to weight management practices (see Figure 1.3). Dunnage drums shall have open vent ports (i.e., not filtered or plugged).

1.4.5 Verify that at least one approved filter is installed in each loaded drum, in accordance with Section 2.5 of the $\mathrm{CH}$-TRAMPAC.

1.4.6 Verify that all waste drums are properly labeled and drums are approved for the shipment being assembled.

\section{NOTE}

In Step 1.4.7, at least one container ID label on each drum must be visible when drums are assembled into a payload assembly.

\section{NOTE}

Drums in an assembly should be approximately the same height such that a flat stacking surface is achieved. That is, the maximum difference between the shortest and tallest drums in an assembly shall not exceed $1 / 2$ in.

1.4.7 Place four drums on slip sheet using weight distribution shown in Figure 1.3.

1.4.8 Verify that the locking bolt on each drum is positioned toward center of payload.

1.4.9 Install adhesive-backed bumper pads on the top chine of each drum.

1.4.10 Stretch wrap upper portion of drums with nine wraps so wraps extend down the sides of the drums a maximum of 22 in. with NO overlap on top of drums. 


\section{NOTE}

The reinforcing plate should rest flat on top of the drums. Tape may be used to secure the reinforcing plate to the drums prior to applying stretch wrap.

\subsubsection{Place reinforcing plate on top.}

1.4.12 Verify that the guide tube holes are aligned with bottom slip sheet/pallet holes by inserting and removing guide tubes and adjusting assembly, as required.

1.4.13 Apply nine additional wraps of stretch wrap so there is overlap on top of drums (see Figure 1.4).

1.4.14 If not already installed, insert four guide tube(s) labeled "Payload Without Spacer" into drum payload assembly.

1.4.15 If beta-gamma, alpha, and neutron surveys are required, survey using site-specific procedures.

\subsection{Preparing 100-Gallon Drum Payload Assembly}

1.5.1 Verify that cotter pins are installed in lift pin assemblies on new style pallets.

1.5.2 Place clean pallet, right-side-up on floor or stretch wrap machine for use as the bottom support of the drum payload assembly.

1.5.3 Place slip sheet on top of pallet.

1.5.4 Verify that the guide tube holes on slip sheet and pallet are aligned.

\section{NOTE}

The diameter of all drums, including the locking ring, must be less than or equal to 32 in.

\section{NOTE}

If shipping less than six loaded drums, (TRUPACT-II), or three loaded drums (HalfPACT), empty dunnage drums must be used to form the payload while adhering to weight management practices (see Figure 1.5, 100-Gallon Drum Payload Assembly). Dunnage drums shall have open vent ports (i.e., not filtered or plugged).

1.5.5 Verify that at least one approved filter is installed in each loaded drum, in accordance with Section 2.5 of the CH-TRAMPAC. 
1.5.6 Verify that all waste drums are properly labeled and drums are approved for the shipment being assembled.

\section{NOTE}

In Step 1.5.7, at least one container ID label on each drum must be visible when drums are assembled into a payload assembly.

\section{NOTE}

Drums in an assembly should be approximately the same height such that a flat stacking surface is achieved. That is, the maximum difference between the shortest and tallest drums in an assembly shall not exceed $1 / 2$ in.

1.5.7 Place three drums on slip sheet.

1.5.8 If the drums are equipped with lock rings/bolts, verify that the locking bolt on each drum is NOT located in the center or near the outer perimeter.

1.5.9 Verify that the heaviest three-pack is on bottom of drum payload assembly for TRUPACT-II (see Figure 1.5).

1.5.10 If payload assembly is for HalfPACT, install adhesive-backed bumper pads on the top chine of each drum.

1.5.11 Stretch wrap upper portion of drums with nine wraps so wraps extend down the sides of the drums a maximum of $22 \mathrm{in}$. with NO overlap on top of drums.

\section{NOTE}

The reinforcing plate should rest flat on top of the drums. Tape may be used to secure the reinforcing plate to the drums prior to applying stretch wrap.

1.5.12 Place reinforcing plate on top.

1.5.13 Verify that the guide tube holes are aligned with bottom slip sheet/pallet holes by inserting and removing guide tubes and adjusting assembly, as required.

1.5.14 Apply nine additional wraps of stretch wrap so there is overlap on top of drums (see Figure 1.5).

1.5.15 If payload assembly is for HalfPACT, GO TO Step 1.5.25.

1.5.16 Place slip sheet on top of bottom layer of drums (on top of reinforcing plate). 
1.5.17 Verify that the guide tube holes are aligned with bottom slip sheet/pallet holes (if desired, guide tubes may be inserted to help maintain pallet alignment).

\section{NOTE}

In Step 1.5.18, at least one container ID label on each drum must be visible when drums are assembled into a payload assembly.

\section{NOTE}

Drums in an assembly should be approximately the same height such that a flat stacking surface is achieved. That is, the maximum difference between the shortest and tallest drums in an assembly shall not exceed $1 / 2$ in.

1.5.18 Place three drums on slip sheet.

1.5.19 Verify that the locking bolt (on each drum) is NOT located in the center or near the outer perimeter.

1.5.20 Install adhesive backed bumper pads on top chine of each drum.

1.5.21 Stretch wrap upper portion of drums with nine wraps so wraps extend down the sides of drums a maximum of 22 in. with NO overlap on top of drums.

\section{NOTE}

The reinforcing plate should rest flat on top of the drums. Tape may be used to secure the reinforcing plate to the drums prior to applying stretch wrap.

1.5.22 Place reinforcing plate on top.

1.5.23 Verify that the guide tube holes are aligned with bottom slip sheet/pallet holes by inserting and removing guide tubes and adjusting assembly, as required.

1.5.24 Apply nine additional wraps of stretch wrap so there is overlap on top of drums.

1.5.25 Verify that at least one container ID label on each drum is visible when drums are assembled into payload assembly. 


\section{NOTE}

The 100-gallon drum three-pack requires the guide tubes labeled

"PAYLOAD with SPACER."

\section{NOTE}

The 100-gallon drum six-pack requires the standard length TRUPACT-II guide tubes.

1.5.26 If not already installed, insert guide tube(s) into drum payload assembly adjusting assembly, as required.

1.5.27 If beta-gamma, alpha, and neutron surveys are required, survey using site-specific procedures.

\subsection{Preparing SWB Payload Assembly}

\section{NOTE}

Additional guidance regarding SWB activities, such as loading, handling, filter installation, maintenance, inspection, and repair, is provided in WP 08-PT.01. This document is available on the Internet at http://www.wipp.energy.gov/library/caolib.htm\#containers.

\section{NOTE}

HalfPACT payloads include one SWB and a HalfPACT payload spacer.

\section{NOTE}

The maximum SWB payload assembly height is 74-5/8 in.

1.6.1 Verify that approved filters are installed in each SWB and the remaining ports are plugged (if not filtered), in accordance with Section 2.5 of the $\mathrm{CH}$-TRAMPAC.

\section{NOTE}

If shipping only one loaded SWB in a TRUPACT-II, a second empty dunnage SWB must be used in the top position to form the payload. To allow for pressure changes, dunnage SWBs shall have open vent ports (i.e., not filtered or plugged).

1.6.2 Verify that SWBs are properly labeled and SWBs are approved for the shipment being assembled.

NOTE

An SWB forklift adapter may be used in lieu of a crane/ACGLF.

1.6.3 Place heaviest SWB on floor. 


\section{CAUTION}

Operator shall verify that the two ACGLF counterweights are at 180 degrees and 000 degrees ( \pm 2 degrees) BEFORE lifting ACGLF or lid.

1.6.4 Place second SWB on top of first and align the edges.

1.6.5 Attach SWB turnbuckles or adjustable slings (in three places) to top and bottom SWBs as follows:

- $\quad$ One on each outer lift clip on one side

- One on the middle clip on the opposite side (see Figure 1.6, SWB Payload Assembly)

1.6.6 Install SWB bumper pads (On the top SWB, the bumpers should be placed at the end of the top ribs only. On the bottom SWB, the bumpers should be placed at the end of the bottom ribs only).

1.6.7 If beta-gamma, alpha, and neutron surveys are required, survey using site-specific procedures.

\subsection{Preparing TDOP Payload Assembly (TRUPACT-II only)}

\section{NOTE}

Additional guidance regarding TDOP operations, such as handling, filter installation, loading, lifting, inspection, maintenance, and repair, is provided in WP 08-PT.02. This document is available on the Internet at http://www.wipp.energy.gov/library/caolib.htm\#containers.

1.7.1 Verify that approved filters are installed and the remaining ports are plugged (if not filtered), in accordance with Section 2.5 of the CH TRAMPAC.

1.7.2 Verify that the TDOP is properly labeled and TDOP is approved for the shipment being assembled.

1.7.3 Install bumper pads on the top and bottom rib of TDOP (four pads on each rib). (See Figure 1.7, TDOP Payload Assembly.)

1.7.4 If beta-gamma, alpha, and neutron surveys are required, survey using site-specific procedures. 
Figure 1.1 - 55-Gallon Drum Placement

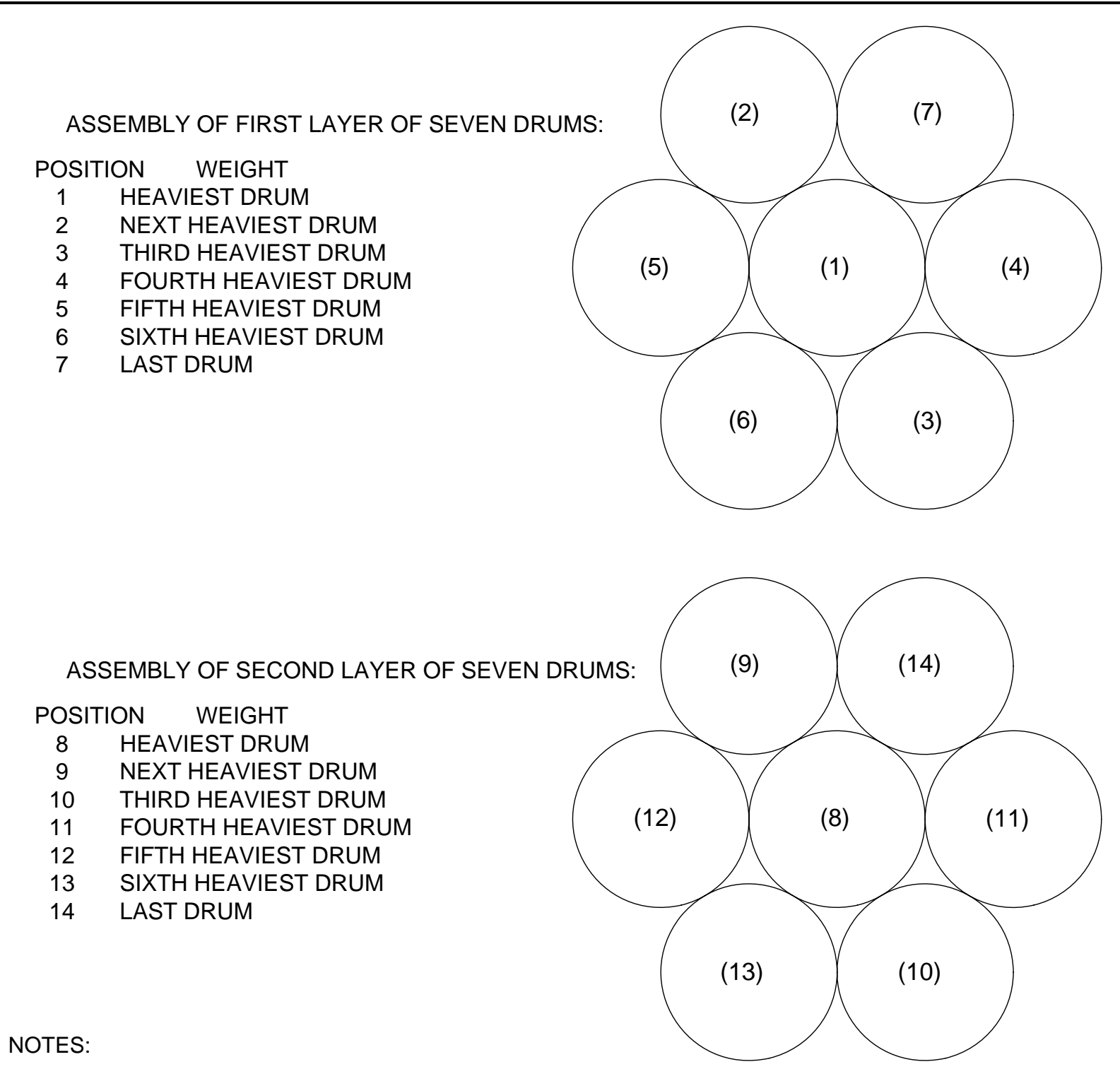

1. IF DUNNAGE IS USED, IT MAY BE PLACED AS NEEDED.

2. VERIFY THAT THE HEAVIEST SEVEN PACK WILL COMPRISE THE LOWER LAYER OF SEVEN DRUMS.

3. DRUMS IN AN ASSEMBLY SHOULD BE APPROXIMATELY THE SAME HEIGHT SUCH THAT A FLAT STACKING SURFACE IS ACHIEVED. THAT IS, THE MAXIMUM DIFFERENCE BETWEEN THE SHORTEST AND TALLEST DRUMS IN AN ASSEMBLY SHALL NOT EXCEED 1/2 IN., WITH THE EXCEPTION OF THE CENTER DRUM IN A SEVEN-PACK ASSEMBLY, WHICH MAY BE UP TO ONE INCH SHORTER BUT NO TALLER THAN THE TALLEST DRUM IN THE SEVEN-PACK ASSEMBLY.

4. TAPE MAY BE USED TO SECURE THE REINFORCEMENT SHEET TABS TO THE DRUMS PRIOR TO APPLYING STRETCH WRAP.

5. ONLY THE COMPONENTS SHOWN IN FIGURE 1.2 ARE APPROVED FOR USE IN 55-GALLON DRUM PAYLOAD ASSEMBLY (STRETCH WRAP AND TAPE NOT SHOWN FOR CLARITY). 
Figure 1.2 - 55-Gallon Drum Payload Assembly

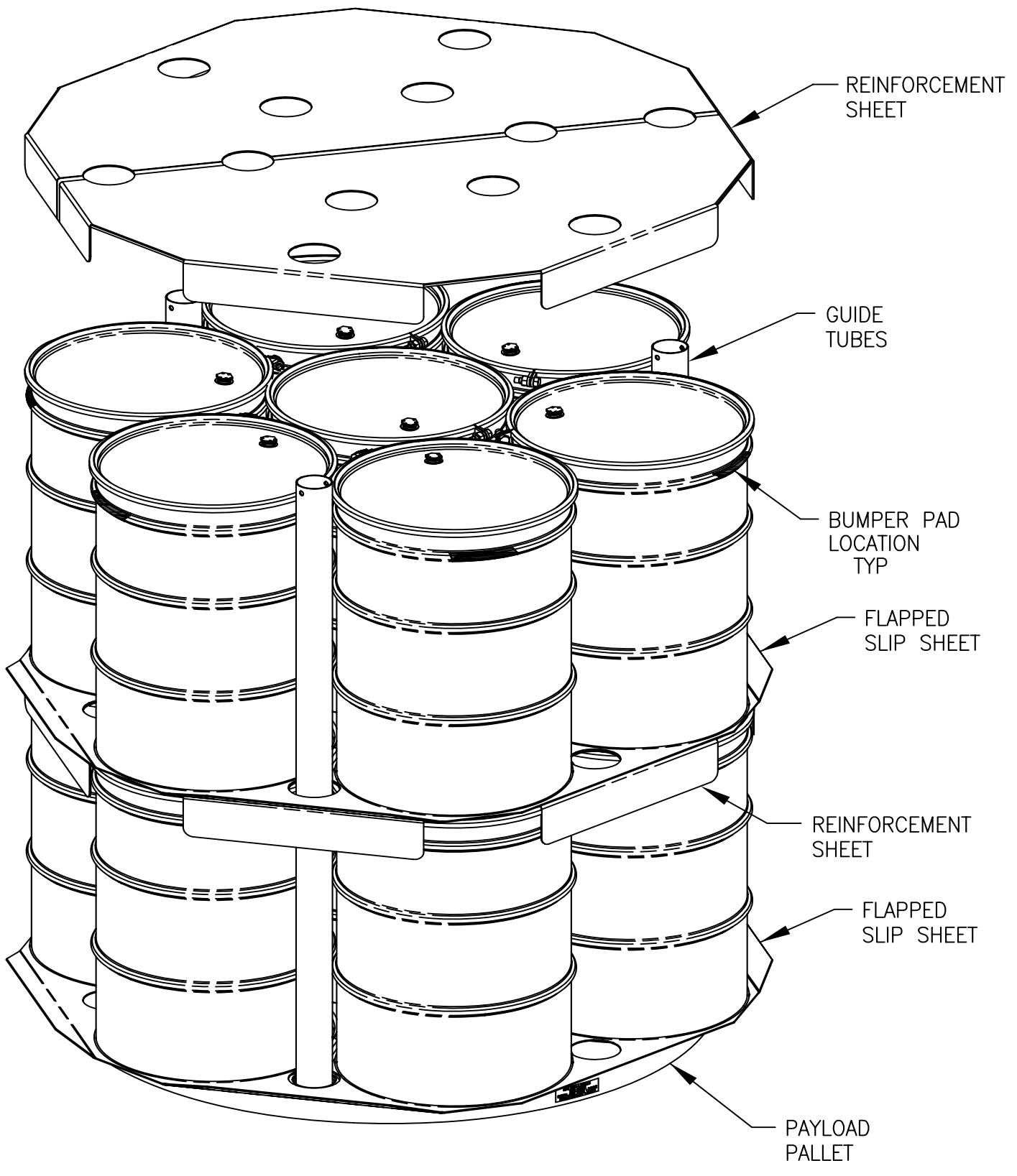


ASSEMBLY OF FOUR 85-GALLON DRUMS:

POSITION WEIGHT

1 HEAVIEST DRUM

2 NEXT HEAVIEST DRUM

3 THIRD HEAVIEST DRUM

4 FOURTH HEAVIEST DRUM

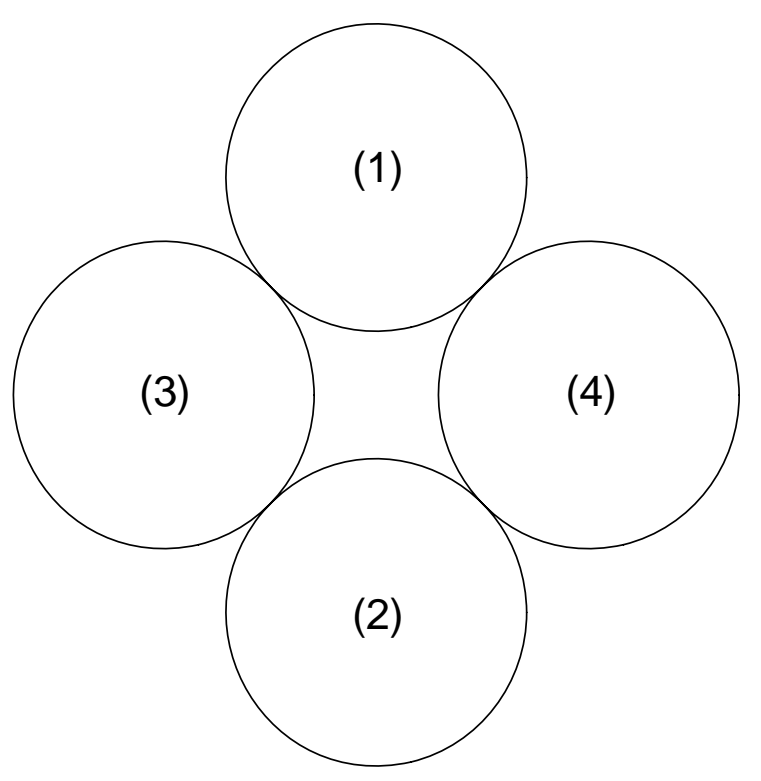

NOTES:

1. IF DUNNAGE IS USED, IT MAY BE PLACED AS NEEDED.

2. IF SHIPPING EIGHT 85-GALLON DRUMS, REPEAT THE ASSEMBLY SHOWN ABOVE.

3. IF SHIPPING EIGHT 85-GALLON DRUMS, VERIFY THAT THE HEAVIEST 4-PACK WILL COMPRISE THE LOWER LAYER OF FOUR DRUMS.

4. DRUMS IN AN ASSEMBLY SHOULD BE APPROXIMATELY THE SAME HEIGHT SUCH THAT A FLAT STACKING SURFACE IS ACHIEVED. THAT IS, THE MAXIMUM DIFFERENCE BETWEEN THE SHORTEST AND TALLEST DRUMS IN AN ASSEMBLY SHALL NOT EXCEED 1/2 IN.

5. TAPE MAY BE USED TO SECURE THE REINFORCEMENT SHEET TABS TO THE DRUMS PRIOR TO APPLYING STRETCH WRAP.

6. ONLY THE COMPONENTS SHOWN IN FIGURE 1.4 ARE APPROVED FOR USE IN 85-GALLON DRUM PAYLOAD ASSEMBLY (STRETCH WRAP AND TAPE NOT SHOWN FOR CLARITY). 
Figure 1.4 - 85-Gallon Drum Payload Assembly

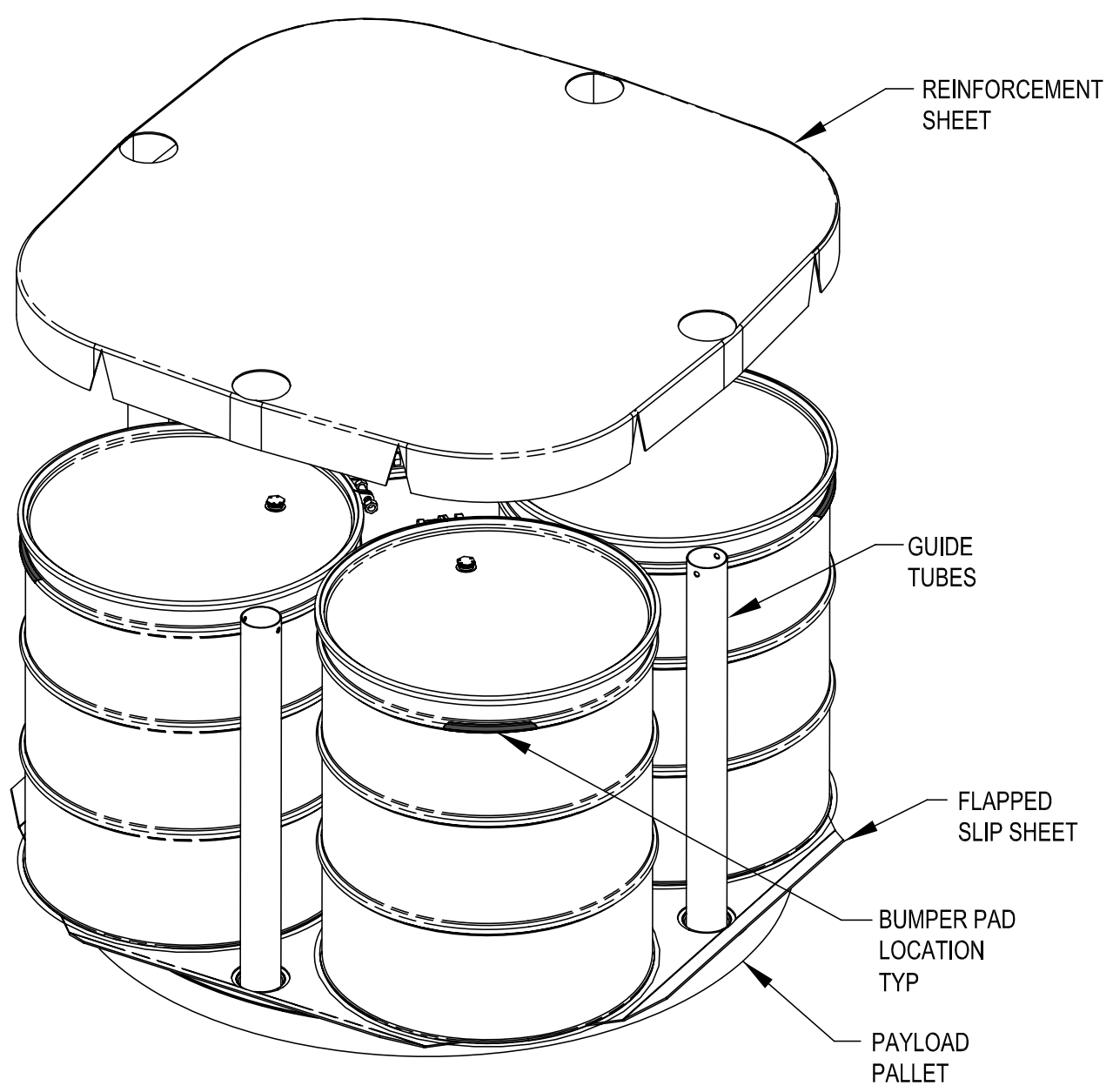


Figure 1.5 - 100-Gallon Drum Payload Assembly

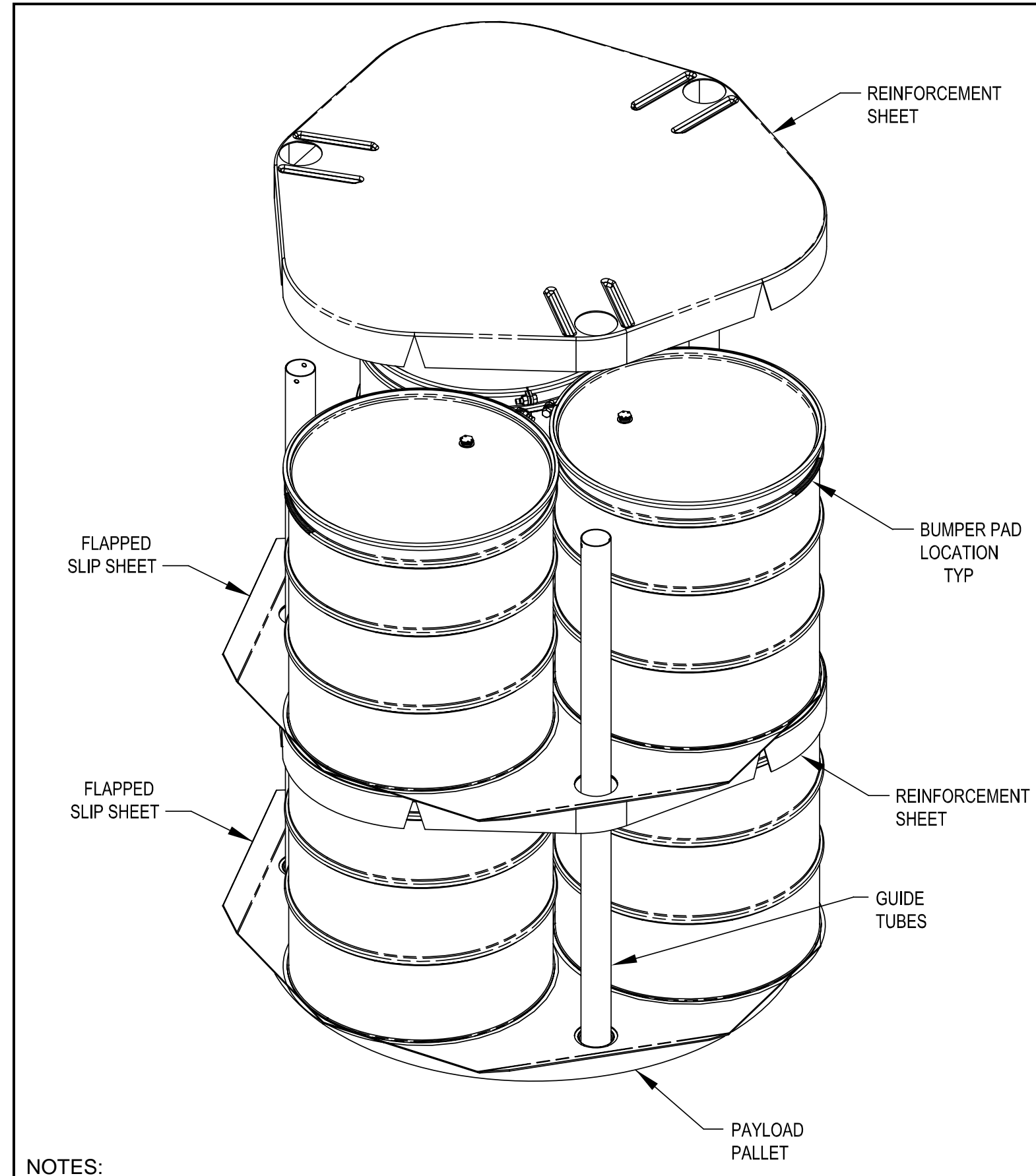

1. DRUMS IN AN ASSEMBLY SHOULD BE APPROXIMATELY THE SAME HEIGHT SUCH THAT A FLAT STACKING SURFACE IS ACHIEVED. THAT IS, THE MAXIMUM DIFFERENCE BETWEEN THE SHORTEST AND TALLEST DRUMS IN AN ASSEMBLY SHALL NOT EXCEED 1/2 IN.

2. TAPE MAY BE USED TO SECURE THE REINFORCEMENT SHEET TABS TO THE DRUMS PRIOR TO APPLYING STRETCH WRAP.

3. ONLY THE COMPONENTS SHOWN IN FIGURE 1.5 ARE APPROVED FOR USE IN 100-GALLON DRUM PAYLOAD ASSEMBLY (STRETCH WRAP AND TAPE NOT SHOWN FOR CLARITY). 
Figure 1.6 - SWB Payload Assembly

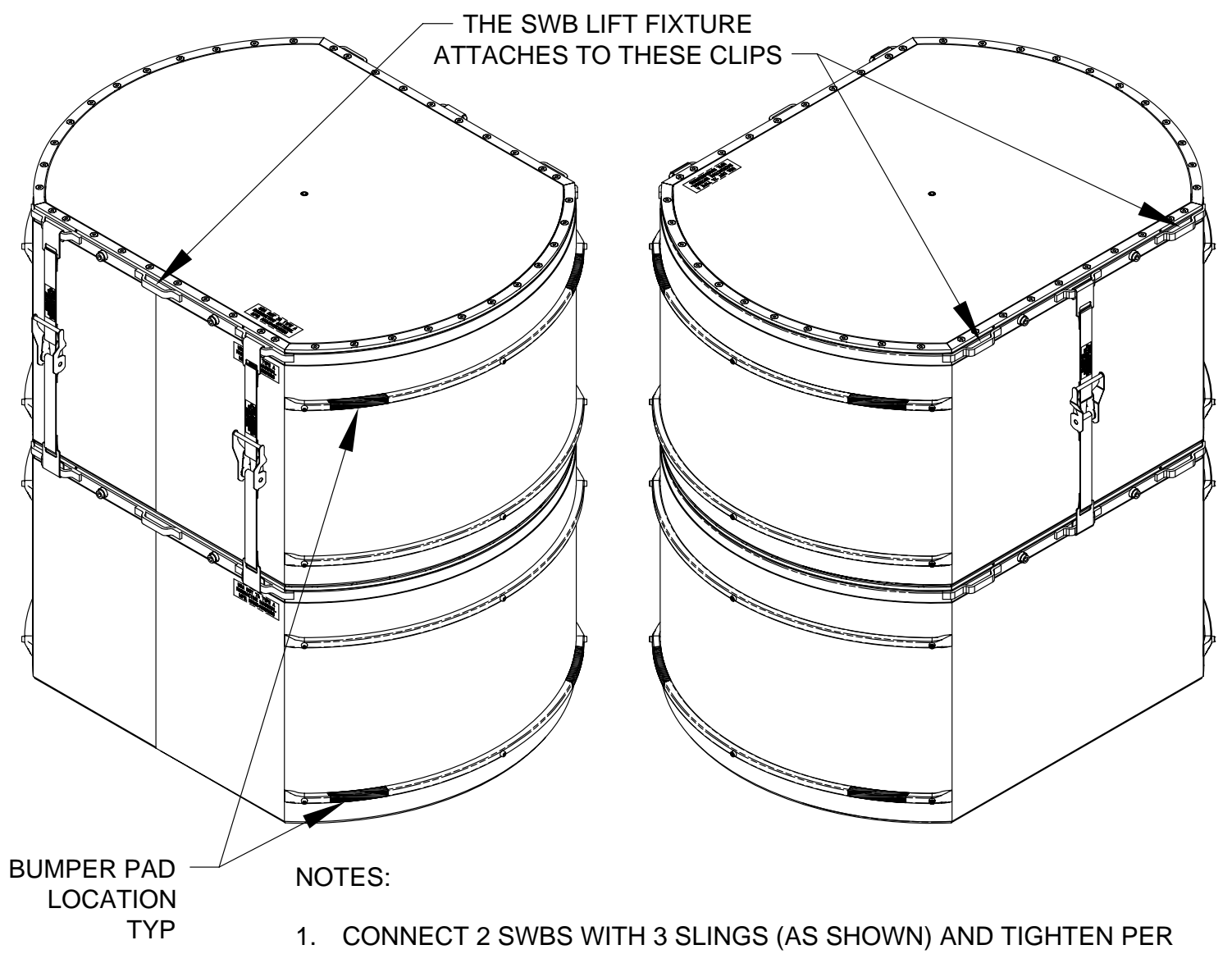
MFGR. INSTRUCTIONS.

2. ONLY THE COMPONENTS SHOWN IN FIGURE 1.6 ARE APPROVED FOR USE IN SWB PAYLOAD ASSEMBLY.

Inspection - Before each use, each SWB adjustable sling assembly shall be visually inspected to verify that the webbing red wear indicator threads are not exposed due to abrasion, and the annual inspection date has not elapsed.

Before lifting, the ratchet buckle shall be visually inspected to verify that the ratchet teeth are securely engaged and there are nominally three wraps (or 1-1/2 turns) of webbing around the mandrel. It is acceptable for the adjustable slings to be installed as shown in Figure 1.6, or in the reverse orientation with the handle pointed down.
The assembly shall also be checked to verify that the webbing is in tension before each loading operation and before each unloading operation.

Annual Inspection - Each SWB sling assembly including webbing, ratchet buckle, and hooks shall be inspected for signs of excessive wear, cracking, or physical damage. If the webbing, ratchet buckle, or hooks are excessively worn, cracked, or damaged, the assembly shall NOT be used. Annual inspection shall be recorded. 
Figure 1.7 - TDOP Payload Assembly

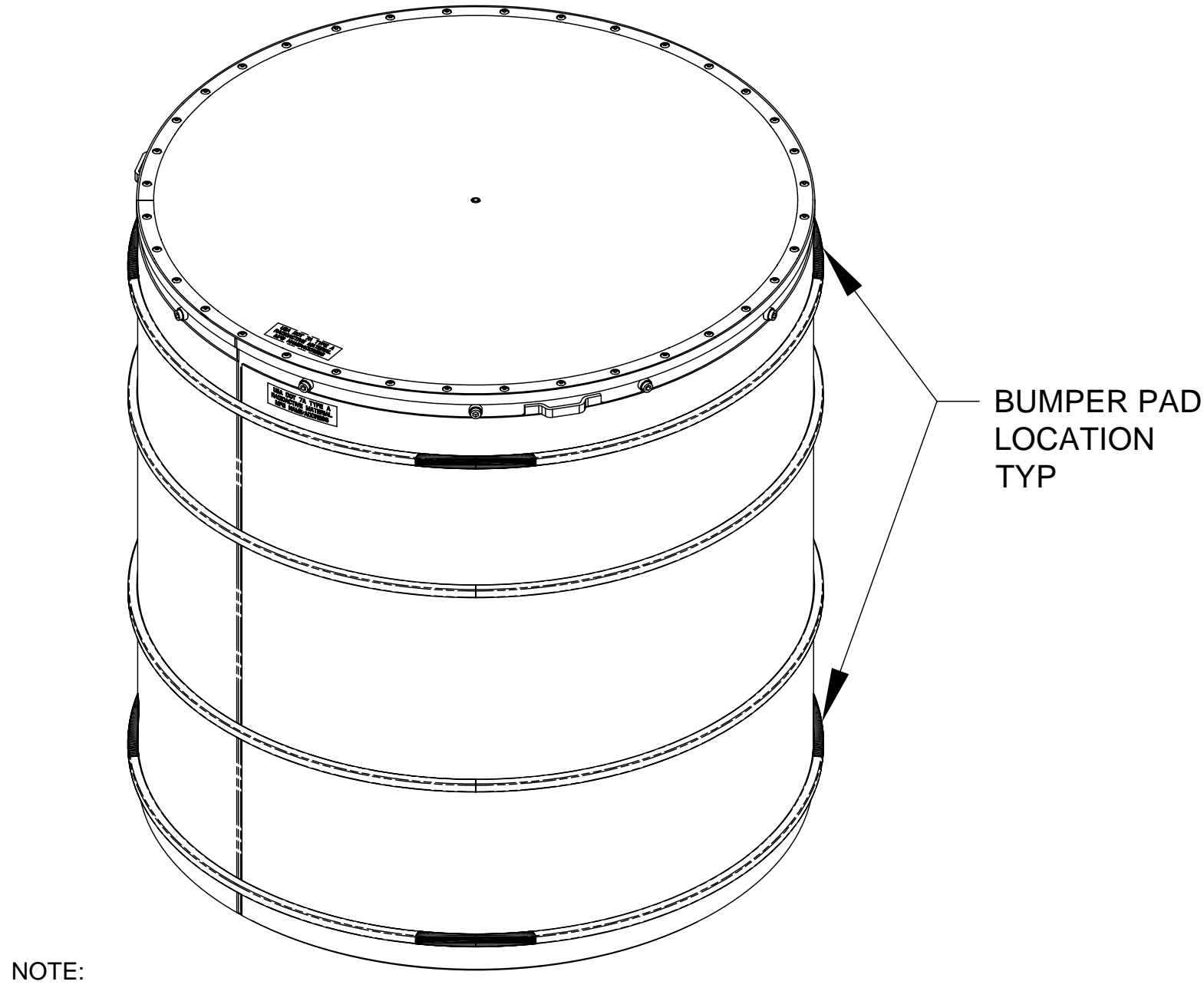

1. ONLY THE COMPONENTS SHOWN IN FIGURE 1.7 ARE APPROVED FOR USE IN TDOP PAYLOAD ASSEMBLY. 


\subsection{NORMAL OPERATING INSTRUCTIONS}

\section{CAUTION}

If the payload pallet will be placed on a square pallet for subsequent movement by forklift, care must be taken to ensure all three pockets used for lifting with the ACGLF rest on a flat surface. Failure to ensure this may result in pallet damage due to the weight of the ACGLF driving the pallet lift point through the pallet.

\section{NOTE}

Torquing of components that are replaced using the minor maintenance work instructions (WIs) may be completed during assembly step and do not require a second or repeat torque when using minor maintenance form.

\section{NOTE}

Transport trailer operations, package loading and unloading from transport trailers, hoisting and rigging activities such as ACGLF operations, equipment checkout and shutdown, and component inspection activities must be performed, but may be performed in any order and in parallel with other activities as long as radiological control steps are not bypassed. Steps involving OCA/ICV lid removal/installation and payload removal/loading may be performed in parallel if there are multiple operators working on the same packaging.

\subsection{Basic Information}

2.1.1 Introduction - This procedure provides operating instructions for the following $\mathrm{CH}$ packaging:

- TRUPACT-II

- HalfPACT

\subsubsection{References}

- $\quad 49$ CFR Part 172, "Hazardous Materials Table, Special Provisions, Hazardous Materials Communications, Emergency Response Information, and Training Requirements"

- $\quad 49$ CFR Part 173, "Shippers - General Requirements for Shipments and Packagings"

- U.S. Department of Energy, Safety Analysis Report for the TRUPACT-II Shipping Package 
- $\quad$ TRUPACT-II Certificate of Compliance No. 9218

- U.S. Department of Energy, Safety Analysis Report for the HalfPACT Shipping Package

- $\quad$ HalfPACT Certificate of Compliance No. 9279

- $\quad$ Contact-Handled Transuranic Waste Authorized Methods for Payload Control (CH-TRAMPAC)

- DOE/WIPP 02-3183, CH Packaging Program Guidance

- DOE/WIPP 02-3185, CH Packaging Maintenance Manual

- $\quad$ WP 08-PT.04, CH Packaging Trailer O\&M Manual

\subsubsection{Equipment}

- $\quad$ Calibrated Measuring and Test Equipment

- $\quad$ Pressure/vacuum gauge, 30 -in. $\mathrm{Hg}$ to $30 \mathrm{psig}$

- Torque wrench with 10 to 65 pound inches (lb-in.) range

- Torque wrench with 30 to 50 pound feet (lb-ft) range

- $\quad$ Crane load cell, 10,000 lb minimum rating

- $\quad$ Other Equipment

- Inner Containment Vessel (ICV)/Outer Containment Vessel (OCV) vent port plug removal/pressure relief tool

- Miscellaneous hardware and vacuum assembly connections

- Vacuum pump

- ICV/OCV outer vent port plug removal and installation tool

- Consumable Materials

- Vacuum grease

- Nickel bearing lubricant

- Denatured alcohol

- Lint free rags 


\subsubsection{Precautions and Limitations}

- Failure to rotate the counterweights on ACGLF to the balance position may cause ACGLF to swing uncontrollably.

- $\quad$ Measures shall be implemented by all users for the identification and control of parts and components. These measures shall be designed to prevent the use of incorrect or defective parts and components on the packaging.

- Jack stands are required on freestanding trailers only when loading/unloading packaging on the trailer.

- Metal tools must not be used to remove O-rings.

- $\quad$ OCV/ICV lids shall be removed using a straight (vertical) pull; side pulls are not permitted.

- $\quad$ Marking devices used on packaging components shall be low in chloride, fluoride, halide, and sulfur content.

\subsection{Packaging (Empty) Receipt}

\section{NOTE}

The packaging loading/unloading operation shall only be performed in a dry environment. In the event of precipitation during outdoor operations, the OCV and ICV cavities shall be covered to prevent precipitation from entering the package interior cavities. If precipitation does enter the interior cavities, all freestanding water shall be removed before shipment and liquid handled according to the sites waste management procedures.

2.2.1 Record OCA serial number on Attachment 1, CH Packaging Receipt and Inspection Data Sheet.

\section{SIGN-OFF}


2.2.2 Verify that the site representative performed the following:

- $\quad$ Released packaging for loading

- Validated shipping documents

- Inspected packaging for damage

- $\quad$ Checked nameplate to verify that packages are proper for contents being shipped

\section{SIGN-OFF}

2.2.3 Verify that packaging maintenance labels are legible and maintenance is current by checking maintenance labels adjacent to name plate and initial Attachment 1.

\section{SIGN-OFF}

2.2.4 Check for LEAK TEST REQUIRED tag near OCA vent port.

2.2.5 If LEAK TEST REQUIRED tag is present, remove tag and forward to supervisor so a leak test report will be sent to the WIPP M\&O CH Packaging Maintenance Engineer.

\section{CAUTION}

A physical check shall be made to verify that the air bags on trailer have fully inflated before trailer is moved. Failure to do so may cause the tires to rub on bottom of rear package.

2.2.6 Position transport trailer in designated parking area.

2.2.7 Lower trailer jacks (landing gear) ensuring trailer is level.

2.2.8 Install wheel chocks.

2.2.9 Install trailer stands on freestanding trailers.

2.3 Releasing Tiedowns and Removal of Packaging from Trailer

2.3.1 IF packaging will NOT be removed from trailer for loading operations,

THEN GO TO Subsection 2.4, OCA Lid Removal.

2.3.2 Release tiedowns from packaging. 


\section{NOTE}

Trailer tiedown guidance is provided in WP 08-PT.04. This document is available on the Internet at http://www.wipp.energy.gov/library/caolib.htm\#containers.

2.3.3 Rotate forklift pocket covers (4) to UP position, OR remove covers and store in designated area.

2.3.4 If required, dry packaging before transport to designated area.

\section{CAUTION}

Forklift tip-back beyond level may damage package exterior surface.

\subsubsection{Transfer packaging to designated area.}

2.4 OCA Lid Removal

2.4.1 Prepare OCA lid by removing the following:

- OCA lift pocket covers

- $\quad$ OCA lock bolts (6)

- $\quad$ OCV seal test port access plug and thermal plug

- $\quad$ OCV vent port access plug and thermal plug

\section{NOTE}

If OCA lid is turned so that the OCV seal test port plug is not accessible, Step 2.4.2 cannot be performed; operator must proceed to Step 2.4.3.

2.4.2 Verify that the OCV seal test port plug is fully seated.

2.4.3 Remove OCV vent port cover.

2.4.4 Remove OCV vent port plug.

\section{CAUTION}

Operator shall verify that the two ACGLF counterweights are at 180 degrees and 000 degrees ( \pm 2 degrees) BEFORE lifting ACGLF or lid.

\subsubsection{Attach ACGLF to OCA lid.}

\subsubsection{Install OCV vent port tool.}


2.4.7 Connect vacuum line to vent port tool.

2.4.8 Start vacuum pump and evacuate to 3 to $15 \mathrm{in.} \mathrm{Hg}$ vacuum gauge.

2.4.9 Rotate OCV lock ring to UNLOCKED position.

2.4.10 Stop vacuum pump.

2.4.11 Disconnect vacuum line from vent port tool.

2.4.12 Remove vent port tool.

2.4.13 Let OCV vent to atmosphere.

\section{CAUTION}

Operator shall verify that the two ACGLF counterweights are at 180 degrees and 000 degrees ( \pm 2 degrees) BEFORE lifting ACGLF or lid.

\section{CAUTION}

Load cell reading MUST NOT exceed 7,500 lb when weight of ACGLF is zeroed out, OR $10,000 \mathrm{lb}$ when weight of ACGLF is included.

\subsubsection{Remove OCA lid.}

2.4.15 IF lid does not lift off, THEN perform the following:

[A] Contact supervisor.

[ B ] GO TO Subsection 3.2, Using Heat Guns OR Subsection 3.3, Pressurizing with Nitrogen or Compressed Air, attempt to remove lid and RETURN TO Step 2.4.16.

\subsubsection{Place OCA lid on storage stand.}


2.5 ICV Lid Removal

\section{CAUTION}

Operator shall verify that the two ACGLF counterweights are at 180 degrees and 000 degrees ( \pm 2 degrees) BEFORE lifting ACGLF or lid.

2.5.1 Attach ACGLF to ICV lid.

2.5.2 Remove ICV vent port cover.

2.5.3 Remove the following:

- $\quad$ ICV outer vent port plug

- $\quad$ ICV lock bolts (3)

- $\quad$ ICV seal test port plug

- $\quad$ OCV seal test port plug

2.5.4 Remove ICV inner vent port plug.

2.5.5 Install ICV vent port tool.

2.5.6 Connect vacuum line to vent port tool.

2.5.7 Start vacuum pump and evacuate to 3 to $15 \mathrm{in}$. $\mathrm{Hg}$ vacuum gauge.

2.5.8 Rotate ICV lock ring to UNLOCKED position.

2.5.9 Stop vacuum pump.

2.5.10 Disconnect vacuum line from vent port tool.

2.5.11 Remove vent port tool.

2.5.12 Vent ICV to atmosphere.

\section{CAUTION}

Load cell reading MUST NOT exceed 5,000 lb when weight of ACGLF is zeroed out, OR $7,500 \mathrm{lb}$ when weight of ACGLF is included.

2.5.13 Remove ICV lid using ACGLF and crane. 
2.5.14 IF lid does not lift off ICV,

THEN perform the following:

[A] Contact supervisor.

[B ] GO TO Subsection 3.2, OR Subsection 3.3, attempt to remove lid and RETURN TO Step 2.5.15.

2.5.15 Place ICV lid on storage stand.

\section{NOTE}

Use of the ACGLF with short legs to remove items from the ICV is NOT permitted.

2.5.16 Remove any payload pallets, guide tubes, slip sheets, reinforcement sheets, dunnage containers, etc.

2.6 Preloading/Shipping Operational Checks and Examinations

2.6.1 Radiological Control Technician (RCT), IF surveys for items in Step 2.7.1, Step 2.8.1, or Step 2.9.1 have been completed previously AND results are below contamination limits, THEN enter applicable data for each step on Attachment 1.

2.6.2 RCT, IF surveys have NOT been completed previously, THEN GO TO Subsection 2.7, OCA Lid Inspection and Cleaning, Subsection 2.8, ICV Lid Inspection and Cleaning, or Subsection 2.9, OCA Body Inspection and Cleaning, as applicable.

\section{NOTE}

Subsections 2.7 through 2.13, ICV Cavity Inspection (and included steps), MUST be completed, but may be performed in any order as long as radiological control steps are not bypassed.

2.7 OCA Lid Inspection and Cleaning

2.7.1 RCT, IF survey has not been completed previously, THEN survey interior and exterior of OCA lid and record applicable data on Attachment 1.

\section{SIGN-OFF}


2.7.2 Inspect OCA lid for the following:

- Visible deformation

- Dents or abnormal flat spots $>1 / 2$ in.

- Abnormal scratches or gouges

- Obvious punctures, tears, or cracks in exposed welds

- $\quad$ Plastic burnout plugs (3) in place and intact

- $\quad$ Fiberglass lift pocket tubes in place

- Distortions or cracks on or around lifting attachments

- $\quad$ Lift pocket covers attached and serviceable

- $\quad$ OCV locking Z-flange screws in place and no visible space between screw head and locking Z-flange; if screws are missing, or a space appears between screw head and locking Z-flange, then go to corresponding WI.

- $\quad$ Guide plates and screws in place, and screws torqued to $21 \pm 2 \mathrm{lb}$-in., or verify there is no looseness in the plate and the screws are recessed.

- Seal surfaces for scratches/gouges perpendicular to machining marks

2.7.3 Remove foreign material from the following:

- $\quad$ Lock ring

- $\quad$ Sealing surfaces

- $\quad$ Test port access threads

2.7.4 Verify that the arrow above seal test port aligns with UNLOCKED arrow on lock ring.

2.7.5 Initial Attachment 1 to document OCA lid components and hardware are satisfactory.

\section{SIGN-OFF}


2.8 ICV Lid Inspection and Cleaning

\section{NOTE}

O-rings are considered clean when they are absent of free-standing vacuum grease, dirt, debris, and other foreign matter.

2.8.1 RCT, IF survey has NOT been completed previously, THEN survey interior and exterior of ICV lid and record applicable data on Attachment 1.

\section{SIGN-OFF}

2.8.2 Inspect ICV lid for the following:

- Visible deformation

- $\quad$ Punctures

- Abnormal scratches or gouges

- Distortions on or around lifting attachments

- $\quad$ Upper spacer and screws installed and no visible space between screw head and spacer top plate; if screws are missing, or a space appears between screw head and spacer top plate, then go to corresponding WI.

- Debris shield installed and undamaged

- $\quad$ Lock ring undamaged

- $\quad$ Damaged or missing screws from wiper O-ring holder

- $\quad$ Seal surfaces for scratches/gouges perpendicular to machining marks

2.8.3 Remove foreign material from the following:

- Lock ring flange

- Debris shield

- $\quad$ Sealing surfaces

2.8.4 Remove ICV wiper O-ring.

2.8.5 Clean ICV wiper O-ring and inspect for wear or damage that could impair its function. 
2.8.6 IF O-ring is damaged,

THEN GO TO corresponding WI and RETURN TO Step 2.8.9.

2.8.7 Lubricate wiper O-ring with a light coat of vacuum grease.

2.8.8 Install wiper O-ring.

2.8.9 Initial Attachment 1 to document ICV lid components and hardware are satisfactory.

\section{SIGN-OFF}

2.9 OCA Body Inspection and Cleaning

2.9.1 RCT, IF survey has NOT been completed previously, THEN survey OCA body exterior and ICV body interior and record applicable data on Attachment 1.

\section{SIGN-OFF}

2.9.2 Remove upper and lower main O-rings and set aside for cleaning and inspection.

2.9.3 Inspect OCA body for the following:

- Visible deformation

- Obvious punctures or tears

- Obvious cracks in exposed welds

- Dents or abnormal flat spots $>1 / 2$ in.

- Abnormal scratches or gouges

- $\quad$ Plastic burnout plugs (6) in place and undamaged

- $\quad$ Forklift pocket cover threaded inserts (8) intact and threads undamaged

- $\quad$ Lock bolt threaded inserts (6) intact and threads undamaged

- Tears or fraying $>1 / 4$ in. in ceramic fiber gasket

- $\quad$ Full width and length of ceramic fiber gasket adhered to lower Z-flange 
- $\quad$ Lock ring stop(s) undamaged

- $\quad$ Upper and lower O-ring grooves and seal surfaces for scratches/gouges perpendicular to machining marks

2.9.4 Remove foreign material from the following:
- $\quad$ Test port threads
- Vent port threads
- Lock ring flange
- O-ring grooves
- $\quad$ Sealing surfaces

2.9.5 Verify air flow through OCV helium test ports.

2.9.6 Initial Attachment 1 to document OCA body inspection is satisfactory.

\section{SIGN-OFF}

\subsection{OCA Components Inspection and Cleaning}

\section{NOTE}

O-rings are considered clean when they are absent of free-standing vacuum grease, dirt, debris, and other foreign matter.

2.10.1 Clean and inspect the following for wear or damage that could impair their function:

- $\quad$ OCV vent port plug and handling O-ring

- OCV vent port cover and O-rings

- OCV seal test port plug and seal O-ring

- $\quad$ Lock bolts (6)

- $\quad$ OCV seal test port access plug

- $\quad$ OCV vent port access plug

2.10.2 IF components are damaged,

THEN GO TO corresponding WI and RETURN TO Step 2.10.4.

2.10.3 Apply a light coat of vacuum grease to the following:

- $\quad$ OCV vent port plug threads

- $\quad$ OCV vent port cover threads and seal O-ring

- $\quad$ OCV seal test port plug threads and seal O-ring

2.10.4 Verify that the annulus debris seal is installed and undamaged. 
2.10.5 Lightly coat the following with nickel bearing lubricant:

- $\quad$ OCA lock bolt threads (6)

- OCV seal test port access plug threads

- OCV vent port access plug threads

2.10.6 Clean and inspect upper and lower main O-rings and vent port plug seal O-ring for damage that could impair containment integrity.

2.10.7 IF O-rings are damaged,

THEN GO TO corresponding WI and RETURN TO Step 2.10.9.

\section{NOTE}

Lubrication and installation of upper and lower main O-rings may be performed after Step 2.16.19, but prior to Subsection 2.18, OCA Lid Installation.

2.10.8 Lubricate upper and lower main O-rings and vent port plug seal O-ring with a light coat of vacuum grease.

\subsubsection{Install:}

- $\quad$ OCV upper main O-ring

- $\quad$ OCV lower main O-ring with identifying mark near vent port

- $\quad$ OCV vent port plug seal O-ring

\section{SIGN-OFF}

2.10.10 Initial Attachment 1 to document OCA component and hardware inspections are satisfactory.

\section{SIGN-OFF}

\subsection{ICV Body Inspection and Cleaning}

2.11.1 Remove upper and lower main O-rings and set aside for cleaning and inspection.

2.11.2 Inspect for the following:

- $\quad$ Lock ring stop(s) undamaged

- $\quad$ Lock bolt threaded inserts installed and threads undamaged 
2.11.3 Remove foreign material from the following:

- $\quad$ Test port threads

- Vent port threads

- $\quad$ Lock ring flange

- O-ring grooves

- Filter ports

- $\quad$ Sealing surfaces

2.11.4 Inspect the following:

- $\quad$ Upper and lower O-ring grooves and sealing surfaces for scratches/gouges perpendicular to machining marks

- Vent port threads for damage

- $\quad$ Seal test port threads for damage

- $\quad$ Lock ring flange for galling and burrs

- Lower spacer installed with no punctures in top plate

- $\quad$ Lower spacer screws installed and no detectable gap between screw head and spacer top plate

2.11.5 Verify airflow through ICV helium test ports.

2.11.6 Initial Attachment 1 to document ICV body inspection is satisfactory.

\section{SIGN-OFF}

\subsection{ICV Components Inspection and Cleaning}

\section{NOTE}

O-rings are considered clean when they are absent of free-standing vacuum grease, dirt, debris, and other foreign matter.

2.12.1 Clean and inspect the following for wear or damage that could impair their function:

- $\quad$ ICV vent port cover and seal (gasket or O-ring)

- $\quad$ ICV outer vent port plug

- $\quad$ ICV inner vent port plug and seal O-ring

- $\quad$ ICV seal test port plug and seal O-ring

- ICV lock bolts (3)

2.12.2 IF components are damaged,

THEN GO TO corresponding WI and RETURN TO Step 2.12.4. 
2.12.3 Apply a light coat of vacuum grease to the following:

- $\quad$ ICV vent port cover threads (and O-ring if installed)

- $\quad$ ICV outer vent port plug threads

- $\quad$ ICV inner vent port plug threads and seal O-ring

- $\quad$ ICV seal test port plug threads and seal O-ring

2.12.4 Coat ICV lock bolt threads (3) lightly with nickel bearing lubricant.

2.12.5 Clean upper and lower main O-rings and ICV outer vent port plug seal O-ring, and inspect for damage that could impair containment integrity.

2.12.6 IF O-rings are damaged,

THEN GO TO corresponding WI and RETURN TO Step 2.12.8.

\section{NOTE}

Lubrication and installation of upper and lower main O-rings may be performed after Step 2.16.18, but prior to Subsection 2.17, ICV Lid Installation.

2.12.7 Lubricate upper and lower main O-rings and ICV outer vent port plug seal O-ring with a light coat of vacuum grease.

2.12.8 Install:

- $\quad$ ICV upper main O-ring

- $\quad$ ICV lower main O-ring with identifying mark near vent port

- $\quad$ ICV outer vent port plug seal O-ring

\section{SIGN-OFF}

2.12.9 Initial Attachment 1 to document ICV components and hardware inspections are satisfactory.

\section{SIGN-OFF}

\subsection{ICV Cavity Inspection}

2.13.1 Check ICV cavity for water by visually inspecting the absorbent material inserted into hole in lower spacer assembly. 


\section{NOTE}

Disposal of absorbent material and water will be at direction of RCT.

2.13.2 IF water is inside ICV,

THEN perform one of the following:

- $\quad$ Remove water through center hole of lower spacer assembly using wet/dry vacuum

- Attach absorbent material to rod and insert in hole in center of lower spacer assembly

2.13.3 IF water is inside ICV, THEN GO TO Subsection 3.1, Empty ICV Assembly Removal, perform steps and RETURN TO Step 2.13.4.

2.13.4 Initial Attachment 1 to document ICV is free of water.

\section{SIGN-OFF}

2.13.5 Verify that the ICV cavity is free of foreign objects (i.e., smears, gloves, filters, etc.) and initial Attachment 1.

\section{SIGN-OFF}

\subsection{Pre-Loading Operations}

2.14.1 Verify that all pre-loading cleaning and inspections are complete.

\section{SIGN-OFF}

2.15 Packaging Receipt and Inspection Data Sheet Validation

\section{NOTE}

Step 2.15.1 may be performed after Step 2.16.18, but prior to beginning of Subsection 2.17.

2.15.1 Supervisor, review/validate and sign Attachment 1.

\section{SIGN-OFF}


2.16 Loading Payload Assembly

\section{NOTE}

For shipments to WIPP, shipper shall verify that each payload container number has been entered into WIPP Waste Information System (WWIS) and verify that the shipment has been approved by WIPP WWIS Data Administrator, and the final submittal has occurred.

2.16.1 Record OCA serial number on Attachment 2, CH Packaging Loading Data Sheet.

\section{SIGN-OFF}

2.16.2 Record pallet or SWB ratchet strap serial numbers on Attachment 2.

\section{SIGN-OFF}

2.16.3 Verify that the pallet or SWB ratchet straps annual inspection due date has not elapsed, and record on Attachment 2 the annual inspection due date that is shown on pallet or SWB ratchet strap's stickers.

\section{SIGN-OFF}

2.16.4 Verify that the payload is assembled using requirements delineated in the CH-TRAMPAC and initial Attachment 2.

\section{SIGN-OFF}

\section{CAUTION}

Operator shall verify that the two ACGLF counterweights are at 180 degrees and 000 degrees ( \pm 2 degrees) BEFORE lifting ACGLF or lid.

2.16.5 Attach appropriate legs/adapter to ACGLF.

\section{NOTE}

HalfPACT payloads require a HalfPACT payload spacer for all assemblies except the "tall" (40-1/4 in.) 85-gallon four-pack.

2.16.6 Install HalfPACT payload spacer, if needed, otherwise, GO TO Step 2.16.7. 
2.16.7 Lower ACGLF long legs into drum payload assembly guide tubes,

OR lower SWB or TDOP adaptor until no load is indicated on crane load cell.

2.16.8 Lock ACGLF legs,

OR attach SWB lift fixture to upper SWB or TDOP adaptor to TDOP as applicable.

2.16.9 Raise payload 2 to 6 in.

2.16.10 If necessary, balance payload using counter weight controls at ACGLF console until a reading of \pm 0.5 degrees is obtained.

\section{NOTE}

Payload assembly weight shall be equal to or less than the limits specified in the CH-TRAMPAC.

2.16.11 Record payload assembly weight (drum [or SWBs, TDOP] + spacer + pallet + guide tubes + slip sheets + ratchet straps + bumper pads + stretch wrap, etc.) on Attachment 2.

\section{SIGN-OFF}

2.16.12 Obtain packaging weight from WIPP WWIS Packaging Reference Data Table.

2.16.13 Record empty packaging weight on Attachment 2 .

\section{SIGN-OFF}

2.16.14 Add two previously recorded weight values to calculate the total package weight and record on data sheet.

\section{SIGN-OFF}

2.16.15 Verify that the total loaded package weight does not exceed the limits below:
- TRUPACT-II
$19,250 \mathrm{lb}$
- HalfPACT
$18,100 \mathrm{lb}$

2.16.16 Raise and position payload assembly over ICV cavity using crane and ACGLF.

2.16.17 Verify that the payload is centered over ICV BEFORE lowering load. 


\section{CAUTION}

Care should be exercised to avoid hitting, scraping, or binding the payload assembly against ICV body flange and internal surface.

\subsubsection{Lower payload assembly into ICV.}

2.16.19 Record weight positions of ACGLF on top of payload near leg opposite the electrical junction boxes.

\section{CAUTION}

Operator shall verify that the two ACGLF counterweights are at 180 degrees and 000 degrees ( \pm 2 degrees) BEFORE lifting ACGLF or lid.

\subsubsection{Remove ACGLF/adaptor from payload.}

2.17 ICV Lid Installation

2.17.1 Match ICV lid and body serial numbers and record ICV serial number on Attachment 2.

\section{SIGN-OFF}

2.17.2 Record torque wrench serial numbers and calibration due date on Attachment 2.

\section{SIGN-OFF}

\section{CAUTION}

Operator shall verify that the two ACGLF counterweights are at 180 degrees and 000 degrees ( \pm 2 degrees) BEFORE lifting ACGLF or lid.

2.17.3 Attach ACGLF to ICV lid.

2.17.4 Align UNLOCKED arrows and install ICV lid onto ICV body using crane and ACGLF.

2.17.5 Install ICV vent port tool into ICV vent port.

2.17.6 Connect vacuum line to ICV vent port tool. 


\section{CAUTION}

Vacuum should not exceed 15-in. Hg when evacuating ICV cavity.

2.17.7 Start vacuum pump and evacuate to 3 to $15 \mathrm{in.} \mathrm{Hg}$ vacuum gauge.

2.17.8 Rotate ICV lock ring to LOCKED position.

2.17.9 Stop vacuum pump.

2.17.10 Disconnect vacuum line from vent port tool.

2.17.11 Remove ICV vent port tool.

2.17.12 Install ICV inner vent port plug.

2.17.13 Torque inner vent port plug to 55 to $65 \mathrm{lb}$-in.

\section{SIGN-OFF}

2.17.14 Perform ICV preshipment leakage rate test per Section 4.0, Preshipment Leakage Rate Testing.

\section{SIGN-OFF}

2.17.15 Install ICV lock bolts (3).

2.17.16 Torque each ICV lock bolt to 28 to $32 \mathrm{lb}-\mathrm{ft}$.

\section{SIGN-OFF}

2.18 OCA Lid Installation

2.18.1 Verify that all items (tools, parts, rags, etc.) have been removed from the lower Z-flange/seal flange area(s).

\section{SIGN-OFF}

2.18.2 Match OCA lid and body serial numbers.

2.18.3 Record OCA serial number on Attachment 2.

\section{SIGN-OFF}




\section{CAUTION}

Operator shall verify that the two ACGLF counterweights are at 180 degrees and 000 degrees ( \pm 2 degrees) BEFORE lifting ACGLF or lid.

2.18.4 Attach ACGLF to OCA lid.

2.18.5 Align UNLOCKED arrows and install OCA lid onto OCA body.

2.18.6 Verify that the OCV vent port plug is retracted into OCV vent port tool.

2.18.7 Install OCV vent port tool into OCV vent port.

2.18.8 Connect vacuum line to OCV vent port tool.

2.18.9 Start vacuum pump and evacuate to 3 to $15 \mathrm{in}$. $\mathrm{Hg}$ vacuum gauge.

2.18.10 Rotate OCV lock ring to LOCKED position.

2.18.11 Stop vacuum pump.

2.18.12 IF existing connection will be used for OCV leak test, THEN GO TO Step 2.18.14.

2.18.13 Disconnect vacuum line from vent port tool.

2.18.14 GO TO Section 4.0, perform OCV preshipment leakage rate test.

\section{SIGN-OFF}

2.18.15 Install OCA lock bolts (6).

2.18.16 Torque each OCA lock bolt to 28 to $32 \mathrm{lb}$ - $\mathrm{ft}$ and initial Attachment 2.

\section{SIGN-OFF}

2.18.17 Install OCA lift pocket covers.

2.18.18 Install tamper-indicating security seal in both lock bolt on OCA lock ring assembly and OCV vent port access plug. 
2.18.19 Record tamper-indicating security seals serial numbers on Attachment 2.

\section{SIGN-OFF}

2.18.20 Supervisor, review/validate and sign Attachment 2 .

\section{SIGN-OFF}

2.19 Installation of Package onto Transport Trailer

\section{NOTE}

When loading packages on trailer, or loading payload into packaging that is already on trailer, the following applies:

- $\quad$ Packages having a gross weight difference (heaviest to lightest) of $1,000 \mathrm{lb}$ or less can be considered equal and do not require a specific sequence for positioning on the trailer.

- $\quad$ Packages having a gross weight difference (heaviest to lightest), greater than $1,000 \mathrm{lb}$ shall be positioned on the trailer as follows:

\begin{tabular}{|l|l|l|l|l|}
\hline \multirow{3}{*}{$\begin{array}{l}\text { TRAILER } \\
\text { FRONT }\end{array}$} & 1. Heaviest & Medium & Lightest & \\
\cline { 2 - 4 } & 2. Heaviest & Lightest & None & TRAILER \\
\cline { 2 - 4 } & REAR \\
\cline { 2 - 4 } & 3. Heaviest & None & None & \\
\hline
\end{tabular}

2.19.1 Record the following on Attachment 3, Loaded CH Package Trailer Data Sheet:

- $\quad$ Shipment number

- $\quad$ Trailer number

- $\quad$ Package number(s)

\section{SIGN-OFF}

2.19.2 Verify that the annual trailer inspection is current.

2.19.3 Record trailer inspection performed date on Attachment 3.

\section{SIGN-OFF}




\section{NOTE}

Trailer tiedown guidance is provided in WP 08-PT.04. This document is available on the Internet at http://www.wipp.energy.gov/library/caolib.htm\#containers.

2.19.4 Inspect tiedowns for the following:

- Damage

- Defects

2.19.5 IF packaging was removed for loading operations, THEN perform the following:

[ A ] Position transport trailer in designated area.

[ B ] Lower trailer jacks (landing gear), ensuring trailer is level.

[ C ] Install wheel chocks.

[D ] Install jack stands on freestanding trailers.

\section{CAUTION}

Forklift tip-back beyond level may damage package exterior surface.

[E] Transport package to transport trailer.

[ F ] Load package designated for position \#1 onto trailer with vent port on driver side of trailer.

[ G ] If applicable, load package designated for position \#2 onto trailer with vent port on driver side of trailer.

[ $\mathrm{H}$ ] If applicable, load package designated for position \#3 onto trailer with vent port on driver side of trailer.

\section{NOTE}

Trailer tiedown guidance is provided in WP 08-PT.04. This document is available on the Internet at http://www.wipp.energy.gov/library/caolib.htm\#containers.

[ I ] Install four tiedown assemblies for each package loaded on trailer.

[ J ] Install package forklift pocket access covers. 
2.19.6 Record package positions and weights on Attachment 3.

\section{SIGN-OFF}

\section{NOTE}

The total weight of tractor, trailer, and payload cannot exceed $80,000 \mathrm{lb}$. If the total weight of the tractor, trailer, and payload is greater than or equal to $77,500 \mathrm{lb}$, the shipment should be scaled to ensure that the $20,000 \mathrm{lb}$ trailer axle weight limitation and $80,000 \mathrm{lb}$ gross weight limitation are not exceeded.

2.19.7 Record total weight of all loaded packages as payload weight on Attachment 3.

\section{SIGN-OFF}

2.19.8 Verify that the package(s) is in compliance with 49 CFR Part 172, Subpart D "Marking," Subpart E, "Labeling," and Subpart F, "Placarding," and initial Attachment 3.

\section{SIGN-OFF}

2.19.9 Complete information transfer to shipping papers, including packaging pallet ID numbers and SWB ratchet strap serial numbers, as required, for the specific shipment.

2.19.10 Verify that shipping papers are in accordance with 49 CFR Part 172, Subpart C, "Shipping Papers," and initial Attachment 3.

\section{SIGN-OFF}

2.19.11 Initial for trailer loading complete on Attachment 3.

\section{SIGN-OFF}

2.19.12 Supervisor, review/validate and sign Attachment 3.

\section{SIGN-OFF}




\section{NOTE}

The package unloading operation shall only be performed in a dry environment. In the event of precipitation during outdoor unloading or loading operations, OCV and ICV cavities shall be covered to prevent precipitation from entering the interior cavities. If precipitation does enter interior cavities, all freestanding water shall be removed before shipment and liquid handled according to the site's waste management procedures.

2.20.1 Record OCA serial number on Attachment 4, Loaded Package Receipt and Processing Data Sheet.

\section{SIGN-OFF}

2.20.2 Verify that the site representative has performed the following and initial Attachment 4:

- Validated shipping documents

- Inspected package(s) for damage

- $\quad$ Released package(s) for unloading

\section{SIGN-OFF}

2.20.3 Survey package for external radiation and contamination using site-specific procedures and initial Attachment 4.

\section{SIGN-OFF}

\section{CAUTION}

A physical check shall be made to verify that the air bags on the trailer have fully inflated before trailer is moved. Failure to do so may cause the tires to rub on bottom of rear package.

2.20.4 Position transport trailer in designated area.

2.20.5 Lower trailer jacks (landing gear), ensuring trailer is level.

2.20.6 Install wheel chocks.

2.20.7 Install trailer stands on freestanding trailers.

2.21 Releasing Tiedowns and Removal of Package from Trailer

2.21.1 IF package will NOT be removed from trailer, THEN GO TO Subsection 2.22, OCA Lid Removal. 
2.21.2 Release tiedowns from packaging.

\section{NOTE}

Additional trailer tiedown guidance is provided in WP 08-PT.04. This document is available on the Internet at http://www.wipp.energy.gov/library/caolib.htm\#containers.

2.21.3 Rotate four forklift pocket covers to UP position, OR remove four covers and store in designated area.

2.21.4 If required, dry package before transport to designated area.

\section{CAUTION}

Forklift tip-back beyond level may damage package exterior surface.

2.21.5 Transfer package to unloading area.

2.22 OCA Lid Removal

2.22.1 Remove and dispose of security seals.

2.22.2 If seal is broken or missing, follow applicable site policy.

2.22.3 Remove the following components to prepare OCA lid for removal:

- OCA lift pocket covers

- $\quad$ OCV test port access plug and thermal plug

- $\quad$ OCV vent port access plug and thermal plug

- $\quad$ OCA lock bolts (6)

\section{NOTE}

If OCA lid is turned so that the OCV seal test port plug is not accessible, Step 2.22.4 cannot be performed, and operator must proceed to Step 2.22.5.

2.22.4 Verify that the OCV seal test port plug is fully seated.

2.22.5 Remove OCV vent port cover.

\section{NOTE}

Torque on OCV vent port plug may be relieved prior to installation of OCV vent port tool. 
2.22.7 Retrieve OCV vent port plug into vent port tool.

2.22.8 Connect vacuum line to vent port tool.

2.22.9 Start vacuum pump and evacuate to 3 to $15 \mathrm{in}$. $\mathrm{Hg}$ vacuum gauge.

2.22.10 Rotate OCV Lock ring to UNLOCKED position.

2.22.11 Stop vacuum pump.

2.22.12 Disconnect vacuum line from vent port tool.

2.22.13 Remove vent port tool.

\section{CAUTION}

Operator shall verify that the two ACGLF counterweights are at 180 degrees and 000 degrees ( \pm 2 degrees) BEFORE lifting ACGLF or lid.

\subsubsection{Attach ACGLF to OCA lid.}

\section{CAUTION}

Load cell reading MUST NOT exceed 7,500 lb when weight of ACGLF is zeroed out, OR $10,000 \mathrm{lb}$ when weight of ACGLF is included.

2.22.15 Raise OCA lid slowly about 6 in. above the top of ICV lid, OR as directed by RCT.

2.22.16 IF lid does not lift off,

THEN perform the following:

[A] Contact supervisor.

[ B ] GO TO Subsection 3.2 or Subsection 3.3, attempt to remove lid, and RETURN TO Step 2.22.17.

HOLD POINT

2.22.17 RCT, survey OCA lid interior surface and ICV lid exterior surface for radiation/contamination following site-specific procedures. 
2.22.18 Place OCA lid on storage stand.

\subsection{ICV Lid Removal}

\section{CAUTION}

Operator shall verify that the two ACGLF counterweights are at 180 degrees and 000 degrees ( \pm 2 degrees) BEFORE lifting ACGLF or lid.

2.23.1 Attach ACGLF to ICV lid.

2.23.2 Remove ICV vent port cover.

2.23.3 Remove the following:

- $\quad$ ICV outer vent port plug

- $\quad$ ICV seal test port plug

- $\quad$ ICV lock bolts (3)

- $\quad$ OCV seal test port plug

\section{WARNING}

ICV inner vent port plug MUST NOT be removed if torque is relieved prior to installing ICV vent port tool. Plug removal may result in contamination of personnel and area.

\section{NOTE}

Torque on ICV inner vent port plug may be relieved prior to installation of ICV vent port tool.

2.23.4 Install ICV vent port tool.

2.23.5 Connect vacuum hose to vent port tool.

2.23.6 Retrieve ICV inner vent port plug into ICV vent port tool.

\section{CAUTION}

Vacuum should not exceed 15-in. Hg when attempting to open ICV.

2.23.7 Start vacuum pump and evacuate to 3 to $15 \mathrm{in}$. $\mathrm{Hg}$ vacuum gauge.

2.23.8 Rotate ICV lock ring to UNLOCKED position. 
2.23.9 Stop vacuum pump.

2.23.10 Disconnect vacuum line from ICV vent port tool.

\section{HOLD POINT}

2.23.11 RCT, survey for radiation/contamination using site-specific procedures.

\section{SIGN-OFF}

2.23.12 Remove ICV vent port tool and ICV inner vent port plug.

\section{CAUTION}

Load cell reading MUST NOT exceed 5,000 lb when weight of ACGLF is zeroed out, OR $7,500 \mathrm{lb}$ when weight of ACGLF is included.

2.23.13 Raise ICV lid slowly to clear ICV body and hold it about $2 \mathrm{ft}$ above the top of ICV body flange,

OR as directed by RCT.

2.23.14 IF lid does not lift off ICV,

THEN perform the following:

[A] Contact Supervisor.

[ B ] GO TO Subsection 3.2, OR Subsection 3.3, attempt to remove lid, and RETURN TO Step 2.23.15.

\section{HOLD POINT}

2.23.15 RCT, survey ICV lid interior surface and top of payload for radiation/contamination using site-specific procedures.

\section{SIGN-OFF}

2.23.16 Place ICV lid on storage stand. 
2.24 Unloading Payload Assembly

\section{CAUTION}

Operator shall verify that the two ACGLF counterweights are at 180 degrees and 000 degrees ( \pm 2 degrees) BEFORE lifting ACGLF or lid.

2.24.1 Attach ACGLF with appropriate legs/adaptor to payload.

2.24.2 Position ACGLF counterweights to predetermined positions as marked on top of payload.

\section{NOTE}

Steps 2.24.3 and 2.24.4 are to be performed concurrently to remove payload.

2.24.3 Raise payload assembly slowly.

2.24.4 Inspect payload for damage.

\section{SIGN-OFF}

\section{HOLD POINT}

2.24.5 RCT, survey payload assembly as it is raised for radiation/contamination using site-specific procedures.

\section{SIGN-OFF}

2.24.6 If payload is damaged, follow site-specific procedures.

2.24.7 Place payload assembly in designated area.

2.24.8 Supervisor, review/validate and sign Attachment 4.

\section{SIGN-OFF}

2.25 Packaging Operational Checks and Examinations

2.25.1 Record OCA serial number on Attachment 5, Empty Packaging Shipment Data Sheet.

\section{SIGN-OFF}


2.25.2 Record torque wrench serial numbers and calibration due date on Attachment 5.

\section{SIGN-OFF}

2.25.3 Verify that packaging maintenance labels are legible and maintenance is current by checking maintenance labels adjacent to name plate and initial Attachment 5 .

\section{SIGN-OFF}

2.25.4 RCT, IF surveys for items in Step 2.26.1, Step 2.27.1, or Step 2.28.1 have been completed previously AND results are below contamination limits,

THEN enter applicable data for each step on Attachment 5.

2.25.5 RCT, IF surveys have NOT been completed previously, THEN GO TO Subsection 2.26, OCA Lid Inspection and Cleaning, Subsection 2.27, ICV Lid Inspection and Cleaning, or Subsection 2.28, OCA Components Inspection and Cleaning, as applicable.

\section{NOTE}

Subsections 2.26 through 2.32, ICV Cavity Inspection (and included steps), must be completed, but may be performed in any order as long as radiological control steps are not bypassed.

2.26 OCA Lid Inspection and Cleaning

2.26.1 RCT, IF survey has NOT been completed previously, THEN survey OCV lid interior and exterior and record applicable data on Attachment 5.

\section{SIGN-OFF}

2.26.2 Inspect OCA lid for the following:

- Visible deformation

- Dents or abnormal flat spots $>1 / 2$ in.

- Abnormal scratches or gouges

- Obvious punctures, tears, or cracks in exposed welds

- $\quad$ Plastic burnout plugs (3) in place and intact

- $\quad$ Fiberglass lift pocket tubes in place 
- Distortions or cracks on or around lifting attachments

- Lift pocket covers attached and serviceable

- $\quad$ OCV locking Z-flange screws in place and no visible space between screw head and locking Z-flange; if screws are missing, or a space appears between screw head and locking Z-flange, then go to corresponding WI.

- $\quad$ Guide plates and screws in place and screws torqued to $21 \pm 2 \mathrm{lb}$-in., or verify that there is no looseness in the plate and screws are recessed.

- $\quad$ Seal surfaces for scratches/gouges perpendicular to machining marks

2.26.3 Remove foreign material from the following:

- Lock ring flange

- $\quad$ Sealing surfaces

- $\quad$ Test port access threads

2.26.4 Verify that the arrow above seal test port aligns with UNLOCKED arrow on lock ring.

2.26.5 Initial Attachment 5 to document OCA lid components and hardware are satisfactory.

\section{SIGN-OFF}

\subsection{ICV Lid Inspection and Cleaning}

\section{NOTE}

O-rings are considered clean when they are absent of free-standing vacuum grease, dirt, debris, and other foreign matter.

2.27.1 RCT, IF survey has NOT been completed previously, THEN survey ICV lid interior and exterior and record applicable data on Attachment 5.

\section{SIGN-OFF}

2.27.2 Inspect ICV lid for the following:

- Visible deformation

- $\quad$ Punctures

- Abnormal scratches or gouges 
- Distortions on or around lifting attachments

- $\quad$ Upper spacer and screws installed and no visible space between screw head and spacer top plate; if screws are missing, or a space appears between screw head and spacer top plate, then go to corresponding WI.

- Debris shield installed and undamaged

- $\quad$ Lock ring undamaged

- Damaged or missing screws from wiper O-ring holder

- $\quad$ Seal surfaces for scratches/gouges perpendicular to machining marks

2.27.3 Remove foreign material from the following:

- Lock ring flange

- Debris shield

- $\quad$ Sealing surfaces

2.27.4 Remove ICV wiper O-ring.

2.27.5 Clean ICV wiper O-ring and inspect for wear or damage that could impair its function.

2.27.6 IF O-ring is damaged, THEN GO TO corresponding WI and RETURN TO Step 2.27.9.

2.27.7 Lubricate wiper O-ring with a light coat of vacuum grease.

2.27.8 Install wiper O-ring.

2.27.9 Initial Attachment 5 to document ICV lid, components, and hardware are satisfactory.

\section{SIGN-OFF}

2.28 OCA Body Inspection and Cleaning

2.28.1 RCT, IF survey was NOT completed previously, THEN survey OCA body exterior and ICV body interior and record applicable data on Attachment 5.

\section{SIGN-OFF}

2.28.2 Remove upper and lower main O-rings and set aside for cleaning and inspection. 
2.28.3 Inspect OCA body for the following:

- Visible deformation

- Obvious punctures or tears

- Obvious cracks in exposed welds

- Dents or abnormal flat spots $>1 / 2$ in.

- Abnormal scratches or gouges

- $\quad$ Plastic burnout plugs (6) in place and undamaged

- $\quad$ Forklift pocket cover threaded inserts (8) intact and threads undamaged

- $\quad$ Lock bolt threaded inserts (6) intact and threads undamaged

- $\quad$ Tears or fraying $>1 / 4$ in. in the ceramic fiber gasket

- $\quad$ Full width and length of ceramic fiber gasket adhered to lower Z-flange

- $\quad$ Lock ring stop(s) undamaged

- $\quad$ Upper and lower O-ring grooves and seal surfaces for scratches/gouges perpendicular to machining marks

2.28.4 Remove foreign material from the following:

- $\quad$ Test port threads

- Vent port threads

- $\quad$ Lock ring flange

- $\quad$ Sealing surfaces

- O-ring grooves

2.28.5 Verify airflow through OCV helium test ports.

2.28.6 Initial Attachment 5 to document OCA body inspection is satisfactory.

\section{SIGN-OFF}


2.29 OCA Components Inspection and Cleaning

\section{NOTE}

O-rings are considered clean when they are absent of free-standing vacuum grease, dirt, debris, and other foreign matter.

2.29.1 Clean and inspect the following for wear or damage that could impair their function:

- $\quad$ OCV vent port cover and O-rings

- $\quad$ OCV vent port access plug

- $\quad$ OCV vent port plug and handling O-ring

- $\quad$ OCV seal test port access plug

- $\quad$ OCV seal test port plug and seal O-ring

- $\quad$ Lock bolts (6)

2.29.2 IF components are damaged,

THEN GO TO corresponding WI and RETURN TO Step 2.29.4.

2.29.3 Apply a light coat of vacuum grease to the following:

- $\quad$ OCV vent port plug threads

- $\quad$ OCV vent port cover threads and seal O-ring

- $\quad$ OCV seal test port plug threads and O-ring

2.29.4 Verify that the annulus debris seal is installed and undamaged.

2.29.5 Apply a light coat of nickel bearing lubricant to the following:

- OCA lock bolt threads (6)

- OCV seal test port access plug threads

- OCV vent port access plug threads

2.29.6 Clean upper and lower main O-rings and vent port plug seal O-ring, and inspect for damage that could impair containment integrity.

2.29.7 IF O-rings are damaged,

THEN GO TO corresponding WI and RETURN TO Step 2.29.9.

2.29.8 Lubricate upper and lower main O-rings and vent port plug seal O-ring with a light coat of vacuum grease. 
2.29.9 Install:

- $\quad$ OCV upper main O-ring

- $\quad$ OCV lower main O-ring with identifying mark near vent port

- $\quad$ OCV vent port plug seal O-ring

\section{SIGN-OFF}

2.29.10 Initial Attachment 5 to document OCA component and hardware inspections are satisfactory.

\section{SIGN-OFF}

2.30 ICV Body Inspection and Cleaning

2.30.1 Remove upper and lower main O-rings and set aside for cleaning and inspection.

2.30.2 Inspect ICV body for the following:

- $\quad$ Lock ring stop(s) undamaged

- $\quad$ Lock bolt threaded inserts (3) installed and threads undamaged

2.30.3 Remove foreign material from the following:

- $\quad$ Test port threads

- Vent port threads

- O-ring grooves

- $\quad$ Filter ports

- $\quad$ Sealing surfaces

- Lock ring flange

2.30.4 Inspect the following:

- Upper and lower O-ring grooves and seal surfaces for scratches/gouges perpendicular to machining marks

- Vent port threads for damage

- Seal test port threads for damage

- $\quad$ Lock ring flange for galling and burrs

- Lower spacer installed with no punctures in top plate 
- Lower spacer screws installed and no detectable gap between screw head and spacer top plate

2.30.5 Verify airflow through ICV helium test ports.

2.30.6 Initial Attachment 5 to document ICV body inspection is satisfactory.

\section{SIGN-OFF}

\subsection{ICV Components Inspection and Cleaning}

\section{NOTE}

O-rings are considered clean when they are absent of free-standing vacuum grease, dirt, debris, and other foreign matter.

2.31.1 Clean and inspect the following for wear or damage that could impair their function:

- $\quad$ ICV vent port cover and seal (gasket or O-ring)

- $\quad$ ICV outer vent port plug

- $\quad$ ICV inner vent port plug and seal O-ring

- $\quad$ ICV seal test port plug and seal O-ring

- $\quad$ ICV lock bolts (3)

2.31.2 IF components are damaged, THEN GO TO corresponding WI and RETURN TO Step 2.31.4.

2.31.3 Apply a light coat of vacuum grease to the following:

- $\quad$ ICV vent port cover threads (and O-ring if installed)

- $\quad$ ICV outer vent port plug threads

- $\quad$ ICV inner vent port plug threads and seal O-ring

- $\quad$ ICV seal test port plug threads and seal O-ring

2.31.4 Apply a light coat of nickel bearing lubricant to threads of ICV lock bolts (3).

2.31.5 Clean and inspect upper and lower main O-rings and ICV outer vent port plug seal O-ring for damage that could impair containment integrity.

2.31.6 IF O-rings are damaged, THEN GO TO corresponding WI and RETURN TO Step 2.31.8.

2.31.7 Lubricate upper and lower main O-rings and ICV outer vent port plug seal O-ring with a light coat of vacuum grease. 


\subsubsection{Install:}

- $\quad$ ICV upper main O-ring

- $\quad$ ICV lower main O-ring with identifying mark near vent port

- $\quad$ ICV outer vent port plug seal O-ring

\section{SIGN-OFF}

2.31.9 Initial Attachment 5 to document ICV components and hardware inspections are satisfactory.

\section{SIGN-OFF}

2.32 ICV Cavity Inspection

2.32.1 Check ICV cavity for water by visually inspecting the absorbent material inserted into hole in lower spacer assembly.

\section{NOTE}

Disposal of absorbent material and water will be at direction of RCT.

2.32.2 IF water is inside ICV,

THEN remove water as follows:

- $\quad$ Remove water through center hole of lower spacer assembly using wet/dry vacuum.

- Attach absorbent material to rod and insert in hole in center of lower spacer assembly.

2.32.3 IF water is inside ICV,

THEN GO TO Subsection 3.1, perform steps and RETURN TO Step 2.32.4.

2.32.4 Initial Attachment 5 to document ICV is free of water.

\section{SIGN-OFF}

2.32.5 Verify that the ICV cavity is free of foreign objects (i.e., smears, gloves, filters, etc.) and initial Attachment 5.

\section{SIGN-OFF}


2.32.6 When shipping pallets and ratchet straps from the WIPP facility, verify that the annual inspection due date is more than one month from the day of loading and initial Attachment 5.

\section{SIGN-OFF}

2.32.7 Verify that all preshipment inspections are complete and initial Attachment 5.

\section{SIGN-OFF}

\section{NOTE}

If items are loaded into the ICV, the ACGLF may be used with the long or short legs.

\section{NOTE}

If the ACGLF with short legs is used to load items into the ICV, a separate technician shall guide the cables into and out of the ICV to prevent damage to the lower seal flange.

2.32.8 If applicable, load pallets, guide tubes and other items into ICV.

\subsection{ICV Lid Installation}

2.33.1 Match ICV lid and body serial numbers.

2.33.2 Record ICV serial number on Attachment 5.

\section{SIGN-OFF}

\section{CAUTION}

Operator shall verify that the two ACGLF counterweights are at 180 degrees and 000 degrees ( \pm 2 degrees) BEFORE lifting ACGLF or lid.

2.33.3 Attach ACGLF to ICV lid.

2.33.4 Align UNLOCKED arrows and install ICV lid onto ICV body using crane and ACGLF.

2.33.5 Install ICV vent port tool into ICV vent port.

2.33.6 Connect vacuum line to ICV vent port tool.

2.33.7 Start vacuum pump and evacuate to 3 to $15 \mathrm{in.} \mathrm{Hg}$ vacuum gauge. 
2.33.8 Rotate ICV lock ring to LOCKED position.

2.33.9 Stop vacuum pump.

2.33.10 Disconnect vacuum line from vent port tool.

2.33.11 Remove ICV vent port tool.

2.33.12 Let ICV vent to atmosphere.

2.33.13 Install and torque the following components:

- $\quad I C V$ inner vent port plug; torque to 55 to $65 \mathrm{lb}$-in.

- $\quad$ ICV seal test port plug; torque to 55 to $65 \mathrm{lb}$-in.

- $\quad$ OCV seal test port plug; torque to 55 to $65 \mathrm{lb}$-in.

- $\quad$ ICV lock bolts (3); torque to 28 to $32 \mathrm{lb}-\mathrm{ft}$.

2.33.14 Install ICV outer vent port plug; torque to 55 to $65 \mathrm{lb}$-in.

2.33.15 Install ICV vent port cover; torque to 55 to $65 \mathrm{lb}$-in.

2.33.16 Initial on Attachment 5 that ICV hardware and OCV seal test port plug are torqued within designated range.

SIGN-OFF

2.34 OCA Lid Installation

2.34.1 Verify that all items (tools, parts, rags, etc.) have been removed from the lower Z-flange/seal flange area(s).

\section{SIGN-OFF}

2.34.2 Match OCA lid and body serial numbers.

2.34.3 Record OCA serial number on Attachment 5.

\section{SIGN-OFF}

\section{CAUTION}

Operator shall verify that the two ACGLF counterweights are at 180 degrees and 000 degrees ( \pm 2 degrees) BEFORE lifting ACGLF or lid.

2.34.4 Attach ACGLF to OCA lid.

2.34.5 Align UNLOCKED arrows and install OCA lid onto OCA body. 
2.34.6 Install OCV vent port tool into OCV vent port.

2.34.7 Connect vacuum line to OCV vent port tool.

2.34.8 Start vacuum pump and evacuate to 3 to $15 \mathrm{in}$. Hg vacuum gauge.

2.34.9 Rotate OCV lock ring to LOCKED position.

2.34.10 Stop vacuum pump.

2.34.11 Disconnect vacuum line from vent port tool.

2.34.12 Remove OCV vent port tool.

2.34.13 Let OCV vent to atmosphere.

2.34.14 Install OCV vent port plug; torque to 55 to $65 \mathrm{lb}$-in.

2.34.15 Install OCV vent port cover; torque to 55 to $65 \mathrm{lb}$-in.

2.34.16 Install the following:

- $\quad$ OCV seal test port thermal plug and access plug; torque access plug to 35 to $45 \mathrm{lb}-\mathrm{ft}$.

- $\quad$ OCV vent port thermal plug and access plug; torque access plug to 35 to $45 \mathrm{lb}$-ft.

- $\quad$ OCA lock bolts (6); torque to 28 to $32 \mathrm{lb}-\mathrm{ft}$.

- $\quad$ OCA lift pocket covers.

2.34.17 Initial on Attachment 5 that OCV/OCA hardware is torqued within designated range.

\section{SIGN-OFF}

2.34.18 Verify that preshipment preparations are complete and unit is ready for transport and initial Attachment 5 .

\section{SIGN-OFF}

2.34.19 Supervisor, review/validate and sign Attachment 5.

\section{SIGN-OFF}


2.35 Installation of Packaging onto Transport Trailer

\section{NOTE}

When loading packages on trailer, or loading payload into packaging that is already on trailer, the following applies:

- $\quad$ Packages having a gross weight difference (heaviest to lightest) of $1,000 \mathrm{lb}$ or less can be considered equal and do not require a specific sequence for positioning on the trailer.

- $\quad$ Packages having a gross weight difference (heaviest to lightest), greater than 1,000 lb shall be positioned on the trailer as follows:

\begin{tabular}{|l|l|l|l|l|}
\hline \multirow{3}{*}{$\begin{array}{l}\text { TRAILER } \\
\text { FRONT }\end{array}$} & 1. Heaviest & Medium & Lightest & \\
\cline { 2 - 4 } & 2. Heaviest & Lightest & None & TRAILER \\
\cline { 2 - 4 } & 3. Heaviest & None & None & \\
\hline
\end{tabular}

2.35.1 Record the following on Attachment 6, Trailer Data Sheet:

- $\quad$ Shipment number

- Trailer number

- $\quad$ Packaging number(s)

\section{SIGN-OFF}

2.35.2 Verify that the annual trailer inspection is current.

2.35.3 Record trailer inspection performed date on Attachment 6.

\section{SIGN-OFF}

\section{NOTE}

Additional trailer tiedown guidance is provided in WP 08-PT.04. This document is available on the Internet at http://www.wipp.energy.gov/library/caolib.htm\#containers.

2.35.4 Inspect tiedowns for the following:

- Damage

- Defects 
2.35.5 IF TRUPACT-II was removed for unloading operations, THEN perform the following:

[ A ] Position transport trailer in designated area.

[B ] Lower trailer jacks (landing gear) ensuring trailer is level.

[ C ] Install wheel chocks.

[D ] Install jack stands on freestanding trailers.

\section{CAUTION}

Tip-back beyond level may damage package exterior surface.

[ E ] Transport packaging to transport trailer.

[ F ] Load packaging designated for position \#1 onto trailer with vent port on driver side of trailer.

[ G ] If applicable, load packaging designated for position \#2 onto trailer with vent port on driver side of trailer.

[ $\mathrm{H}$ ] If applicable, load packaging designated for position \#3 onto trailer with vent port on driver side of trailer.

\section{NOTE}

Additional trailer tiedown guidance is provided in WP 08-PT.04.

This document is available on the Internet at http://www.wipp.energy.gov/library/caolib.htm\#containers.

[ I] Install four tiedown assemblies for each packaging loaded on trailer.

[ J ] Install packaging forklift pocket access covers.

2.35.6 Record packaging serial number(s) and weights on Attachment 6.

\section{SIGN-OFF}

2.35.7 Record total weight of all loaded packaging as payload weight on Attachment 6.

\section{SIGN-OFF}


2.35.8 Verify that the shipment is in compliance with 49 CFR Part 172 , Subpart D, Subpart E, and Subpart F and initial Attachment 6.

\section{SIGN-OFF}

2.35.9 Complete information transfer to shipping documents as required for the specific shipment.

2.35.10 Verify that shipping papers are in accordance with 49 CFR Part 172, Subpart C, and initial Attachment 6.

\section{SIGN-OFF}

2.35.11 Initial for trailer loading complete on Attachment 6 .

\section{SIGN-OFF}

2.35.12 Supervisor, review/validate entries and sign Attachment 6.

\section{SIGN-OFF}

\subsection{ABNORMAL OPERATIONS}

\section{NOTE}

WIPP Packaging Maintenance Engineer shall be contacted when performing Subsections 3.1, 3.2, or 3.3.

\subsection{Empty ICV Assembly Removal}

3.1.1 Verify that the ICV lid has been installed and locked.

3.1.2 Mark ICV and OCV with match lines using a low-chloride marker. (These marks will be used to orient the ICV in the OCV during reinstallation.)

\section{CAUTION}

Operator shall verify that the two ACGLF counterweights are at 180 degrees and 000 ( \pm 2 degrees) degrees respectively.

3.1.3 Attach ACGLF to ICV lid.

3.1.4 If annulus foam ring is present, remove and set aside for later use. 


\section{CAUTION}

Load cell reading MUST NOT exceed 5,000 lb when weight of ACGLF is zeroed out, OR $7,500 \mathrm{lb}$ when weight of ACGLF is included.

3.1.5 Remove empty ICV assembly from OCV body using crane and ACGLF.

\section{NOTE}

If required by site-specific policy to ensure personnel safety, RCT shall survey OCV interior for radiation/contamination BEFORE initiating OCV inspection process.

3.1.6 Inspect visually for presence of water in bottom of OCV.

3.1.7 If freestanding water is NOT observed in bottom of OCV body, GO TO Step 3.1.11.

CAUTION
Operator shall obtain protective clothing and equipment in accordance
with site Safety Manual before entering OCV cavity. Operator also shall
enter the OCV cavity using precautions to preclude damage to OCV body
sealing flange.

3.1.8 Use wet/dry vacuum and/or absorbent materials to remove freestanding water.

\section{NOTE}

Cleaning and waste materials shall be managed according to site waste management procedures.

3.1.9 Remove equipment and exit OCV cavity using precautions not to damage OCV body sealing flange.

3.1.10 Verify that the OCV is free of standing water. 


\section{CAUTION}

Operator shall verify that the two ACGLF counterweights are at 180 degrees and 000 degrees ( \pm 2 degrees) respectively.

\section{NOTE}

When Step 3.1.11 is complete, ICV vent port should be within one foot of OCV vent port and the ICV should be sitting vertically within the OCV (i.e., not leaning to the side).

3.1.11 Reinstall ICV assembly into OCV body using crane and ACGLF.

3.1.12 If annulus debris seal was removed in Step 3.1.4, reinstall annulus debris seal.

3.2 Using Heat Guns to Remove Stuck Lids

3.2.1 Heat ICV or OCV lid O-rings (as necessary) for up to 1 hour using heat guns.

\section{CAUTION}

Operator shall verify that the two ACGLF counterweights are at 180 degrees and 000 degrees ( \pm 2 degrees) respectively.

\section{CAUTION}

When lifting ICV lid, load cell reading MUST NOT exceed 5,000 lb when weight of ACGLF is zeroed out, OR 7,500 lb when weight of ACGLF is included.

\section{CAUTION}

When lifting OCA lid, load cell reading MUST NOT exceed 7,500 lb when weight of ACGLF is zeroed out, OR $10,000 \mathrm{lb}$ when weight of ACGLF is included.

3.2.2 Attempt to raise lid using the slowest possible speed.

3.2.3 Raise lid as directed by RCT and RETURN TO normal operations. 
3.3 Pressurizing with Nitrogen or Compressed Air to Remove Stuck Lids

3.3.1 Obtain the following:

- $\quad$ Nitrogen bottle with $\geq 500 \mathrm{lb}$ pressure or other air source capable of being regulated in 1-psi increments

- $\quad$ Pressure Assembly (Figure 3.1, Flow Diagram for Nitrogen Bottle/Compressed Air ICV/OCA Lid Pressurization)

- If not already installed, ICV/OCV vent port tools, as applicable

3.3.2 Perform the following for compressed air or nitrogen:

[ A ] Assemble Pressure Assembly (see Figure 3.1 for example of a pressure assembly).

[ B ] If not already installed, install vent port tool hand-tight.

[ C ] Connect Pressure Assembly to quick disconnect on vent port tool.

[D] Close valve V-1.

[E] Close valve V-2.

[ F ] Verify that the supply valve is closed.

[ G ] Verify that the back pressure relief valve is fully backed off.

[ $\mathrm{H}$ ] Verify that the pressure regulator is fully backed off.

[ I ] Connect supply line and regulator to nitrogen-bottle or compressed air source.

[ J ] Open supply valve and adjust $\mathrm{N}_{2}$ or air supply regulator to a maximum of 150 psig.

[ K ] Adjust R1 to about 2.1 psig.

[ L ] Adjust R2 until it begins to relieve pressure.

[ M ] Adjust R1 to fully backed off.

[ N ] Bleed briefly through V-1. 
[ O ] Adjust R1 to about 1 psig.

3.3.3 Verify that the counterweights are at 180 degrees and 000 degrees.

\section{WARNING}

The ICV or OCV should not be pressurized above 2 psi to avoid personnel injury. A loaded ICV MUST NOT be pressurized unless precautions are taken to prevent possible contamination when lid is raised.

\section{CAUTION}

When lifting ICV lid, load cell reading MUST NOT exceed 5,000 lb when weight of ACGLF is zeroed out, OR 7,500 lb when weight of ACGLF is included.

\section{CAUTION}

When lifting OCV lid, load cell reading MUST NOT exceed 7,500 lb when weight of ACGLF is zeroed out, OR $10,000 \mathrm{lb}$ when weight of ACGLF is included.

3.3.4 Attempt to lift lid using crane at the slowest rate possible while monitoring load cell.

3.3.5 Perform the following while attempting to lift lid with crane:

[ A ] Throttle valve $V-2$, keeping pressure $\leq 2$ psi.

[ B ] When lid becomes loose, close V-2.

[ C ] Close supply valve.

[D ] Open V-1 to depressurize assembly.

[ E ] Disconnect supply line from pressure assembly.

[ F ] Disconnect pressure assembly from vent port tool.

[ G ] Disconnect vent port tool and survey tool if applicable.

[ H ] Disconnect supply line and regulator from nitrogen bottle or compressed air source. 
3.3.6 Raise lid as directed by RCT AND continue with normal operations.

3.3.7 IF after pressurizing to 2 psi lid still does not lift, THEN contact the WIPP M\&O Contractor $\mathrm{CH}$ Packaging Maintenance Engineer.

\subsection{Venting}

\section{NOTE}

In the event a sealed package cannot be shipped within the time frame set forth in the TRUPACT-II or HalfPACT Packaging SAR, the package must be vented.

3.4.1 IF venting is required,

THEN perform applicable Subsections 2.22, OCA Lid Removal, and 2.23, ICV Lid Removal.

3.4.2 Wait three minutes.

3.4.3 GO TO Subsection 2.17, reinstall lids using Subsections 2.17 and 2.18. 
Figure 3.1 - Flow Diagram for Nitrogen Bottle/Compressed Air ICV/OCA Lid Pressurization

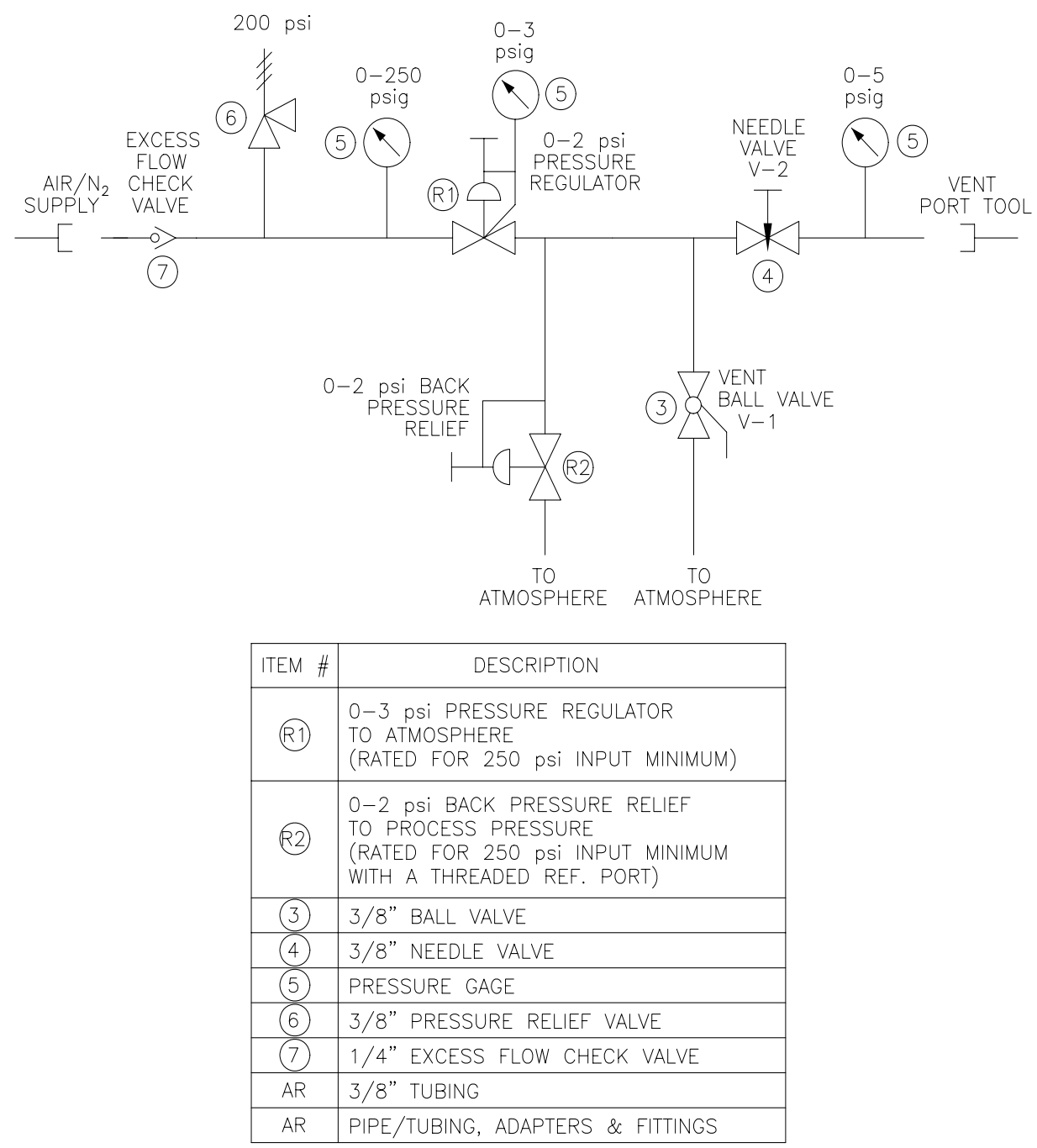


4.0 PRESHIPMENT LEAKAGE RATE TESTING

4.1 Basic Information

4.1.1 Introduction - This procedure provides instructions for performing ICV and OCV preshipment leakage rate tests on the following packaging seals, using a nondestructive helium $(\mathrm{He})$ leak test:

- $\quad$ ICV upper main O-ring seal

- $\quad$ ICV outer vent port plug seal O-ring

- $\quad$ OCV upper main O-ring seal

- $\quad$ OCV vent port plug seal O-ring

\section{NOTE}

Supplementary data sheets may be used in support of leakage rate tests performed by this procedure.

\subsubsection{References}

- U.S. Department of Energy, Safety Analysis Report for the TRUPACT-Il Shipping Package

- U.S. Department of Energy, Safety Analysis Report for the HalfPACT Shipping Package

- DOE/MIPP 02-3183, CH Packaging Program Guidance

- $\quad$ DOE/WIPP 02-3185, CH Packaging Maintenance Manual

- $\quad$ ANSI N 14.5, 1997, Radioactive Materials Leakage Tests on Packages for Shipment

- $\quad$ ASNT, Recommended Practice No. SNT-TC-1A, June 1980

- $\quad$ WP 13-RP.01, Test Report for WP 13-QA1082 Procedure Qualification

\subsubsection{Equipment}

\section{MEASURING AND TEST EQUIPMENT}

- Varian 938-41 or 959 Helium Leak Detector with

7 to $14 \mathrm{cfm}$ mechanical vacuum pump

- $\quad$ Roughing pump

- Helium leak standard for calibrating leak detector 
- $\quad$ Pressure/vacuum gauge, 30-in. $\mathrm{Hg}$ to $30 \mathrm{psig}$

- Temperature measuring device, $32^{\circ} \mathrm{F}$ to $120^{\circ} \mathrm{F}$ $\left(0^{\circ} \mathrm{C}\right.$ to $\left.50^{\circ} \mathrm{C}\right)$

- Ambient atmospheric pressure measuring device

- Watch or stopwatch, digital or sweep second hand (no calibration required)

- Torque wrench with 10 to $65 \mathrm{lb}$-in. range

- Torque wrench with 30 to $50 \mathrm{lb}$-ft range

SPECIAL TEST EQUIPMENT

- ICV/OCV vent port plug removal/pressure relief tools

- $\quad$ ICV/OCV vent port plug/cover removal and installation tools

- ICV/OCV seal leak check tools

- ICV/OCV leak detection tools

- Miscellaneous hardware and test connections

CONSUMABLE MATERIALS

- Welding grade helium (with certificate of conformance [C of C])

- $\quad$ Argon or nitrogen (purge gas)

\subsubsection{Precautions and Limitations}

The following leak test procedure may be used, or each user may develop and qualify a procedure in accordance with the guidelines of ANSI N14.5, 1997. Sites that opt to qualify their own leak test procedure must submit procedure qualification record and procedure to Site Documents@wipp.ws, for approval.

- $\quad$ Leak testing of $\mathrm{CH}$ packaging shall be performed by personnel qualified in accordance with the American Society for Nondestructive Testing Practice No. SNT-TC-1A, June 1980 edition and supplement. 
- $\quad$ This procedure is qualified per WP 13-RP.01, Test Report for WP 13-QA1082 Procedure Qualification for the Varian 938-41 and 959 MSLD and test line configuration defined in that report. $\mathrm{CH}$ packaging users adopting this leak test must not deviate from the test configuration(s) used to qualify the procedure.

- $\quad$ The helium leak detector shall be calibrated to a minimum sensitivity of $1.3 \times 10^{-7}$ standard cubic centimeters per second (scc/s) He.

- The leakage rate acceptance criteria of $\leq 1.0 \times 10^{-7} \mathrm{scc} / \mathrm{s}$ of air equates to a leakage rate of $\leq 2.6 \times 10^{-7} \mathrm{scc} / \mathrm{s} \mathrm{He}$. The He leakage rate is only valid for a component of $>4.4^{\circ} \mathrm{C}$. The acceptable He leakage rate increases with temperature, but as a conservative measure, an acceptance criteria of $\leq 2.6 \times 10^{-7} \mathrm{scc} / \mathrm{s}$ He will be used.

\subsubsection{Prerequisite Actions}

- Verify air flow through leak check and leak detection tools.

- Verify that packaging surface is free of contaminates that might mask a leak. The interior and exterior surfaces shall be dry.

\subsection{ICV Upper Main O-Ring Seal}

4.2.1 Record the following on Attachment 7, ICV Preshipment Leakage-Rate Test Data Sheet:

- $\quad$ ICV body serial number (S/N)

- ICV lid S/N

- Date of leak test

- Helium leak detector $\mathrm{S} / \mathrm{N}$ and model

- $\quad$ Pressure/vacuum gauge $\mathrm{S} / \mathrm{N}$ and calibration due date

- $\quad$ Thermometer $\mathrm{S} / \mathrm{N}$ and calibration due date

- $\quad$ Torque wrench $S / N$ s and calibration due dates

- $\quad$ Standard leak $S / N$ and calibration due date

- $\quad$ Barometer S/N and calibration due date

- Helium source with $C$ of $C$ connected to backfill system

\section{SIGN-OFF}

\section{NOTE}

Steps 4.2.15 through 4.2.19 may be performed in parallel with Steps 4.2.2 through 4.2.14. 
4.2.3 If temperature is less than $4.4^{\circ} \mathrm{C}$, stop test until surface temperature $\geq 4.4^{\circ} \mathrm{C}$.

4.2.4 Record surface temperature on Attachment 7.

\section{SIGN-OFF}

4.2.5 Verify that the outer vent port plug is retracted into ICV vent port plug removal/pressure relief tool.

4.2.6 Install ICV vent port tool into ICV vent port.

4.2.7 Attach vacuum pump assembly and He gas supply to vent port tool (see Figure 4.1, ICV Main O-Ring Seal Test).

4.2.8 Open isolation valve to vacuum pump.

4.2.9 Start vacuum pump.

4.2.10 Record ambient atmospheric pressure (Patm) on Attachment 7.

\section{SIGN-OFF}

4.2.11 Evacuate ICV vent port cavity to $90 \%$ vacuum (90\% of atmospheric pressure) or better.

4.2.12 Record vacuum reading (V1) on Attachment 7.

\section{SIGN-OFF}

4.2.13 Calculate He concentration correction factor (CCF) as follows:

$$
\mathrm{CCF}=\frac{\mathrm{Patm}}{\mathrm{V} 1}
$$

\subsubsection{Record CCF on Attachment 7.}

\section{SIGN-OFF}

4.2.15 Perform pretest calibration of leak detector (to the temperaturecorrected standard leak value) and record results on Attachment 7.

\section{SIGN-OFF}

4.2.16 Install ICV seal leak check tool in ICV seal test port.

4.2.17 Connect leak detector to ICV leak check tool (see Figure 4.1). 
4.2.18 Verify that the isolation valve is open.

4.2.19 Evacuate space between O-ring seals through ICV seal test port.

4.2.20 Close vacuum pump isolation valve AND stop vacuum pump.

\section{NOTE}

To measure $\mathrm{a} \geq 2.6 \times 10^{-7} \mathrm{scc} / \mathrm{s}$ He leakage rate, the indicated $\mathrm{He}$ background will be allowed to stabilize at $7 \times 10^{-7} \mathrm{scc} / \mathrm{s} \mathrm{He}$ or less and remain below the limit for a minimum of 3 minutes.

4.2.21 Record He background (RB) on Attachment 7 .

\section{SIGN-OFF}

4.2.22 Open He valve and backfill cavity with He to a pressure slightly greater than atmospheric pressure (+1 psi, -0 psi).

4.2.23 Close He valve.

4.2.24 Record backfill pressure reading on Attachment 7 .

\section{SIGN-OFF}

4.2.25 Begin timing for 3-minute dwell time.

4.2.26 Monitor pressure gauge and add $\mathrm{He}$ as required to maintain $\mathrm{He}$ atmosphere in the cavity.

\section{NOTE}

A dwell time of 3 minutes will be used to determine leakage rate of ICV upper main O-ring seal.

4.2.27 Record displayed He reading (RT) after 3-minute dwell time on Attachment 7.

\section{SIGN-OFF}

\section{NOTE}

Steps 4.3.1 through 4.3.6 may be performed in parallel with

Steps 4.2.28 through 4.2.35.

4.2.28 Remove test assembly from leak detector.

4.2.29 Install calibrated leak to leak detector. 
4.2.30 Perform post-test calibration deviation check of leak detector and record results on Attachment 7.

\section{SIGN-OFF}

4.2.31 Calculate the ICV upper main O-ring seal leakage rate using the correct condition below and record on Attachment 7:

\section{NOTE}

If the He background (RB) is greater than the displayed He reading at the end of dwell time (RT), the value of (RT) will be substituted for the value of (RB) when performing leak rate calculations. If condition [ $\mathrm{C}$ ] applies, and this note is applicable to that condition (ending up with a negative number), zero will be used as the leakage rate.

\section{NOTE}

The difference between displayed He reading (DR) with standard leak installed, including Zero Reading Variance (if applicable) and Temperature Correction Value (TC), is used to determine post-test calibration deviation. Additional guidance is provided in DOE/WIPP 02-3183, Section 4.2.9.

[A] If there is no difference in the Temperature Correction Value (TC) from the displayed He reading with standard leak installed (DR), use the following equation: subtract the He background at the start of test (RB) from the displayed He reading at end of test (RT). The leakage rate is $(R T-R B) \times C C F$. This equals the leakage rate for this segment of the test.

[ B ] If the displayed He reading with standard leak installed (DR) is LESS than the Temperature Correction Value (TC), use the following calculation: (RT + calibration deviation $-\mathrm{RB}$ ) $\times \mathrm{CCF}$. This equals the leakage rate for this segment of the test under this condition of recalibration.

[C ] If the displayed He reading with standard leak installed (DR) is MORE than the Temperature Correction Value (TC), use the following calculation: (RT - calibration deviation $-\mathrm{RB}$ ) $\times$ CCF. This equals the leakage rate for this segment of the test under this condition of recalibration.

\section{SIGN-OFF}

4.2.32 If the acceptance criterion is satisfied $\left(\leq 2.6 \times 10^{-7} \mathrm{scc} / \mathrm{s}\right.$ of $\left.\mathrm{He}\right)$, this segment of the test procedure is complete. 


\section{NOTE}

The leakage rate acceptance criterion is $\leq 2.6 \times 10^{-7} \mathrm{scc} / \mathrm{s} \mathrm{He}$.

4.2.33 IF ICV upper main O-ring seal leakage rate is $>2.6 \times 10^{-7} \mathrm{scc} / \mathrm{s} \mathrm{He}$,

THEN perform the following:

[A] Isolate leak path.

[ B ] GO TO WI-CH.02, replace O-ring seal(s) and/or repair seal surface(s) per WI-CH.12; repeat leak test.

[ C ] If after repeated testing it is apparent the seal cannot pass the test, prepare nonconformance report (NCR) and record on Attachment 7.

\section{SIGN-OFF}

4.2.34 Remove ICV seal leak check tool and associated leak test equipment from ICV seal test port.

4.2.35 Install ICV seal test port plug.

4.2.36 Torque ICV seal test port plug to 55 to $65 \mathrm{lb}$-in. and record on Attachment 7.

\section{SIGN-OFF}

\subsection{ICV Outer Vent Port Plug Seal O-Ring}

\section{NOTE}

The following test should be performed immediately after Subsection 4.2, ICV Upper Main O-Ring Seal, while the He atmosphere is still present in the ICV vent port cavity and to minimize He saturation of O-rings before test completion.

4.3.1 Disconnect vacuum pump assembly and He supply from ICV vent port tool.

4.3.2 Install ICV outer vent port plug.

4.3.3 Remove vent port tool.

4.3.4 Torque ICV outer vent port plug to 55 to $65 \mathrm{lb}$-in and record on Attachment 7. 
4.3.5 Purge vent port to flush out residual helium.

4.3.6 Install a clean ICV leak detection tool in ICV vent port.

\section{NOTE}

If Step 4.3.7 begins within 1 hour of completing the ICV upper main O-ring seal leak test, THEN the pretest calibration is not required. The post-test calibration result can be used for the ICV outer vent port plug seal O-ring pretest calibration, provided no post-test calibration deviation was recorded.

4.3.7 Perform pretest calibration of leak detector (to the temperaturecorrected standard leak value).

4.3.8 Record pretest calibration results on Attachment 7.

\section{SIGN-OFF}

4.3.9 Connect leak detector to ICV leak detection tool (see Figure 4.2, ICV Outer Vent Port Plug Seal O-Ring Test).

4.3.10 Verify that the isolation valve is OPEN.

4.3.11 Evacuate ICV leak detection tool.

\section{NOTE}

To measure $\mathrm{a} \leq 2.6 \times 10^{-7} \mathrm{scc} / \mathrm{s}$ He leakage rate with a He atmosphere already present, indicated He background will be $\leq 2.6 \times 10^{-7} \mathrm{scc} / \mathrm{s} \mathrm{He}$ BEFORE the start of the dwell time.

Dwell time for ICV outer vent port plug seal O-ring test is 3 minutes. An initial indication does NOT necessarily indicate a leak. Some residual $\mathrm{He}$ may still be detected.

4.3.12 Record displayed He reading (RT) after 3-minute dwell time on Attachment 7.

\section{SIGN-OFF}

4.3.13 Remove test assembly from leak detector.

4.3.14 Install calibrated leak to leak detector.

4.3.15 Perform post-test calibration deviation check of leak detector and record results on Attachment 7. 
4.3.16 Calculate ICV outer vent port plug seal O-ring leakage rate using the appropriate condition below and record on Attachment 7:

\section{NOTE}

The difference between displayed He reading (DR) with standard leak installed, including Zero Reading Variance (if applicable) and Temperature Correction Value (TC), is used to determine post-test calibration deviation. Additional guidance is provided in DOE/WIPP 02-3183, Section 4.2.9.

[A] If there is no difference in the Temperature Correction Value (TC) from the displayed He reading with standard leak installed (DR), the displayed He reading at end of test $(\mathrm{RT}) \times \mathrm{CCF}$ equals the leakage rate for this segment of the test.

[ B ] If the displayed He reading with standard leak installed (DR) is LESS than the Temperature Correction Value (TC), use the following calculation: (RT + calibration deviation) $\times$ CCF. This equals the leakage rate for this segment of the test under this condition of recalibration.

[ C ] If the displayed He reading with standard leak installed (DR) is MORE than the Temperature Correction Value (TC), use the following calculation: (RT - calibration deviation) $\times$ CCF. This equals the leakage rate for this segment of the test under this condition of recalibration.

\section{SIGN-OFF}

4.3.17 If the acceptance criterion is satisfied $\left(\leq 2.6 \times 10^{-7} \mathrm{scc} / \mathrm{s}\right.$ of $\left.\mathrm{He}\right)$, this segment of the test procedure is complete. 


\section{NOTE}

The leakage rate acceptance criterion is $\leq 2.6 \times 10^{-7} \mathrm{scc} / \mathrm{s} \mathrm{He}$.

4.3.18 IF ICV outer vent port plug seal O-ring leakage rate is $>2.6 \times 10^{-7} \mathrm{scc} / \mathrm{s} \mathrm{He}$,

THEN perform the following:

[A] Isolate leak path.

[ B ] GO TO WI-CH.01, replace O-ring seal(s) and/or repair seal surface(s) per WI-CH.12, repeat leak test.

[ C ] If after repeated testing it is apparent the seal cannot pass test, prepare NCR and record on Attachment 7.

\section{SIGN-OFF}

4.3.19 Remove ICV leak detection tool from ICV vent port.

4.3.20 Install ICV vent port cover.

4.3.21 Torque ICV vent port cover to 55 to $65 \mathrm{lb}$-in. and initial Attachment 7.

\section{SIGN-OFF}

\subsubsection{RETURN TO Step 2.17.15.}

\subsection{OCV Upper Main O-Ring Seal}

4.4.1 Record the following on Attachment 8, OCV Preshipment Leakage Rate Test Data Sheet:

- OCV body S/N

- OCV lid S/N

- Date of leak test

- Helium leak detector $\mathrm{S} / \mathrm{N}$ and model

- $\quad$ Pressure/vacuum gauge $S / N$ and calibration due date

- $\quad$ Thermometer $\mathrm{S} / \mathrm{N}$ and calibration due date

- $\quad$ Torque wrench $S / N$ s and calibration due dates

- $\quad$ Standard leak S/N and calibration due date

- $\quad$ Barometer S/N and calibration due date

- Helium source with $C$ of $C$ connected to backfill system

\section{SIGN-OFF}




\section{NOTE}

Steps 4.4.12 through 4.4.17 may be performed in parallel with Steps 4.4.2 through 4.4.11.

4.4.2 Measure OCV surface temperature and record on Attachment 8.

\section{SIGN-OFF}

4.4.3 If temperature is less than $4.4^{\circ} \mathrm{C}$, stop test until surface temperature $>4.4^{\circ} \mathrm{C}$.

4.4.4 Attach vacuum pump assembly and He gas supply to vent port tool (see Figure 4.3, OCV Main O-Ring Seal Test).

4.4.5 Open isolation valve to vacuum pump.

4.4.6 Start vacuum pump.

4.4.7 Record ambient atmospheric pressure (Patm) on Attachment 8.

\section{SIGN-OFF}

4.4.8 Evacuate OCV cavity to $90 \%$ vacuum (90\% of atmospheric pressure) or better.

4.4.9 Record vacuum reading (V1) on Attachment 8.

\section{SIGN-OFF}

4.4.10 Calculate He concentration correction factor as follows:

$$
\mathrm{CCF}=\frac{\mathrm{Patm}}{\mathrm{V} 1}
$$

\subsubsection{Record CCF on Attachment 8.}

\section{SIGN-OFF}

4.4.12 Perform pretest calibration of leak detector (to the temperaturecorrected standard leak value).

4.4.13 Record pretest calibration results on Attachment 8.

\section{SIGN-OFF}

4.4.14 Install OCV seal leak check tool in OCV seal test port.

4.4.15 Connect leak detector to OCV leak check tool (see Figure 4.3). 
4.4.16 Verify that the isolation valve is open.

4.4.17 Evacuate space between O-ring seals through OCV seal test port.

4.4.18 Close vacuum pump isolation valve AND stop vacuum pump.

\section{NOTE}

To measure a $2.6 \times 10^{-7} \mathrm{scc} / \mathrm{s}$ He leakage rate, the indicated He background will be allowed to stabilize at $\leq 7 \times 10^{-7} \mathrm{scc} / \mathrm{s}$ He and remain below the limit for a minimum of 3 minutes.

\subsubsection{Record He background (RB) on Attachment 8.}

\section{SIGN-OFF}

4.4.20 Open He valve and backfill OCV cavity with He to a pressure slightly greater than atmospheric pressure (+1 psi, -0 psi).

\subsubsection{Close He valve.}

4.4.22 Record backfill pressure reading on Attachment 8 .

\section{SIGN-OFF}

4.4.23 Begin timing for 3-minute dwell time.

4.4.24 Monitor pressure gauge and add $\mathrm{He}$ as required to maintain $\mathrm{He}$ atmosphere in the cavity.

\section{NOTE}

A dwell time of 3 minutes will be used to determine leakage rate of OCV upper main O-ring seal.

4.4.25 Record displayed He reading (RT) after 3-minute dwell time on Attachment 8.

\section{SIGN-OFF}

\section{NOTE}

Steps 4.5.1 through 4.5.6 may be performed in parallel with Steps 4.4.26 through 4.4.34.

4.4.26 Remove test assembly from leak detector.

4.4.27 Install calibrated leak to leak detector. 
4.4.28 Perform post-test calibration deviation check of leak detector and record results on Attachment 8.

\section{SIGN-OFF}

4.4.29 Calculate OCV main O-ring seal leakage rate using the appropriate condition below and record on Attachment 8 .

\section{NOTE}

If the He background (RB) is greater than the displayed He reading at the end of dwell time (RT), the value of (RT) will be substituted for the value of (RB) when performing leak rate calculations. If condition [ C ] applies, and this note is applicable to that condition (ending up with a negative number), zero will be used as the leakage rate.

\section{NOTE}

The difference between displayed He reading (DR) with standard leak installed, including Zero Reading Variance (if applicable) and Temperature Correction Value (TC), is used to determine post-test calibration deviation. Additional guidance is provided in DOE/WIPP 02-3183, Section 4.2.9.

[A] If there is no difference in the Temperature Correction Value (TC) from the displayed He reading with standard leak installed (DR), use the following equation: subtract the He background at the start of test (RB) from the displayed He reading at end of test (RT). The leakage rate is $(R T-R B) \times C C F$. This equals the leakage rate for this segment of the test.

[B ] If the displayed He reading with standard leak installed (DR) is LESS than the Temperature Correction Value (TC), use the following calculation: (RT + calibration deviation $-\mathrm{RB}$ ) $\times$ CCF. This equals the leakage rate for this segment of the test under this condition of recalibration.

[C ] If the displayed He reading with standard leak installed (DR) is MORE than the Temperature Correction Value (TC), use the following calculation: (RT - calibration deviation $-\mathrm{RB}$ ) $\times$ CCF. This equals the leakage rate for this segment of the test under this condition of recalibration.

\section{SIGN-OFF}

4.4.30 If acceptance criterion is satisfied $\left(\leq 2.6 \times 10^{-7} \mathrm{scc} / \mathrm{s}\right.$ of $\left.\mathrm{He}\right)$, this segment of the test procedure is complete. 


\section{NOTE}

The leakage rate acceptance criterion is $\leq 2.6 \times 10^{-7} \mathrm{scc} / \mathrm{s} \mathrm{He}$.

4.4.31 IF OCV main O-ring seal leakage rate is $>2.6 \times 10^{-7} \mathrm{scc} / \mathrm{s} \mathrm{He}$, THEN perform the following:

[A ] Isolate leak path.

[ B ] GO TO WI-CH.02, replace O-ring seal(s) and/or repair seal surface(s) per WI-CH.12, and repeat leak test.

[ C ] If after repeated testing it is apparent the seal cannot pass test, prepare NCR and record on Attachment 8.

\section{SIGN-OFF}

4.4.32 Remove OCV seal leak check tool and associated leak test equipment from OCV seal test port.

4.4.33 Install OCV seal test port plug.

4.4.34 Torque OCV seal test port plug to 55 to $65 \mathrm{lb}$-in and record on Attachment 8.

\section{SIGN-OFF}

\subsection{OCV Vent Port Plug Seal O-Ring}

\section{NOTE}

The following test should be performed immediately after Subsection 4.4, OCV Upper Main O-Ring Seal, while the He atmosphere is still present in the OCV cavity and to minimize He saturation of the O-rings before test completion.

4.5.1 Disconnect vacuum pump assembly and He supply from OCV vent port tool.

4.5.2 Install OCV vent port plug.

4.5.3 Remove vent port tool.

4.5.4 Torque OCV vent port plug to 55 to $65 \mathrm{lb}$-in. and record on Attachment 8.

\section{SIGN-OFF}

4.5.5 Purge vent port to flush out residual helium. 
4.5.6 Install a clean OCV leak detection tool in OCV vent port.

\section{NOTE}

If Step 4.5.7 begins within 1 hour of completing the OCV upper main O-ring seal leak test, THEN the pretest calibration is not required. The post-test calibration result can be used for the OCV vent port plug seal O-ring pretest calibration, provided no post-test calibration deviation was recorded.

4.5.7 Perform pretest calibration of leak detector (to the temperaturecorrected standard leak value).

4.5.8 Record pretest calibration results on Attachment 8.

\section{SIGN-OFF}

4.5.9 Connect leak detector to OCV leak detection tool (see Figure 4.4, OCV Vent Port Plug Seal O-Ring Test).

4.5.10 Verify that the isolation valve is OPEN.

4.5.11 Evacuate OCV leak detection tool.

\section{NOTE}

To measure $\mathrm{a} \leq 2.6 \times 10^{-7} \mathrm{scc} / \mathrm{s}$ He leakage rate with a He atmosphere already present, the indicated He background will be $\leq 2.6 \times 10^{-7} \mathrm{scc} / \mathrm{s} \mathrm{He}$ before the start of the dwell time.

Dwell time for OCV vent port plug seal O-ring test is 3 minutes. An initial indication does NOT necessarily indicate a leak. Some residual He may still be detected.

4.5.12 Record displayed He reading (RT) after 3-minute dwell time on Attachment 8.

\section{SIGN-OFF}

4.5.13 Remove test assembly from leak detector.

4.5.14 Install calibrated leak to leak detector.

4.5.15 Perform post-test calibration deviation check of leak detector and record results on Attachment 8.

\section{SIGN-OFF}


4.5.16 Calculate OCV vent port plug seal O-ring leakage rate using the appropriate condition below and record on Attachment 8:

\section{NOTE}

The difference between displayed He reading (DR) with standard leak installed, including Zero Reading Variance (if applicable) and Temperature Correction Value (TC), is used to determine post-test calibration deviation. Additional guidance is provided in DOE/WIPP 02-3183, Section 4.2.9.

[A] If there is no difference in the Temperature Correction Value (TC) from the displayed He reading with standard leak installed (DR), the displayed He reading at end of test $(\mathrm{RT}) \times \mathrm{CCF}$ equals the leakage rate for this segment of the test.

[ B ] If the displayed He reading with standard leak installed (DR) is LESS than the Temperature Correction Value (TC), use the following calculation: (RT + calibration deviation) $\times$ CCF. This equals the leakage rate for this segment of the test under this condition of recalibration.

[ C ] If the displayed He reading with standard leak installed (DR) is MORE than the Temperature Correction Value (TC), use the following calculation: (RT - calibration deviation) $\times$ CCF. This equals the leakage rate for this segment of the test under this condition of recalibration.

\section{SIGN-OFF}

4.5.17 If acceptance criterion is satisfied $\left(\leq 2.6 \times 10^{-7} \mathrm{scc} / \mathrm{s}\right.$ of $\left.\mathrm{He}\right)$, this segment of the test procedure is complete. 


\section{NOTE}

The leakage rate acceptance criterion is $\leq 2.6 \times 10^{-7} \mathrm{scc} / \mathrm{s} \mathrm{He}$.

4.5.18 IF OCV vent port plug seal O-ring leakage rate is $>2.6 \times 10^{-7} \mathrm{scc} / \mathrm{s} \mathrm{He}$,

THEN perform the following:

[A] Isolate leak path.

[ B ] GO TO WI-CH.01, replace O-ring seal(s) and/or repair seal surface(s) per WI-CH.12, and repeat leak test.

[ C ] If after repeated testing it is apparent the seal cannot pass test, prepare NCR and record on Attachment 8.

\section{SIGN-OFF}

4.5.19 Remove OCV leak detection tool from OCV vent port.

4.5.20 Install OCV vent port cover.

4.5.21 Torque OCV vent port cover to 55 to $65 \mathrm{lb}$-in. and record on Attachment 8.

\section{SIGN-OFF}

4.5.22 Install OCV seal test port thermal plug and access plug.

4.5.23 Torque OCV seal test port access plug to $35 \mathrm{to} 45 \mathrm{lb}-\mathrm{ft}$ and record on Attachment 8.

\section{SIGN-OFF}

4.5.24 Install OCV vent port thermal plug and access plug.

4.5.25 Torque OCV vent port access plug to 35 to $45 \mathrm{lb}$-ft and record on Attachment 8.

\section{SIGN-OFF}

\subsubsection{RETURN TO Step 2.18.15.}


Figure 4.1 - ICV Main O-Ring Seal Test

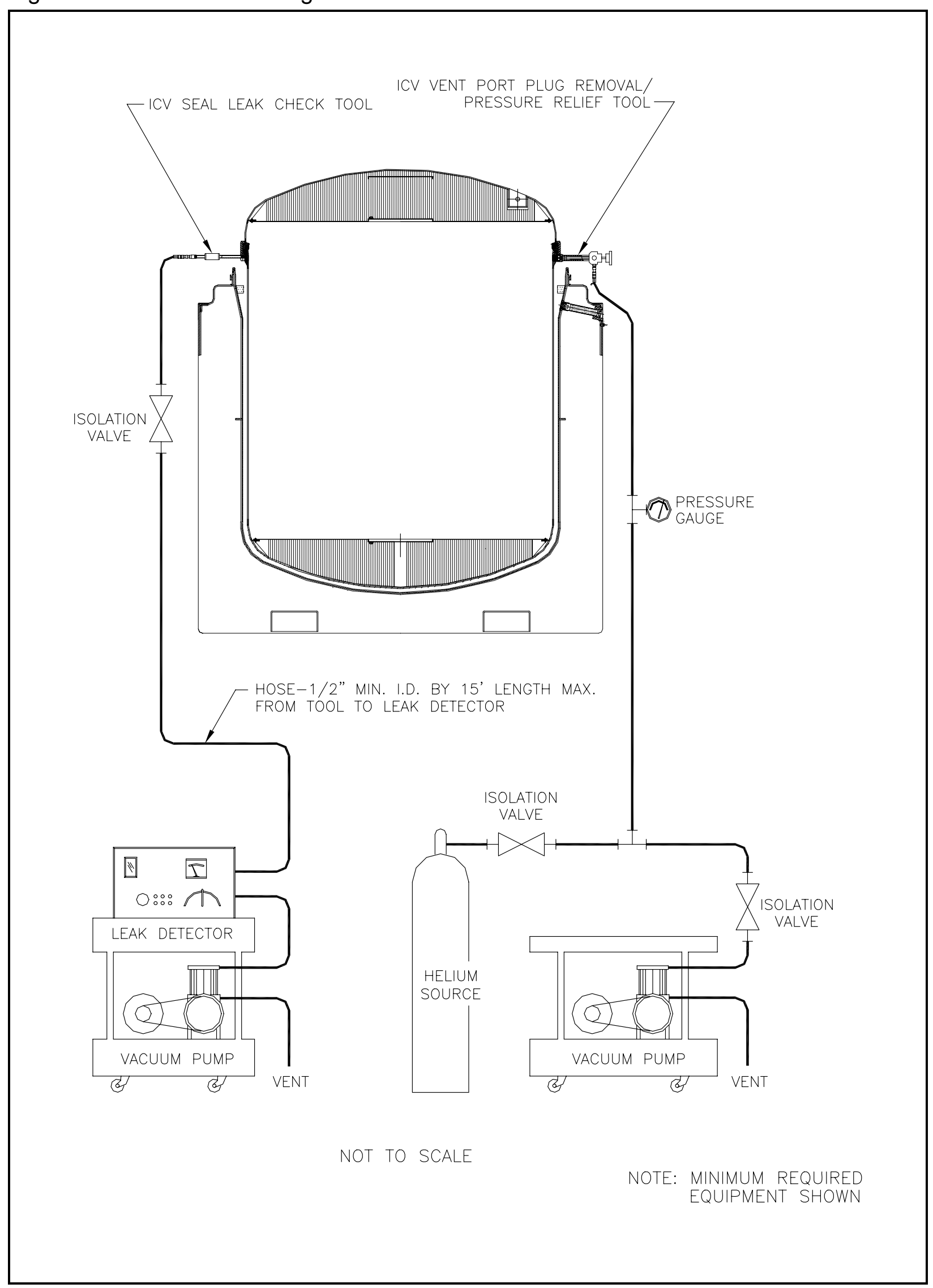


Figure 4.2 - ICV Outer Vent Port Plug Seal O-Ring Test

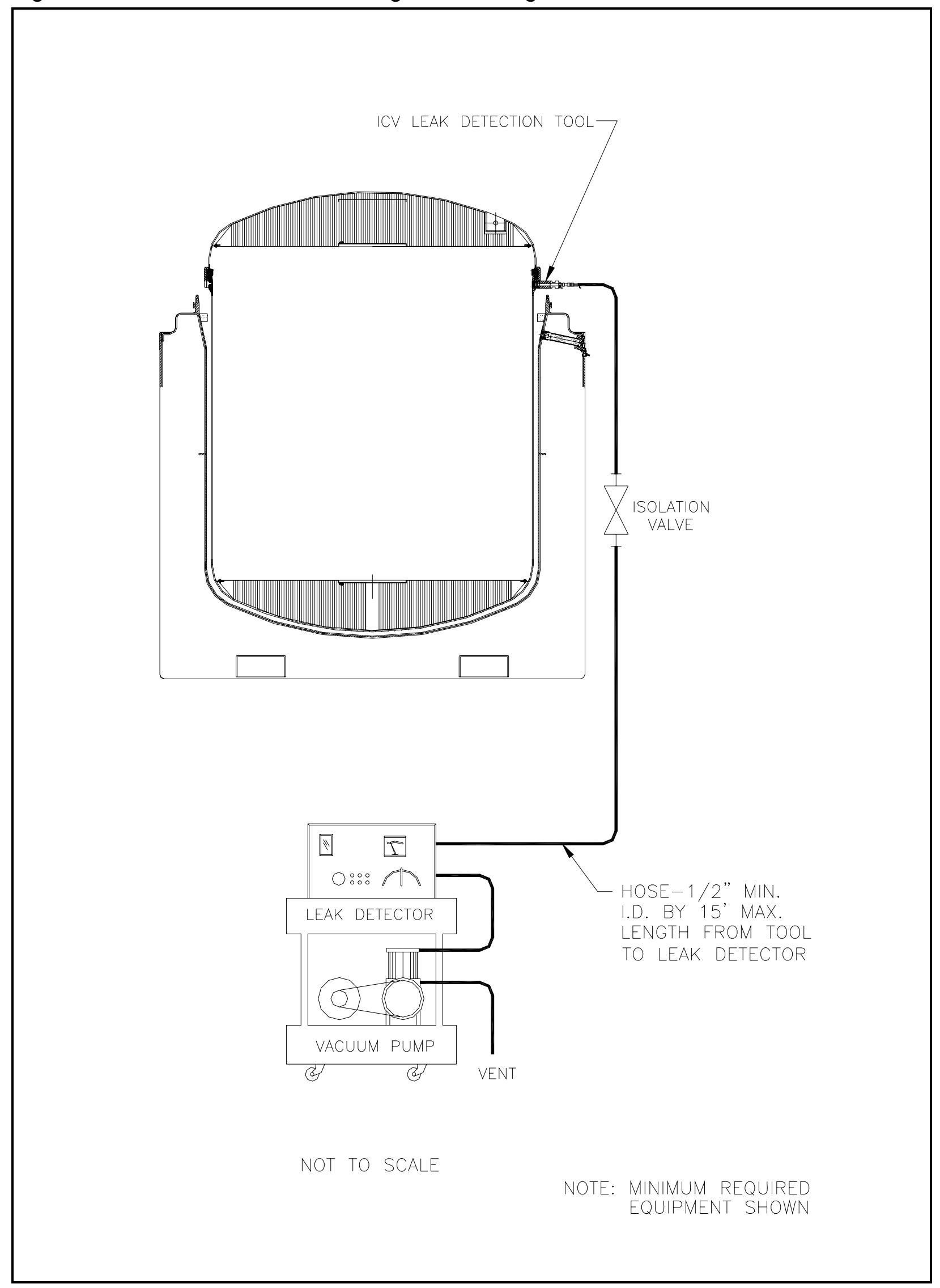


Figure 4.3 - OCV Main O-Ring Seal Test

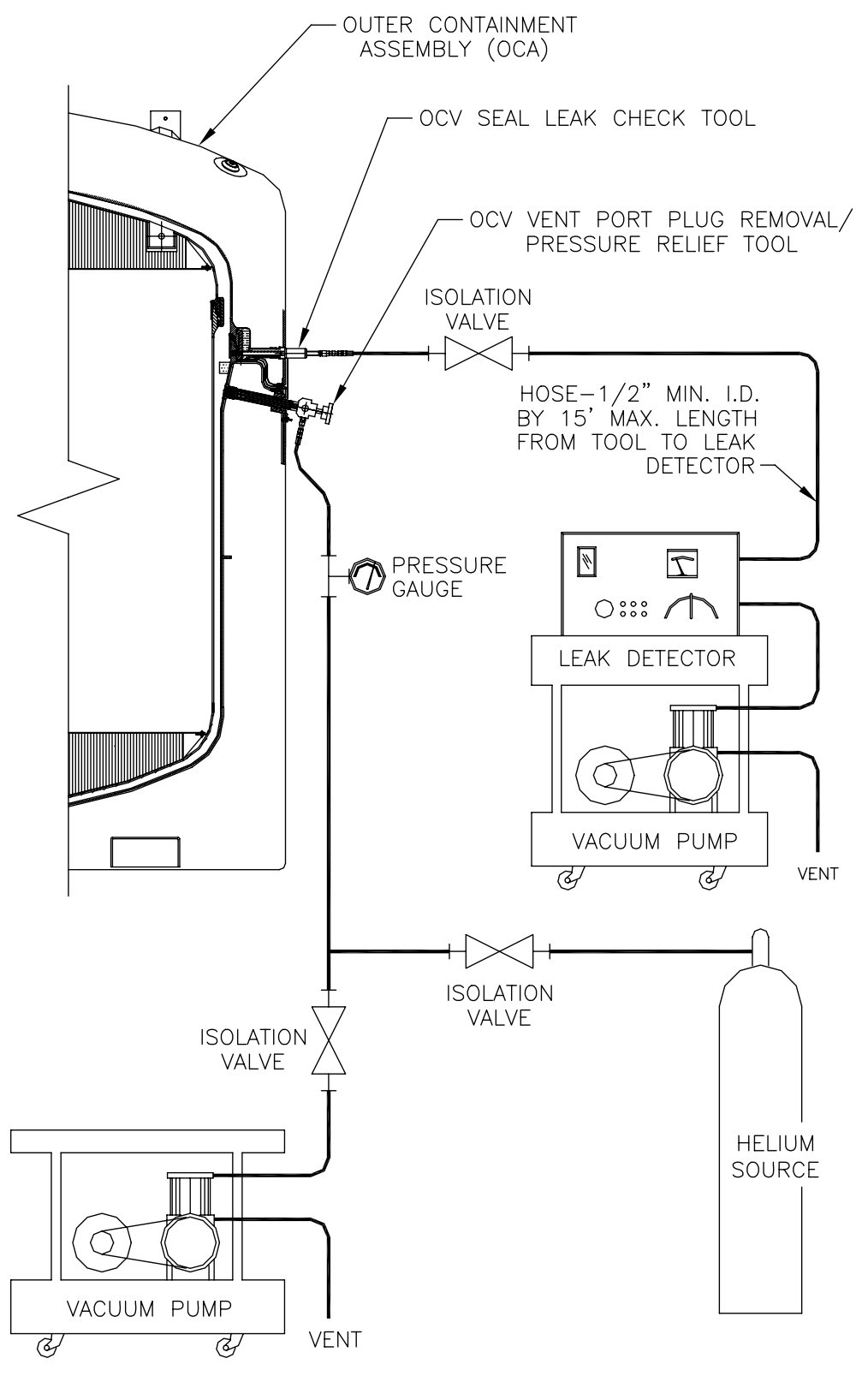

NOT TO SCALE 
Figure 4.4 - OCV Vent Port Plug Seal O-Ring Test

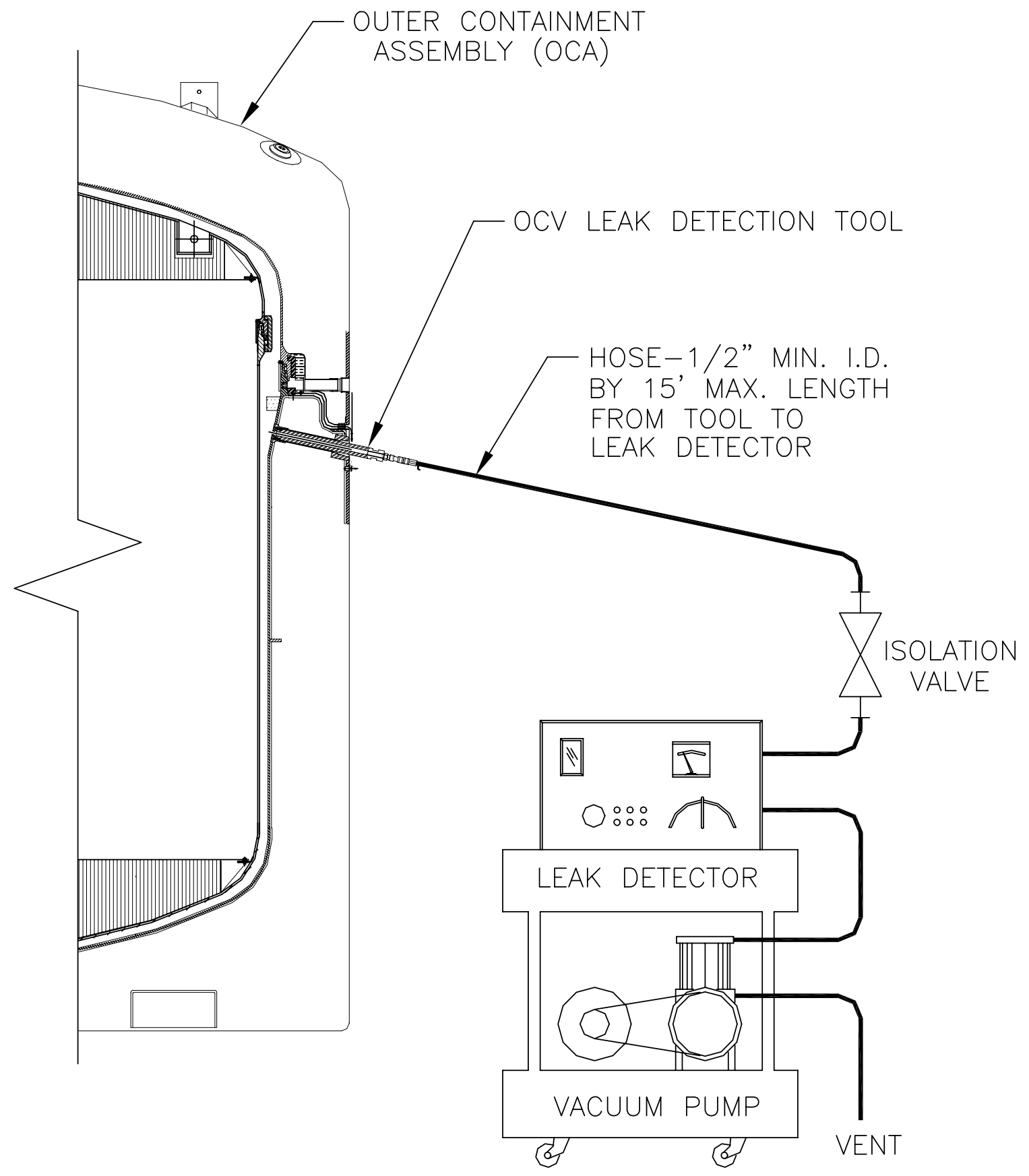

NOT TO SCALE

NOTE: 1. MINIMUM REQUIRED EQUIPMENT SHOWN 
Attachment 1 - CH Packaging Receipt and Inspection Data Sheet

\begin{tabular}{|c|c|c|}
\hline \multicolumn{3}{|c|}{ CH PACKAGING RECEIPT AND INSPECTION DATA SHEET } \\
\hline STEP(S) & DESCRIPTION & INITIALS \\
\hline \multicolumn{3}{|l|}{ Facility: } \\
\hline 2.2 .1 & OCA serial No: & \\
\hline \multicolumn{3}{|c|}{ PERFORMANCE } \\
\hline 2.2 .2 & $\begin{array}{l}\text { Shipping documents validated, packaging undamaged and released, and } \\
\text { nameplate checked }\end{array}$ & \\
\hline 2.2 .3 & Maintenance labels present and maintenance is current & \\
\hline 2.7 .1 & $\begin{array}{l}\text { Activity on smears below DOT acceptable limits } \\
\text { Survey No: }\end{array}$ & \\
\hline 2.7 .5 & OCA lid components and hardware satisfactory & \\
\hline 2.8 .1 & $\begin{array}{l}\text { Activity on smears below DOT acceptable limits } \\
\text { Survey No: }\end{array}$ & \\
\hline 2.8 .9 & ICV lid components and hardware satisfactory & \\
\hline 2.9 .1 & $\begin{array}{l}\text { Activity on smears below DOT acceptable limits } \\
\text { Survey No: }\end{array}$ & \\
\hline 2.9 .6 & OCA body inspection satisfactory & \\
\hline \multirow{3}{*}{2.10 .9} & OCV upper main O-ring installed in upper groove & \\
\hline & $\begin{array}{l}\text { OCV lower main O-ring installed in lower groove with identifying mark near vent } \\
\text { port }\end{array}$ & \\
\hline & OCV vent port plug seal O-ring installed & \\
\hline 2.10 .10 & OCA components and hardware satisfactory & \\
\hline 2.11 .6 & ICV body inspection satisfactory & \\
\hline \multirow{3}{*}{2.12 .8} & ICV upper main O-ring installed in upper groove & \\
\hline & ICV lower main O-ring installed in lower groove with identifying mark near vent port & \\
\hline & ICV outer vent port plug seal O-ring installed & \\
\hline 2.12 .9 & ICV components and hardware satisfactory & \\
\hline 2.13.4 & ICV free of water & \\
\hline 2.13 .5 & ICV cavity free of foreign objects & \\
\hline 2.14 .1 & Preloading preparations and inspections complete & \\
\hline
\end{tabular}

Performers, enter printed name, signature, date and initials: 


\begin{tabular}{|lll}
\hline DOE/WIPP 02-3184 Rev. 7 & Page 103 of 115
\end{tabular}

Attachment 1 - CH Packaging Receipt and Inspection Data Sheet

\begin{tabular}{||l|l|l||}
\hline \hline \multicolumn{3}{|c||}{ CH PACKAGING RECEIPT AND INSPECTION DATA SHEET } \\
\hline STEP(S) & \multicolumn{1}{|c||}{ DESCRIPTION } & INITIALS \\
\hline Facility: & Date: & \\
\hline 2.2 .1 & OCA serial No: & \\
\hline
\end{tabular}

REMARKS:

REVIEW/VALIDATIONS:

Supervisor: (Print Name) Signature

Date 


\section{Attachment 2 - CH Packaging Loading Data Sheet}

\begin{tabular}{|c|c|c|}
\hline \multicolumn{3}{|c|}{ CH PACKAGING LOADING DATA SHEET } \\
\hline STEP(S) & DESCRIPTION & INITIALS \\
\hline \multicolumn{3}{|l|}{ Facility: } \\
\hline 2.16 .1 & OCA S/N: & \\
\hline \multicolumn{3}{|c|}{ PERFORMANCE } \\
\hline 2.16 .2 & $\begin{array}{l}\text { Pallet S/N: } \\
\text { SWB Ratchet Strap S/Ns: OR }\end{array}$ & \\
\hline 2.16 .3 & $\begin{array}{l}\text { Annual inspection due date: } \\
\text { Pallet:_ Ratchet straps: }\end{array}$ & \\
\hline 2.16 .4 & Payload assembled in accordance with the $\mathrm{CH}$-TRAMPAC & \\
\hline 2.16 .11 & Payload assembly weight:_ & \\
\hline 2.16 .13 & Empty packaging weight: & \\
\hline 2.16 .14 & $\begin{array}{l}\text { Loaded package total weight: } \\
\text { Not to exceed: }(19,250 \mathrm{lb}-\text { TRUPACT-II or } 18,100 \mathrm{lb}-\text { HalfPACT })\end{array}$ & \\
\hline 2.17 .1 & ICV serial number: & \\
\hline 2.17 .2 & $\begin{array}{ll}\text { Torque wrench } \mathrm{S} / \mathrm{N}: & \text { Due: } \\
\text { Torque wrench } \mathrm{S} / \mathrm{N}: & \text { Due: }\end{array}$ & \\
\hline 2.17 .13 & ICV inner vent port plug at specified value & \\
\hline 2.17 .14 & ICV preshipment leakage rate test performed & \\
\hline 2.17 .16 & ICV lock bolts at specified value & \\
\hline 2.18 .1 & Items removed from Z-flange/seal flange area(s) & \\
\hline 2.18 .3 & OCA S/N: & \\
\hline 2.18 .14 & OCV preshipment leakage rate test performed & \\
\hline 2.18 .16 & OCA lock bolts at specified values & \\
\hline 2.18 .19 & $\begin{array}{l}\text { Tamper-indicating security seals installed and numbers recorded } \\
\text { Seal No: } \quad \text { Seal Date: } \\
\text { Seal No: }\end{array}$ & \\
\hline
\end{tabular}

Performers, enter printed name, signature, date and initials:

Printed Name

REMARKS:

REVIEW/VALIDATIONS: 
Attachment 3 - Loaded CH Package Trailer Data Sheet

\begin{tabular}{||l|l|l||}
\hline \hline \multicolumn{3}{|c||}{ LOADED CH PACKAGE TRAILER DATA SHEET } \\
\hline STEP(S)
\end{tabular}

Performers, enter printed name, signature, date and initials:

Printed Name

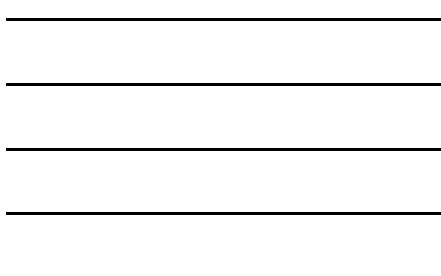

REMARKS:

REVIEW/VALIDATIONS: 


\section{Attachment 4 - Loaded Package Receipt and Processing Data Sheet}

\begin{tabular}{||l|l|l||}
\hline \multicolumn{3}{|c||}{ LOADED PACKAGE RECEIPT AND PROCESSING DATA SHEET } \\
\hline STEP(S) & \multicolumn{1}{|c||}{ DESCRIPTION } & \multicolumn{1}{|c||}{ PER: } \\
\hline Facility: & \multicolumn{1}{|c||}{ PERORMANCE } \\
\hline 2.20 .1 & OCA S/N: & \\
\hline 2.20 .2 & Shipping documents validated, package undamaged and released & \\
\hline 2.20 .3 & Package external survey complete and below DOT acceptable limits & \\
\hline 2.22 .17 & Activity on smears at or below acceptable limits & \\
\hline 2.23 .11 & Activity on smears at or below acceptable limits & \\
\hline 2.23 .15 & Activity on smears at or below acceptable limits & \\
\hline 2.24 .4 & Payload inspected for damage & \\
\hline 2.24 .5 & Activity on smears at or below acceptable limits & \\
\hline
\end{tabular}

Performers, enter printed name, signature, date and initials:

Printed Name

REMARKS:

REVIEW/VALIDATIONS: 


\section{Attachment 5 - Empty Packaging Shipment Data Sheet}

\begin{tabular}{|c|c|c|}
\hline \multicolumn{3}{|c|}{ EMPTY PACKAGING SHIPMENT DATA SHEET } \\
\hline STEP(S) & DESCRIPTION & INITIALS \\
\hline \multicolumn{3}{|l|}{ Facility: } \\
\hline \multicolumn{3}{|c|}{ PERFORMANCE } \\
\hline 2.25 .1 & OCA S/N: & \\
\hline \multirow[t]{2}{*}{2.25 .2} & Torque wrench S/N: & \\
\hline & Torque wrench S/N:__ Due: & \\
\hline 2.25 .3 & Maintenance labels are present and maintenance is current & \\
\hline 2.26 .1 & $\begin{array}{l}\text { OCA lid interior and exterior survey complete and below DOT acceptable limits: } \\
\text { Survey No:_ Survey Date: }\end{array}$ & \\
\hline 2.26 .5 & OCA lid components and hardware satisfactory & \\
\hline 2.27 .1 & $\begin{array}{l}\text { ICV lid interior and exterior survey complete and below DOT acceptable limits: } \\
\text { Survey No: Survey Date: }\end{array}$ & \\
\hline 2.27 .9 & ICV lid components and hardware satisfactory & \\
\hline 2.28 .1 & $\begin{array}{l}\text { OCA body exterior and ICV body interior surveys complete and below DOT acceptable } \\
\text { limits. Survey No: }\end{array}$ & \\
\hline 2.28 .6 & OCA body inspection satisfactory & \\
\hline \multirow{3}{*}{2.29 .9} & OCV upper main O-ring installed in upper groove & \\
\hline & OCV lower main O-ring installed in lower groove with identifying mark near vent port & \\
\hline & OCV vent port plug seal O-ring installed & \\
\hline 2.29 .10 & OCA body inspection and hardware satisfactory & \\
\hline 2.30 .6 & ICV body inspection satisfactory & \\
\hline \multirow{3}{*}{2.31 .8} & ICV upper main O-ring installed in upper groove & \\
\hline & ICV lower main O-ring installed in lower groove with identifying mark near vent port & \\
\hline & ICV outer vent port plug seal O-ring installed & \\
\hline 2.31 .9 & ICV components and hardware satisfactory & \\
\hline 2.32 .4 & ICV free of water & \\
\hline 2.32 .5 & ICV cavity free of foreign objects & \\
\hline 2.32 .6 & Pallet and ratchet strap inspection due date greater than one month from today & \\
\hline 2.32 .7 & Preshipment inspections complete & \\
\hline 2.33 .2 & ICV serial number: & \\
\hline 2.33 .16 & $\begin{array}{l}\text { ICV hardware and OCV seal test port plug torqued within designated range: } \\
\square \text { ICV inner vent port plug } \\
\square \text { ICV seal test port plug } \\
\square \text { OCV seal test port plug } \\
\square \text { ICV lock bolt(s) at } 28 \text { to } 32 \mathrm{lb}-\mathrm{ft} \\
\square \text { ICV outer vent port plug } \\
\square \text { ICV vent port cover }\end{array}$ & \\
\hline 2.34 .1 & Items removed from Z-flange/seal flange area(s) & \\
\hline
\end{tabular}




\section{Attachment 5 - Empty Packaging Shipment Data Sheet}

\begin{tabular}{|c|c|c|}
\hline \multicolumn{3}{|c|}{ EMPTY PACKAGING SHIPMENT DATA SHEET } \\
\hline STEP(S) & DESCRIPTION & INITIALS \\
\hline \multicolumn{2}{|l|}{ Facility: } & Date: \\
\hline \multicolumn{3}{|c|}{ PERFORMANCE } \\
\hline 2.25 .1 & OCA S/N: & \\
\hline 2.34 .3 & OCA serial number: & \\
\hline 2.34 .17 & $\begin{array}{l}\text { OCV hardware torqued within designated range: } \\
\square \text { OCV vent port plug } \\
\square \text { OCV vent port cover } \\
\square \text { OCV test port access plug at } 35 \text { to } 45 \mathrm{lb} \text {-ft } \\
\square \text { OCV vent port access plug at } 35 \text { to } 45 \mathrm{lb} \text {-ft } \\
\square \text { OCA lock bolts at } 28 \text { to } 32 \mathrm{lb} \text {-ft }\end{array}$ & \\
\hline 2.34 .18 & Preshipment preparations complete, unit ready for transport & \\
\hline
\end{tabular}

Performers, enter printed name, signature, date and initials:

Printed Name

REMARKS:

REVIEW/VALIDATIONS: 


\section{Attachment 6 - Trailer Data Sheet}

\begin{tabular}{|c|c|c|c|}
\hline \multicolumn{4}{|c|}{ TRAILER DATA SHEET } \\
\hline STEP(S) & \multicolumn{2}{|c|}{ DESCRIPTION } & INITIALS \\
\hline \multicolumn{3}{|l|}{ Facility: } & \\
\hline \multicolumn{4}{|c|}{ PERFORMANCE } \\
\hline 2.35 .1 & \multicolumn{2}{|c|}{$\begin{array}{l}\text { Shipment No.: } \\
\text { Trailer No.: } \\
\text { Packaging Nos.: }\end{array}$} & \\
\hline 2.35 .3 & \multicolumn{2}{|l|}{ Trailer inspection date: } & \\
\hline 2.35 .6 & $\begin{array}{l}\text { Position \#1 packaging S/N: } \\
\text { Position \#2 packaging S/N: } \\
\text { Position \#3 packaging S/N: }\end{array}$ & $\begin{array}{ll}\text { Weight: } & \mathrm{lb} \\
\text { Weight: } & \mathrm{lb} \\
\text { Weight: } & \mathrm{lb}\end{array}$ & \\
\hline 2.35.7 & \multicolumn{2}{|c|}{ Payload weight:_ lb } & \\
\hline 2.35 .8 & \multicolumn{2}{|c|}{ Shipment complies with 49 CFR Part 172, Subparts D, E, and F } & \\
\hline 2.35 .10 & \multicolumn{2}{|c|}{ Shipping papers are in accordance with 49 CFR Part 172, Subpart C } & \\
\hline 2.35 .11 & \multicolumn{2}{|l|}{ Trailer loading complete } & \\
\hline
\end{tabular}

Performers, enter printed name, signature, date and initials:

Printed Name

REMARKS:

REVIEW/VALIDATIONS:

Supervisor: (Print Name) Signature Date




\section{Attachment 7 - ICV Preshipment Leakage-Rate Test Data Sheet}






\section{Attachment 7 - ICV Preshipment Leakage-Rate Test Data Sheet}

\begin{tabular}{|c|c|c|}
\hline & Leak Rate Calculation for ICV Main O-Ring Test: & \\
\hline 4.2.31[ A ] & \multicolumn{2}{|c|}{ 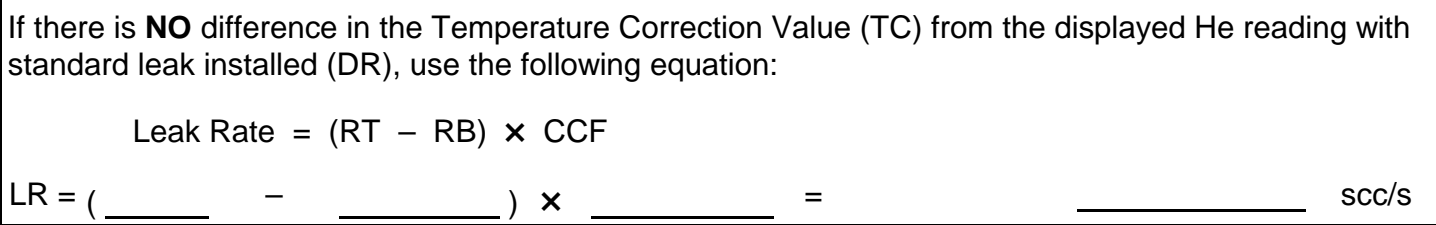 } \\
\hline 4.2.31[ B ] & \multicolumn{2}{|c|}{$\begin{array}{l}\text { If the displayed He reading with standard leak installed }(\mathrm{DR}) \text { is LESS than the Temperature Correction } \\
\text { Value }(\mathrm{TC}) \text {, add the calibration deviation: } \\
\qquad \text { Leak Rate }=(\mathrm{RT}+\text { Calibration Deviation }-\mathrm{RB}) \times \mathrm{CCF} \\
\mathrm{LR}=(\end{array}$} \\
\hline $4.2 .31[\mathrm{C}]$ & \multicolumn{2}{|c|}{$\begin{array}{l}\text { If the displayed He reading with standard leak installed (DR) is MORE than the Temperature Correction } \\
\text { Value }(\mathrm{TC}) \text {, subtract the calibration deviation: } \\
\qquad \text { Leak Rate }=(\mathrm{RT}-\text { Calibration Deviation }-\mathrm{RB}) \times \mathrm{CCF} \\
\mathrm{LR}=(\end{array}$} \\
\hline $4.2 .33[\mathrm{C}]$ & NCR number recorded & Initials \\
\hline 4.2 .36 & ICV seal test port plug at 55 to $65 \mathrm{lb}$-in. & Initials \\
\hline \multirow[t]{2}{*}{4.3 .4} & ICV outer vent port plug at 55 to $65 \mathrm{lb}$-in. & Initials \\
\hline & \multicolumn{2}{|l|}{ Pretest Calibration for ICV Outer Vent Port Plug Seal O-Ring Test: } \\
\hline \multirow[t]{2}{*}{ 4.3.8 } & $\begin{array}{l}\text { Leak rate of standard leak } \\
\text { Temperature at time of calibration } \\
\text { Temperature adjusted leak rate used to calibrate leak detector } \\
\text { Zero reading at time of calibration } \\
\text { Time of calibration }\end{array}$ & $\begin{array}{l}\mathrm{scc} / \mathrm{s} \\
{ }^{\circ} \mathrm{C} \\
\mathrm{scc} / \mathrm{s} \\
\mathrm{scc} / \mathrm{s}\end{array}$ \\
\hline & \multicolumn{2}{|l|}{ Test Data for ICV Outer Vent Port Plug Seal O-Ring Test: } \\
\hline \multirow[t]{2}{*}{4.3 .12} & Displayed He reading after & $\mathrm{scc} / \mathrm{s}$ \\
\hline & \multicolumn{2}{|l|}{ Post-test Calibration Deviation Check for ICV Outer Vent Port Plug Seal O-Ring Test: } \\
\hline 4.3 .15 & $\begin{array}{l}\text { Temperature at time of calibration deviation check } \\
\text { Temperature Correction Value (TC) } \\
\text { Displayed He reading with standard leak installed (DR) } \\
\text { Zero reading at time of calibration deviation check } \\
\text { Time of calibration deviation check }\end{array}$ & $\begin{array}{l}{ }^{\circ} \mathrm{C} \\
\mathrm{scc} / \mathrm{s} \\
\mathrm{scc} / \mathrm{s} \\
\mathrm{scc} / \mathrm{s}\end{array}$ \\
\hline
\end{tabular}




\section{Attachment 7 - ICV Preshipment Leakage-Rate Test Data Sheet}

\begin{tabular}{|c|c|}
\hline & Leak Rate Calculation for ICV Outer Vent Port Plug Seal O-Ring Test: \\
\hline 4.3.16[A ] & $\begin{array}{l}\text { If there is NO difference in the Temperature Correction Value (TC) from the displayed He reading with } \\
\text { standard leak installed (DR), use the following equation: } \\
\text { Leak Rate = RT } \times \text { CCF } \\
\text { LR = }\end{array}$ \\
\hline 4.3.16[ B ] & 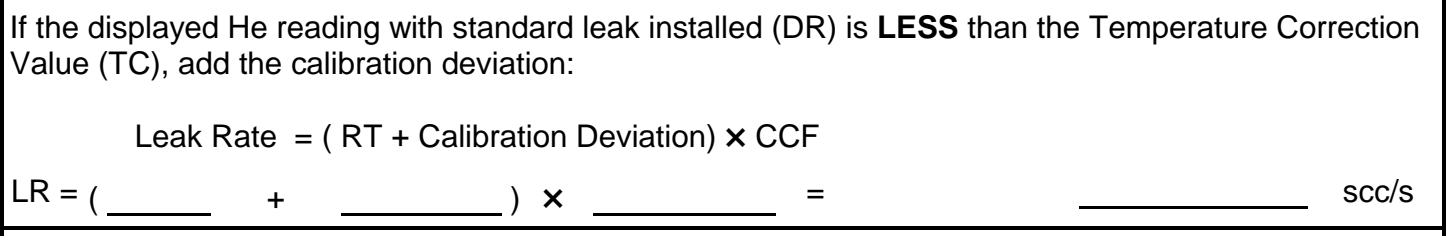 \\
\hline $4.3 .16[C]$ & $\begin{array}{l}\text { If the displayed He reading with standard leak installed (DR) is MORE than the Temperature Correction } \\
\text { Value }(\mathrm{TC}) \text {, subtract the calibration deviation: } \\
\text { Leak Rate }=(\mathrm{RT}-\text { Calibration Deviation }) \times \mathrm{CCF} \\
\mathrm{LR}=\left(\begin{array}{ll}\text { L }\end{array}\right) \times \mathrm{scc} / \mathrm{s}\end{array}$ \\
\hline 4.3.18[ C ] & NCR number recorded \\
\hline \multirow[t]{4}{*}{ 4.3.21 } & ICV vent port cover at 55 to $65 \mathrm{lb}$-in. \\
\hline & Accountability Section \\
\hline & Test performed by/Level \\
\hline & Test reviewed by/Level \\
\hline
\end{tabular}




\section{Attachment 8 - OCV Preshipment Leakage-Rate Test Data Sheet}

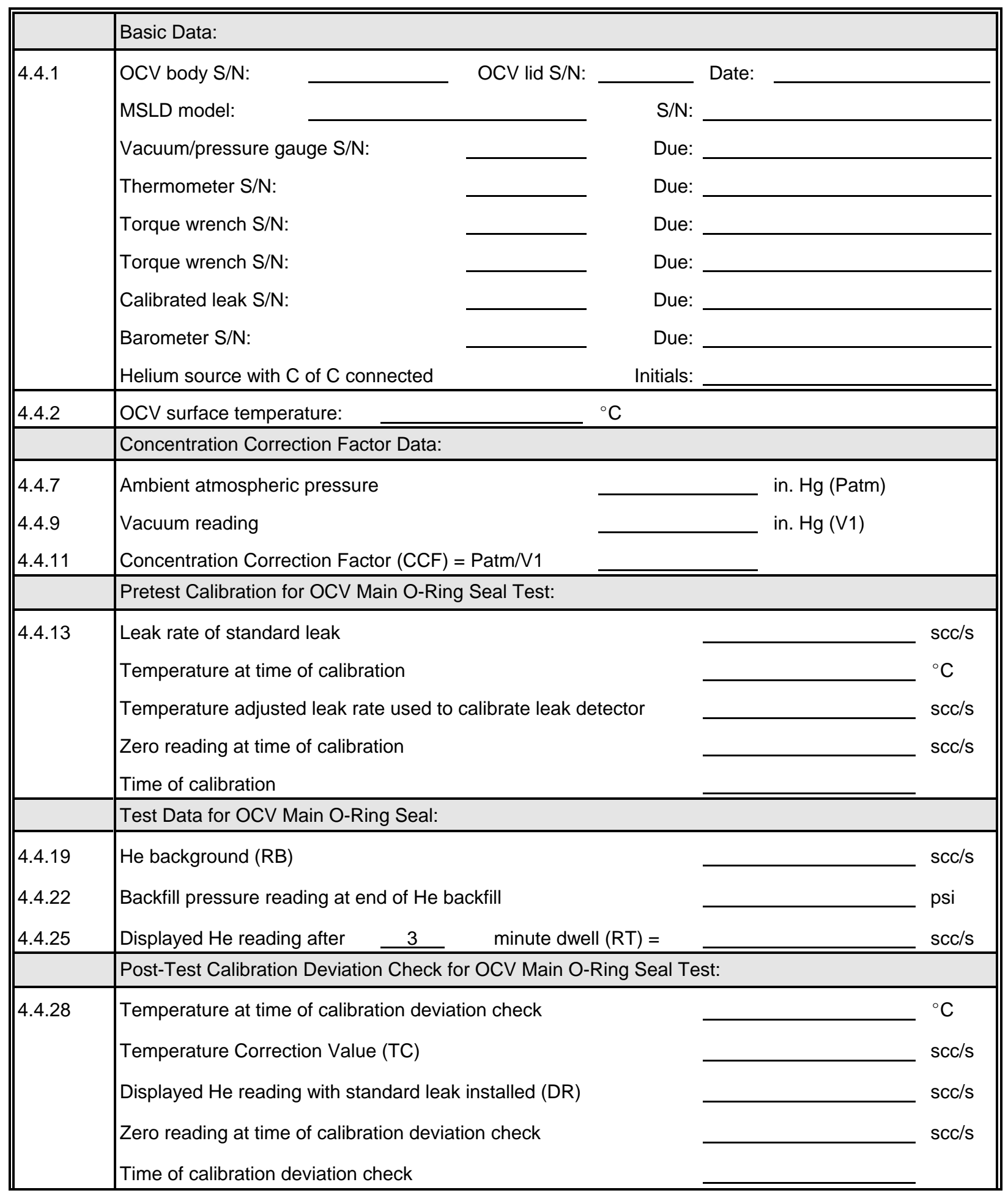




\section{Attachment 8 - OCV Preshipment Leakage-Rate Test Data Sheet}

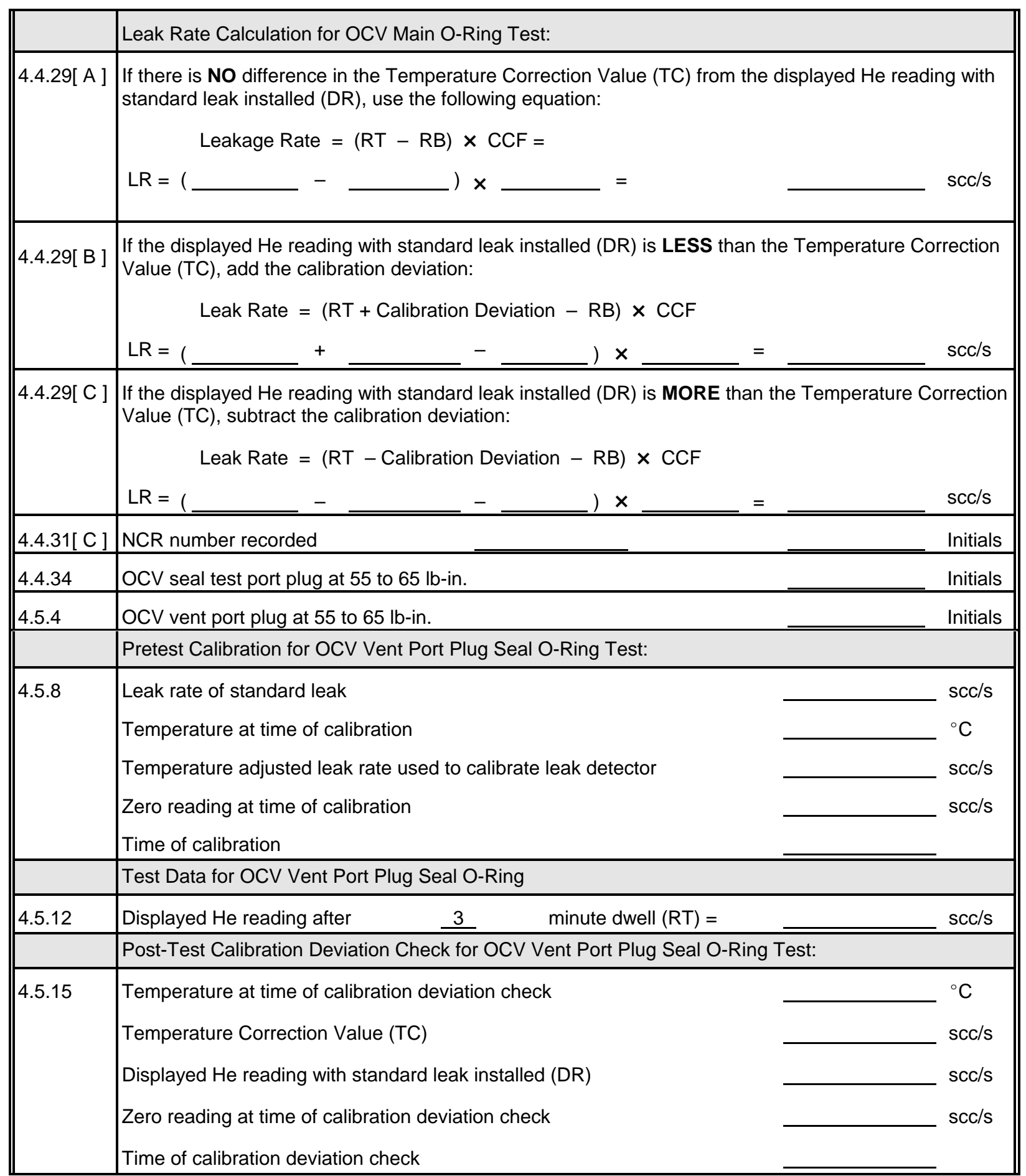




\section{Attachment 8 - OCV Preshipment Leakage-Rate Test Data Sheet}

\begin{tabular}{|c|c|}
\hline & Leak Rate Calculation for OCV Vent Port Plug Seal O-Ring Test: \\
\hline 4.5.16[ A ] & $\begin{array}{l}\text { If there is NO difference in the Temperature Correction Value }(\mathrm{TC}) \text { from the displayed He reading with } \\
\text { standard leak installed }(\mathrm{DR}) \text {, use the following equation: } \\
\text { Leakage Rate }=(\mathrm{RT}) \times \mathrm{CCF} \\
\mathrm{LR}=(\end{array}$ \\
\hline 4.5.16[ B ] & $\begin{array}{l}\text { If the displayed He reading with standard leak installed (DR) is LESS than the Temperature Correction } \\
\text { Value }(\mathrm{TC}) \text {, add the calibration deviation: } \\
\text { Leakage Rate }=(\mathrm{RT}+\text { Calibration Deviation }) \times \mathrm{CCF} \\
\mathrm{LR}=(\end{array}$ \\
\hline 4.5.16[ C ] & $\begin{array}{l}\text { If the displayed He reading with standard leak installed (DR) is MORE than the Temperature Correction } \\
\text { Value (TC), subtract the calibration deviation: } \\
\text { Leakage Rate }=(\mathrm{RT}-\text { Calibration Deviation }) \times \mathrm{CCF} \\
\mathrm{LR}=(\end{array}$ \\
\hline 4.5.18[ C ] & NCR number recorded \\
\hline 4.5 .21 & OCV vent port cover at 55 to $65 \mathrm{lb}$-in. \\
\hline 4.5 .23 & OCV seal test port access plug at 35 to $45 \mathrm{lb}$-ft \\
\hline \multirow[t]{4}{*}{4.5 .25} & OCV vent port access plug at 35 to $45 \mathrm{lb}$-ft \\
\hline & Accountability Section \\
\hline & Tests performed by/Level \\
\hline & Tests reviewed by/Level \\
\hline
\end{tabular}

